\title{
Income Inequality in France, 1900- 2014: Evidence from Distributional National Accounts (DINA)
}

\section{Bertrand Garbinti ${ }^{1}$, Jonathan Goupille-Lebret ${ }^{2} \&$ Thomas Piketty ${ }^{3}$}

\author{
April 2018, WP \#677
}

\begin{abstract}
We combine national accounts, tax and survey data in a comprehensive and consistent manner for France, to build homogenous annual series on the distribution of national income by percentiles, from 1900 to 2014, with detailed breakdown by age, gender and income categories over the 1970-2014 period. Our new series deliver higher inequality levels for the recent decades, because the usual tax-based series miss a rising part of capital income. Growth incidence curves look dramatically different for the 1950-1983 and 19832014 periods. We also show that it has become increasingly difficult to access top wealth groups with labor income only. Next, gender inequality in labor income declined in recent decades, albeit fairly slowly among top labor incomes. Finally, we compare the evolution of income inequality between France and the U.S. ${ }^{4}$
\end{abstract}

Keywords: income distribution, income inequality, national accounts.

JEL classification: D31, E01, H2, N34.

\footnotetext{
${ }^{1}$ Banque de France, CREST

2 Paris School of Economics, INSEAD, GATE-LSE

3 Paris School of Economics

${ }^{4}$ We are grateful to Facundo Alvaredo, Thomas Blanchet, Vincent Biausque, Emmanuel Saez and Gabriel Zucman for numerous conversations. We are also thankful to the DGFiP-GF3C team. The research leading to these results has received funding from the European Research Council under the European Union's 7th Framework Program, ERC Grant Agreement n. 340831. This work is also supported by a public grant overseen by the French National Research Agency (ANR) as part of the "Investissements d'avenir » program (reference: ANR-10-EQPX-17 - Centre d'accès sécurisé aux données - CASD). Updated series are available on the WID.world website (World Wealth and Income Database): http://www.wid.world.
}

Working Papers reflect the opinions of the authors and do not necessarily express the views of the Banque de France. This document is available on publications.banque-france.fr/en 


\section{NON-TECHNICAL SUMMARY}

This paper presents the long-run evolution of pretax national income inequality over the 1900-2014 period. The major long-run transformation is the rise of the share going to the bottom 50\% (the "lower class") and the middle 40\% (the "middle class") and the decline of the share going to the top $10 \%$ (the "upper class"). Regarding the recent trend, the top $10 \%$ income share declined somewhat after the 2008 financial crises, but still significantly higher than in the early 1980s. Most importantly, the top $1 \%$ income share significantly increases between 1983 and 2007: it rose from less than 8\% of total income to over 12\% over this period, i.e. by more than $50 \%$. This is less massive than in the U.S., but still fairly spectacular. Moreover, the higher we go at the top of the distribution, the higher the rise in top income shares which is due both to the rise of very top labor incomes and very top capital incomes.

Between 1983 and 2014, average per adult national income rose by 35\% in real terms in France. However actual cumulated growth was not the same for all income groups: cumulated growth between 1983 and 2014 was 30\% on average for the bottom 50\% of the distribution, $27 \%$ for next $40 \%$, and $50 \%$ for the top 10\%. Most importantly, cumulated growth remains below average until the 95th percentile, and then rises steeply, up to as much as $100 \%$ for the top $1 \%$ and $160 \%$ for the top $0.01 \%$. The contrast with the $1950-$ 1983 period is particularly striking. In effect, during the "Thirty Glorious Years", we observe the exact opposite pattern as in the following thirty years. Between 1950 and 1983, growth rates were very high for the bottom 95\% of the population (about 3.5\% per year, see Figure) and fell abruptly above the 95th percentile (1.8\% at the very top); between 1983 and 2014, growth rates were modest for the bottom $95 \%$ of the population (about 1\% per year) and rose sharply above the 95 th percentile (3\% at the very top).

How can we account for this complete reversal between the 1950-1983 and 1983-2014 subperiods? Our series show that the sharp rise of very top incomes since the 1980s is due both to top capital incomes and top labor incomes. Regarding the rise of top capital incomes, one should distinguish between two effects: the rise of the macroeconomic capital share (an evolution that is due to a combination of economic and institutional factors, including the decline of labor bargaining power and the lift of rent control, and that was reinforced by corporate privatization policies), and the rise of wealth concentration.

We also document the changing correlation between wealth and labor income, showing that it has become increasingly difficult in recent decades to access top wealth groups with labor income only. Next, our breakdowns by age and gender allow us to explore new dimensions of inequality dynamics together with the top income dimension. For instance, we find that gender inequality in labor income declined in recent decades, albeit fairly slowly among top labor incomes. E.g. female share among top $0.1 \%$ earners was only $12 \%$ in 2012 (vs. 7\% in 1994 and 5\% in 1970). Finally, since our new series are anchored to national accounts, they allow for more reliable comparisons across countries. We find that average pre-tax income among bottom 50\% adults is 30\% larger in France than in the U.S., in spite of the fact that aggregate per adult national income is 30\% smaller in France. Posttax comparisons are likely to exacerbate this conclusion. 


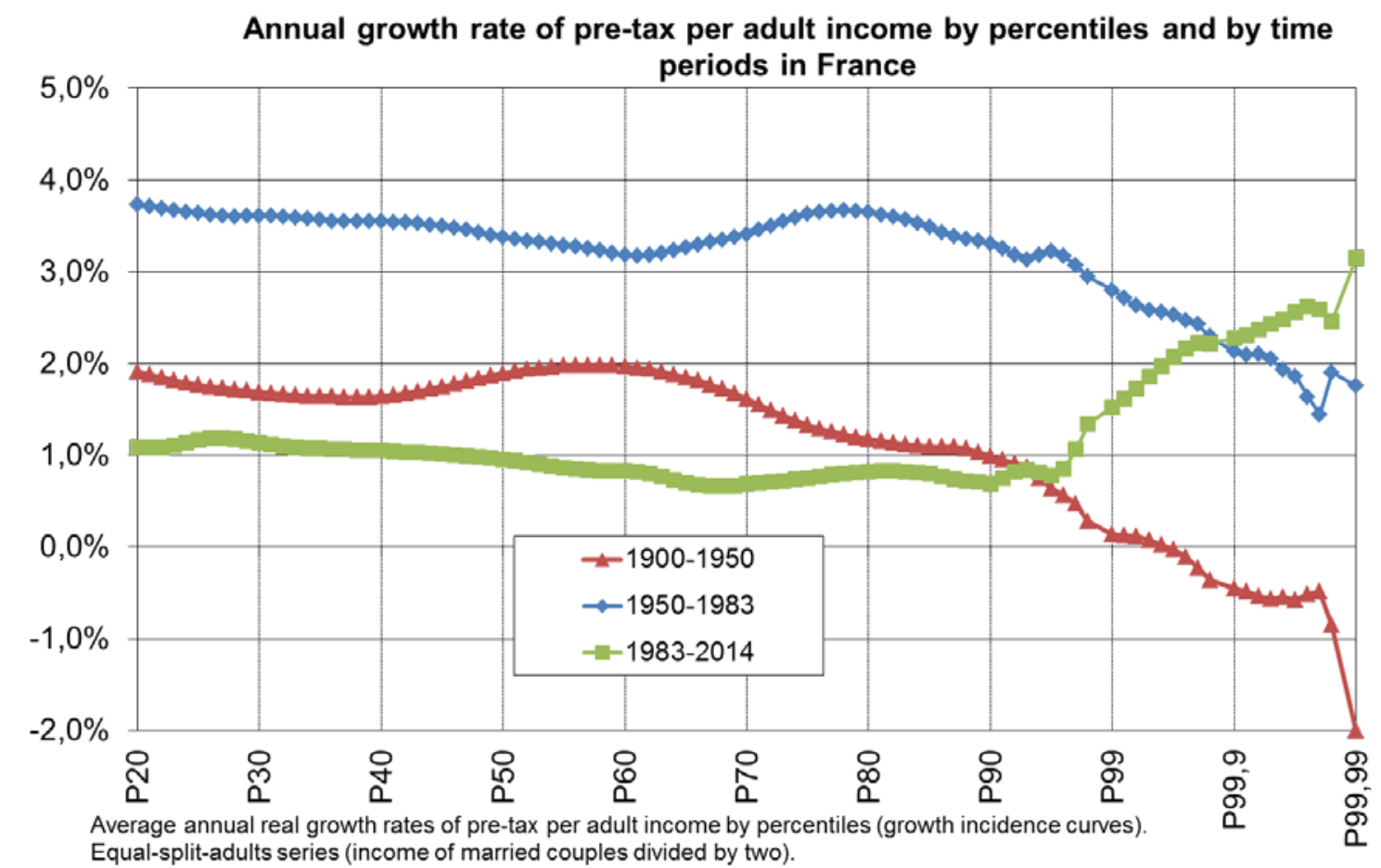

Equal-split-adults series (income of married couples divided by two).

\section{Inégalités de revenu en France, 1900-2014 : Enseignements des Comptes Nationaux Distributifs (DINA)}

\section{RÉSUMÉ}

Nous combinons les comptes nationaux, les données fiscales et les données d'enquête d'une manière globale et cohérente pour la France, afin de construire des séries annuelles homogènes de distribution du revenu national par percentiles, de 1900 à 2014, avec une ventilation par âge, sexe et catégories de revenus entre 1970 et 2014. Nos estimations permettent une analyse plus riche des tendances de long terme que celles précédemment obtenues via des séries fiscales. Nos nouvelles séries présentent des niveaux d'inégalité plus élevés au cours des dernières décennies, parce que les séries habituelles basées sur l'impôt sur le revenu ignorent une partie croissante des revenus du capital. Les courbes d'incidence de la croissance sont très différentes pour les périodes 1950-1983 et 19832014. Nous montrons également qu'il est devenu de plus en plus difficile d'accéder aux groupes les plus riches en patrimoine uniquement avec un revenu du travail. L'inégalité de revenu du travail a diminué au cours des dernières décennies, quoique assez lentement parmi les revenus les plus élevés. Enfin, nous comparons l'évolution des inégalités de revenu entre la France et les États-Unis.

Mots-clés: inégalités des revenus, répartition des revenus, inégalité des revenus, comptes nationaux

Les Documents de travail reflètent les idées personnelles de leurs auteurs et n'expriment pas nécessairement

la position de la Banque de France. Ils sont disponibles sur publications.banque-france.fr 


\section{Section 1. Introduction}

Income inequality has increased significantly in many developed and developing economies over the last decades, with significant variations across countries and regions. At the same time, the rise of emerging countries has contributed to the reduction of inequality between countries. These conflicting trends have attracted considerable interest among academics, policy-makers, and the global public.

Unfortunately we face important limitations in our collective ability to measure income inequality. During the past fifteen years, following up on Kuznets' (1953) pioneering attempt, a number of authors have used administrative tax records to construct longrun series of top income shares (Piketty 2001, 2003; Piketty and Saez, 2003; Atkinson and Piketty 2007, 2010; Alvaredo et al., 2011-2017). These new series have contributed to improve our understanding of inequality trends, particularly the rise of top income shares. Yet they have a number of shortcomings. In particular, they do not offer for the bottom segments of the distribution the same detailed decomposition as for the top part. In order to make progress in this direction, it is critical to combine different data sources in a more systematic manner - typically tax records for the top of the distribution, and survey data for the bottom.

More generally, one important limitation of existing research is the large gap between national accounts - which focus on economic aggregates and macro-economic growth - and inequality studies - which focus on distributions using survey and tax data but usually without trying to be fully consistent with macro aggregates. This gap makes it hard to rigorously address questions such as: how is aggregate economic 
growth distributed between the different income percentiles, from the bottom to the top of the distribution? E.g. what fraction of total growth accrues to the bottom $50 \%$, the middle $40 \%$ and the top $10 \%$ of the distribution? How much is due to changes in the labor and capital shares in national income, and how much is due to changing dispersions of labor earning, capital ownership, and returns to capital? How does per capita growth of the bottom $50 \%$ and $90 \%$ income and wealth groups compare to overall growth, and how is this affected by taxes and transfers?

The present paper attempts to bridge the gap between national accounts and inequality studies more systematically than has been done in the past. We combine national accounts, tax, and survey data in a comprehensive and consistent manner to build "Distributional National Accounts" (DINA), that is, homogenous series on the distribution of total national income in France since 1900. In contrast to previous attempts to construct top income series for France (Piketty 2001, 2003), which are based upon fiscal income, our estimates capture $100 \%$ of national income recorded in the national accounts, and cover the entire distribution, from bottom percentiles to top percentiles. This allows us to provide decompositions of growth by income groups consistent with total economic growth used in macroeconomics.

From a methodological perspective, our key contribution is to construct prototype micro-files of income distribution consistent with macro-aggregates, obtained by statistically matching tax and survey data and making explicit assumptions about the distribution of income categories for which there is no readily available source of information. That is, we combine national accounts, tax and survey data in a comprehensive and consistent manner to build homogenous annual series on the 
distribution of national income by percentiles over the 1900-2014 period, with detailed breakdowns by age, gender and income categories over the 1970-2014 period. The corresponding micro-files and computer codes are available on-line. In a companion paper (Garbinti, Goupille-Lebret and Piketty, 2016), we develop similar methods in order to construct prototype micro-files of wealth distribution that are fully consistent with the income files presented in this paper.

We should stress that the present paper focuses upon the distribution of pre-tax income (with a distinction between pre-tax national income and pre-tax factor income that we will later explain, depending on how we treat pension income and other replacement income). In another companion paper, we include taxes and transfers in our prototype micro-files in order to measure the after-tax after-transfers distribution of income (Bozio, Garbinti, Goupille-Lebret and Piketty, 2017). We should also mention that the present paper belongs to a broad international project aimed at improving inequality measurement, namely the WID.world project. Its general objective is to extend these methods and estimates and to develop homogenous "Distributional National Accounts" (DINA) in as many countries as possible in the coming years (see Alvaredo et al (2016) for general guidelines on the DINA methodology; see Piketty, Saez and Zucman (2018) and Saez and Zucman (2016) for an application to the U.S. case). ${ }^{1}$

Although the present paper is primarily methodological, we also come with a number of novel substantial conclusions. Generally speaking, our DINA-based estimates allow for a much richer analysis of the long-run pattern found in previous tax-based

\footnotetext{
${ }^{1}$ All updated files and results will be made available on-line on the World Wealth and Income Database (WID.world) website: see http://www.WID.world.
} 
series, i.e. a long-run decline in income inequality, largely due to a sharp drop in the concentration of wealth and capital income following the 1914-1945 capital shocks (Piketty 2001, 2003, 2014). First, our new series deliver higher inequality levels than the usual tax-based series for the recent decades, because the latter miss a rising part of capital income. In particular, growth incidence curves look dramatically different for the 1950-1983 and 1983-2014 sub-periods. During the 1950-1983 period, per adult real income rose at almost $4 \%$ per year for most of the population, except for very top percentiles, whose incomes grew at about $1.5 \%$ per year. Between 1983 and 2014, we observe the opposite pattern: for most of the population real growth rates were about $1 \%$ per year or less, except for very top percentiles, who enjoyed real growth rates up to $3 \%$ per year.

We are also able to document the changing correlation between wealth and labor income, and we show that it has become increasingly difficult in recent decades to access top wealth groups with labor income only. More generally, our new series allow us to better analyze the conditions under which wealth concentration might keep rising and possibly return to pre-WW1 levels in the future.

Next, our detailed breakdowns by age and gender allow us to explore new dimensions of inequality dynamics together with the top income dimension. For instance, we find that gender inequality in labor income declined in recent decades, albeit fairly slowly among top labor incomes. E.g. female share among top $0.1 \%$ earners was only 12\% in 2012 (vs. 7\% in 1994 and 5\% in 1970). 
Finally, since our new series are anchored to national accounts, they allow for more reliable comparisons across countries. We find that distributional changes can have large impact on comparisons of well-being across countries. E.g. average pre-tax income among bottom $50 \%$ adults is $30 \%$ larger in France than in the U.S., in spite of the fact that aggregate per adult national income is $30 \%$ smaller in France. Post-tax comparisons are likely to exacerbate this conclusion.

The paper is organized as follows. Section 2 relates our work to the existing literature. Section 3 presents our concepts, methods and data sources. In Section 4 we present our long run results regarding the general evolution of the distribution of national income over the 1900-2014 period. In Section 5 we present detailed inequality breakdowns on labor income vs capital income. In Section 6 we present detailed inequality breakdowns by age and gender for the 1970-2014 period. In Section 7 we compare our French findings to the US DINA series. The conclusion (Section 8) discusses a number of venues for future research. This paper is supplemented by an extensive Online Data Appendix including complete series and additional information about data sources and methodology. 


\section{Section 2. Related literature}

This paper follows a long tradition of research trying to combine national accounts with distributional data. The famous social tables of King produced in the late $17^{\text {th }}$ century were in fact distributional national accounts, showing the distribution of England's income, consumption, and saving across 26 social classes in the year 1688, from baronets to vagrants (see e.g. Stone 1984). Most modern work in this area follows the pioneering contribution of Kuznets (1953), who first combined income tax tabulations (which have been produced annually since the creation of the U.S. federal income tax in 1913) with national income series to estimate top income shares in the U.S. over the period 1913-1948.

Kuznets' methods were further extended by Piketty $(2001,2003)$, who constructed top income shares series for France on the basis of income tax tabulations and national income series available on an annual basis since the creation of the French income tax in 1914. This work contributed to create a new interest to the study of income inequality over the long run using tax return data (see e.g Piketty and Saez (2003) for the U.S.; Atkinson (2005) for the UK and Atkinson and Piketty $(2007,2010)$ for a global perspective on top incomes). This interest has led to the creation in 2011 of The World Top Incomes Database (WTID), a database that gathers homogenous long-term series of top income shares broken down by income source for thirty-one countries. All these contributions used similar sources (income tax tabulations and national accounts) and methods (Pareto interpolation techniques).

As pointed out by Atkinson, Piketty and Saez (2011), these series suffer however from important limitations. In particular they are based on fiscal income, which can 
diverge from national income because of tax exempt income, tax avoidance and evasion. They focus on pretax and pre-transfer income inequality and are therefore silent on redistributive effects of public policies between and across countries. Finally, these series measure only top income shares (typically top 10\% and top 1\%) and hence give no information on the evolution occurring within the bottom of the distribution, letting aside a crucial part of the analysis.

To address these shortcomings, several studies have recently attempted to combine fiscal, survey and national accounts data for a given year (see for instance Landais, Piketty and Saez (2011) and Accardo et al. (2009) for the case of France ${ }^{2}$, see Fixler and Johnson (2014) and Fixler et al. (2015) for the U.S., see Zwijnenburg, Bournot and Giovannelli (2016) for OECD cross-country comparisons ${ }^{3}$ ). In order to make further progress, the World Inequality Lab launched a broad international project, namely the WID.world project, with the aim of providing long-term homogeneous series of income and wealth consistent with national accounts in as many countries as possible in the coming years (see Piketty, Saez and Zucman (2018) and Saez and Zucman (2016) for the U.S. case, this paper and our companion paper Garbinti, Goupille-Lebret and Piketty (2016) for the French case, and Alvaredo et al. (2016) for general guidelines presenting the issues involved in creating distributional national accounts $\left.^{4}\right)$.

\footnotetext{
${ }^{2}$ Landais, Piketty and Saez (2011) pioneering work aimed at reconciling fiscal data, surveys and national accounts in order to study progressivity and redistribution of the French tax system for the year 2010. Accardo et al. (2009) is a work by the French Statistical Institute that breaks down the disposable income and consumption reported in the national accounts for the year 2003 by household characteristics (living standard, age and occupation).

3 The OECD Expert Group on the Distribution of National Accounts, created in 2011, provides crosscountries reconciliation between surveys and national accounts for a given year (see e.g. Zwijnenburg, Bournot and Giovannelli, 2016). More information about the related literature, recent contributions from the OECD, and details about the differences in concepts and methodologies can be found in Piketty, Saez and Zucman (2018).

${ }^{4}$ These guidelines are based on the lessons learned from constructing distributional accounts for the United States and France. This is the reason why these guidelines must be viewed as provisional and exploratory, and will be updated and revised as new country series and methodological advances become available in coming years.
} 


\section{Section 3. Concepts, data sources and methods}

In this section we describe the concepts, data sources and main steps of the methodology that we use in this paper in order to construct our income distribution series. Broadly speaking, we combine three main types of data: national accounts; fiscal data (income tax returns); and household surveys. We first present our income concepts. We then describe our data sources and methods for the recent decades (1970-2014), when we can use micro-files of income tax returns. Finally we proceed to describe our data sources and methods for the long-run historical series (19002014), which rely on income tax tabulations. A longer and more complete discussion of the general methodological issues involved in creating DINA estimates (not specific to France) is presented in Alvaredo et al. (2016). Complete methodological details of our French specific data sources and computations are presented in the Online Data Appendix along with a wide set of tabulated series, data files and computer codes.

\section{Section 3.1. Income concepts}

Our income distribution series are constructed using income concepts that are based upon national accounts categories. ${ }^{5}$ More precisely, we aim to present consistent series based upon four basic income concepts (with a number of variants): pre-tax national income, pre-tax factor income, post-tax disposable income and post-tax national income. By construction, average income per adult is equal to average national income per adult for all concepts (except post-tax disposable income).

\footnotetext{
${ }^{5}$ The reason for using national accounts concepts is not that we believe they are perfectly satisfactory. Our rationale is simply that national accounts are the only existing attempt to define income and wealth in a consistent manner on an international basis.
} 
National income is defined as GDP minus capital depreciation plus net foreign income, following standard national accounts guidelines (SNA 2008).

Pre-tax national income (or more simply pre-tax income) is our benchmark concept to study the distribution of income. Pre-tax income is equal to the sum of all income flows going to labor and capital, after taking into account the operation of the pension system, but before taking into account other taxes and transfers. That is, we deduct pension contributions (as well as other social contributions, as defined by SNA 2008 national accounts guidelines) from incomes, and add pension distributions (as well as other social benefits, as defined by SNA 2008). The same rule applies to fiscal income in most countries: contributions are deductible, and pensions are taxed at the time they are distributed.

In contrast, pre-tax factor income (or more simply factor income) is equal to the sum of all income flows going to labor and capital, before taking into account the operation of the pension system and other taxes and transfers. That is, we do not deduct pension contributions (or other social contributions from incomes and exclude pension distributions (as well as other social benefits) as they are not factor incomes. One problem is that retired individuals typically have very small factor income, so that inequality of factor income tends to rise mechanically with the fraction of old-age individuals in the population, which biases comparisons over time and across countries. This is why we use pre-tax national income as our benchmark concept. On the other hand, looking at the distribution of factor incomes can yield additional insights, especially if we look at it among the working-age population. For instance, it allows to better measure the distribution of labor costs paid by employers. 
Finally, post-tax national income is equal to the sum of all income flows going to labor and capital, after taking into account the operation of the pension system, but after taking into account other taxes and transfers (cash transfers, in-kind transfers, and collective expenditures). In contrast, post-tax disposable income excludes in-kind transfers and collective expenditures. In the present paper, we focus upon pre-tax inequality and provide series using our two pre-tax income concepts. In our companion paper (Bozio, Garbinti, Goupille-Lebret and Piketty, 2017) we analyze the evolution of post-tax inequality and provide series using our two post-tax concepts.

Our preferred income distribution series refer to the distribution of income among equal-split adults (i.e. the income of married couples is divided into two). We also present tax-units series (looking at the income distribution between tax units, i.e. married couples and singles) as well as individualistic-adults series (i.e. labor income is allocated to each individual income earner within the couple). ${ }^{6}$ We further discuss the interpretation of these various series, which in our view convey three complementary and legitimate approaches to inequality measurement.

We compute national income and the various subcomponents of pre-tax national and factor income and post-tax national and disposable income using the official national accounts established by the French national statistical institute (INSEE) for the 19492015 period. For the earlier periods, we use the historical series provided by Piketty and Zucman (2014). All data files and complete methodological details are given in the Data Appendix (see Appendix A).

\footnotetext{
${ }^{6}$ Capital income of married couples is always divided into two (because we do not have other information).
} 
Section 3.2. Data sources and methods for recent decades (1970-2014)

We now describe the data sources and methodology used to estimate the distribution of income for the 1970-2014 period. Over this period we can use the micro-files of income tax returns that have been produced by the French Finance Ministry since 1970. We have access to large annual micro-files since 1988. These files include about 400,000 tax units per year, with large oversampling at the top (they are exhaustive at the very top; since 2010 we also have access to exhaustive micro-files, including about the universe of all tax units, i.e. about 37 million tax units in 20102012). ${ }^{7}$ Before 1988, micro-files are available for a limited number of years (1970, 1975, 1979 and 1984) and are of smaller size (about 40,000 tax units per year). Since 1996, income tax micro-files can also be matched to employment survey data compiled by the French national statistical institute. ${ }^{8}$

These micro-files allow us to estimate the distribution of fiscal income, i.e. income reported on income tax returns. In order to estimate the distribution of national income (pretax and factor), we need to combine income tax micro-files with other data sources, namely national accounts and household surveys, and to apply a number of imputation rules.

We start with pretax national income series. The gap between fiscal income and national income can be decomposed into three components: tax-exempt labor income, tax-exempt capital income, and production taxes. Before we take each of

\footnotetext{
${ }^{7}$ As of July 2016, the latest micro-file available is the 2012 micro-file. For years $2013-2014$ we apply the same method as that described below for 1971-1974, 1976-1978, 1980-1983 and 1985-1987.

8 ERFS files: Enquête Revenus Fiscaux et Sociaux.
} 
these three components in turn, note that income tax micro-files allow us to split fiscal labor income into three components (wages; pension and unemployment benefits; and labor component of mixed income, which we assume for simplicity to be equal to $70 \%$ of total mixed income) and fiscal capital income into four components (tenantoccupied rental income; dividend; interest; and capital component of mixed income, i.e. $30 \%$ of total mixed income) ${ }^{9}$

Tax-exempt labor income, which we define as the gap between national-accounts labor income and fiscal labor income, consists of non-taxable compensation items such as health benefits and a number of other in-kind benefits. In the absence of specific information, we simply impute them in proportion to fiscal labor income. ${ }^{10}$

Tax-exempt capital income raises more complicated issues. Fiscal capital income differs from national capital income for three main reasons. ${ }^{11}$ First, some capital income components are fully tax-exempt and therefore not reported in income tax returns. Tax-exempt capital income includes three main components: income going to tax-exempt life insurance assets ${ }^{12}$; owner-occupied rental income; other taxexempt interest income paid to deposits and saving accounts. Second, some capital

\footnotetext{
${ }^{9}$ Fiscal capital income also includes realized capital gains, but we do not use this variable for imputation purposes in our benchmark series (because it is too lumpy). Income tax micro-files also allow us to split mixed income into different forms of self-employment activities (BIC, bénéfices industriels et commerciaux; BNC, bénéfices non commerciaux; BA, bénéfices agricoles), but we do not use this decomposition.

10 More precisely, we upgrade all observed individual-level fiscal labor incomes by multiplying them by the aggregate ratio between national-accounts labor income and fiscal labor income. We do this separately for wages, pensions and unemployment benefits, and mixed income. See Online Appendix $C$ for full details and computer codes.

${ }^{11}$ Figure 1 from Online Appendix A depicts the evolution of tax-exempt capital income over the 19702014 period.

12 More precisely, this category regroups income attributed to life insurance and pension funds. Before 1998, life insurance income was entirely exempt from income tax. Since 1998, only capital income withdrawn from the account are taxed (see Goupille-Lebret and Infante (2017) for more details). As a result, total life insurance income reported in the tax data correspond to less than $5 \%$ of its counterpart in national accounts.
} 
income components are included into the income tax returns but their aggregate may differ from those reported in national accounts due to tax avoidance or tax evasion. For example, a significant part of dividends is missing in the tax data. ${ }^{13}$

Finally, corporate retained earnings and corporate taxes are not directly received or paid by individuals and are therefore excluded from income tax. One need to make implicit incidence assumptions on how to attribute them.

It is worth stressing that all of these components have increased significantly in recent decades. In particular, life insurance assets did not play an important role until the 1970s, but gradually became a central component of household financial portfolios since the 1980s-1990s. ${ }^{14}$ As a result, these elements are either missing or under-reported in the income tax returns and need to be imputed.

Regarding owner-occupied housing, life insurance assets, and deposits and saving accounts, we use available wealth and housing surveys in order to impute these assets on the basis of labor income, financial income and age. We then attribute the corresponding asset income flows on the basis of average rates of return observed in national accounts for this asset class.

More specifically, the imputation procedure is the following. First, in the household surveys, we define groups according to three dimensions: age, financial income, and labor and replacement income. ${ }^{15}$ Second, for each group and each kind of asset to

\footnotetext{
${ }^{13}$ Individuals can legally avoid dividend tax using complex tax optimization strategies. Such schemes imply that dividends have to be distributed to and kept in holding companies. Dividend tax will eventually occur when the holding company will distribute dividends to its shareholders.

${ }^{14}$ Imputed rent has also become gradually more important over time with the rise of homeownership. In addition, note that imputed rent was actually included in fiscal rental income (together with tenantoccupied rental income) until 1963 in France. Finally, corporate retained earnings and corporate taxes were relatively small until the mid-20 $0^{\text {th }}$ century and also increased significantly in recent decades.

${ }^{15}$ For example, we define approximately 200 groups for the imputation of owner-occupied housing asset. We first split the sample into 10 age groups $(<25 ; 25-30 ; 31-39 ; 40-49 ; 50-54 ; 55-60 ; 61-65$ ; 66-70;71-80; $>80)$. We then divide each age group into 4 percentile groups of financial income (P0-50 ; P50-90 ; P90-99 ; P99-100). Finally, we split again each of these 40 groups (10 age groups
} 
be imputed (owner-occupied housing, deposits, and life insurance), we both compute an extensive margin (the proportion of individuals holding the asset considered) and an intensive margin (share of the total asset owned by the group). Third, in our income tax micro files, we define groups according to the same dimensions (age, financial and labor incomes). Then, within each of these groups, we randomly draw tax units that own the asset accordingly to the corresponding extensive margin (i.e. computed for the asset and the group considered). The intensive margin is then used to impute the asset amount within the asset holders of this group (for more details and examples, see Appendix C in our companion paper Garbinti, Goupille-Lebret and Piketty (2016)). We then attribute the corresponding asset income flows on the basis of average rates of return observed in national accounts for this asset class.

This procedure can be seen as an hot deck procedure in two steps where the information is taken from external sources (housing and wealth surveys). It offers the advantage of respecting the initial distribution of asset holding (in the surveys) without creating outliers.

For capital income components reported in the income tax micro-files ${ }^{16}$, we conduct the following reconciliation exercise. We simply adjust proportionally each of these capital income components in order to match their counterpart in national accounts (reported in Online Appendix A, Table A8). ${ }^{17}$ The assumption behind this simple adjustment is that tax evasion and tax avoidance behaviors do not vary along each income-specific distribution. Alstadsaeter, Johannesen and Zucman (2017) provide

\footnotetext{
*4 groups of financial income) into 5 percentile groups of labor and replacement income (P0-25, P2550, P50-75, P75-90, P90-100).

${ }^{16}$ i.e. tenant-occupied rental income; dividends; interests from debt assets; and capital component of mixed income (i.e. $30 \%$ of total mixed income).

17 That is, we multiply each individual capital income component reported in the micro-files by the corresponding national-income/fiscal-income ratio.
} 
evidence that tax evasion rises sharply with wealth. Our assumption is therefore very conservative and our results should be seen as a lower bound of the true level of income concentration. In particular, the important rise of very top incomes documented since 1983 is likely to be under-estimated.

Regarding corporate retained earnings and corporate taxes, we impute them in proportion to individual dividends, life insurance income, and interests, i.e. total financial income excluding tax-exempt interest income paid to deposits and saving accounts. ${ }^{18}$ More precisely we impute to individuals the fraction that can be attributed to individuals, i.e. we subtract the fraction of domestic corporate capital that can be attributed to the government. We also subtract the fraction that can be attributed to the rest of the world (in case the country has a negative net foreign asset position), or add the fraction that domestic households own in the rest of the world (in case the country has a positive net foreign position). ${ }^{19}$

We now present the main caveat of our imputation choice. If rich people are more likely to retain dividends in holding companies or more generally implement tax optimization or tax evasion strategies that reduce artificially their taxable dividends, our methodology will under-estimate the level of corporate retained earnings and corporate taxes accruing to the richest individuals and therefore under-estimate the level of income inequality. We argue, however, that this bias should mainly affect the level of inequality within the top $1 \%$ and, to a lesser extent, that within the top $10 \%$

\footnotetext{
${ }^{18}$ In France, tax-exempt saving accounts (like livret A) are financial products that are regulated by the State and used to finance social projects.

19 In effect we assume that corporate retained earnings and corporate taxes are the same in domestic corporations and foreign corporations. See Online Appendix $\mathrm{C}$ for a more detailed discussion and for corresponding data files and computer codes.
} 
because financial income is extremely concentrated at the top. ${ }^{20}$ In other words, our methodology is likely to over-estimate the level of corporate earnings and corporate taxes accruing to the poorest individuals of the top $10 \%$ income group and underestimate that of the very top incomes.

An alternative strategy used by Piketty, Saez and Zucman (2018) would be to impute corporate retained earnings in proportion to individual dividends or to use differential evasion rates in order to distribute relatively more retained earnings to the top $0.1 \%$ capital income earners. Such strategies could, however, be difficult to implement in the case of France for two reasons. First, there is a fuzzy frontier between interests and dividends in the tax data. Life insurance income and income from mutual funds are often a mix of both dividends and interests, and this decomposition is not available in income tax returns. Second, such strategies require to use differential evasion rates by income level, which are not available for France.

While we stress that our imputation strategy is rudimentary and imperfect, it has the advantage to provide a lower bound for the rise of very top incomes since the early 1980s.

Finally, note that production taxes (in the SNA 2008 sense) include a number of indirect taxes, including value added taxes, which in effect are paid by corporations before they can distribute labor and capital income flows, and are therefore excluded from fiscal income. Production taxes also include property taxes, which we attribute to individuals in proportion to their owner-occupied and tenant-occupied housing assets. For simplicity, we choose to attribute production taxes other than property taxes in proportion to the sum of individual labor and capital incomes. An alternative

\footnotetext{
20 In 2014 , the top $10 \%$ and the top $1 \%$ income groups earn $77 \%$ and $55 \%$ of total dividends, life insurance income and interests, respectively.
} 
assumption (followed in Landais, Piketty and Saez, 2011) would be to attribute them partly to consumption, i.e. income minus some estimate of saving. To the extent that the purpose of wealth accumulation is wealth in itself (e.g. power, prestige, etc., at least in part) rather than simply postponed consumption, this would be particularly justified.

More generally, we should stress that our implicit tax incidence assumptions are relatively rudimentary and could be improved in future estimates. For instance our assumption to attribute corporate taxes solely to interests, dividends and life insurance income, and property taxes solely to housing assets amounts to assuming that these two forms of assets involve relatively distinct and segmented choice processes. This is to some extent the case, but one might want to adopt a more unified view of portfolio choices, in which case corporate and property taxes should both fall on all assets. In Online Appendix $C$ we look at a number of variants and conclude that they have a relatively small impact on the general patterns and long run evolutions. However this is clearly an issue that would deserve additional research.

We should also mention the fact that a more satisfactory approach to tax incidence should also take into account the impact of taxes on quantities. That is, labor and capital taxes are likely to have an impact on the supply and demand of labor and capital and the level of output. This is clearly beyond the scope of the present paper, but this is something that future research on DINAs should attempt to address, e.g. by making simplified but plausible assumptions on the various supply and demand elasticities. 
Finally, in order to ensure that aggregate pretax national income matches exactly with aggregate national income, we choose for simplicity to attribute government deficit (or surplus) in proportion to all other incomes. In effect, this leaves the distribution unaffected. Another assumption, followed by Piketty, Saez and Zucman (2018) for the U.S., consists of attributing $50 \%$ of government deficit (or surplus) in proportion to taxes and $50 \%$ in proportion to transfers and expenditures. In effect, this is assuming that fiscal adjustment will be borne equally by taxes and spending. In practice, this makes very little difference (except in years with very large deficit or surplus).

Regarding factor income series, the only difference with our benchmark pretax income series is that we set pensions and unemployment benefits to zero, and that we upgrade fiscal labor income (other than pensions and unemployment benefits) so as to match national-accounts labor income. We also take into account the fact that social contributions are not strictly proportional and often involve significant exemptions for low wages or high wages, with important variations over the 19702014 period..$^{21}$

Section 3.3. Data sources and methods for long-run series (1900-2014)

\footnotetext{
${ }^{21}$ We thus simulate the different types of social contributions and apply the relevant schedules that
} vary by earning brackets and over time. For more details, see online Appendix C. 
We now describe the data sources and methodology used to estimate our long-run series. Unfortunately no income tax micro file is available in France before 1970, so we have to use income tax tabulations.

Detailed income tax tabulations have been produced by the French Finance Ministry since the creation of income tax in France in 1914 (first applied in 1915). These tabulations are available on an annual basis throughout the 1915-2014 period (with no exception) and are based upon the universe of all tax units. ${ }^{22}$ They report the number of taxpayers and total income for a large number of income brackets. These tabulations were first used in a systematic manner by Piketty $(2001,2003)$. In the present paper we update and considerably refine these estimates. ${ }^{23}$ Complete methodological details, data files and computer codes are provided in Appendix D. Here we simply describe the main steps.

First, by applying the generalized, non-parametric Pareto interpolation techniques developed by Blanchet, Fournier and Piketty (2017) to these tabulations, we produce annual series of fiscal income for the entire distribution and not only for the top decile (the initial estimates by Piketty $(2001,2003)$ focused on the top decile and did not attempt to go below the $90^{\text {th }}$ percentile). Next, the income tax tabulations also include detailed information on the numbers of married couples and of singles in each income bracket (and also on the numbers of dependent children, which was used in a systematic manner by Landais, 2003). We again use the "gpinter" computer codes developed by Blanchet, Fournier and Piketty (2017) (available on-line on

\footnotetext{
22 As of July 2016, the latest tabulation available is the 2014 tabulation.

${ }^{23}$ We also use estimates of the distribution of income for years 1900 and 1910 that were produced by the French Finance Ministry in the context of the parliamentary debates about the creation of an income tax (using data from various sources, including property taxes and inheritance taxes).
} 
WID.world/research-tools) in order to estimate separately the distribution of fiscal income among tax units and among equal-split individuals (the initial estimates by Piketty $(2001,2003)$ focused on tax units and did not attempt to correct for different tax unit sizes) ${ }^{24}$

In the Online Appendix we provide a systematic comparison for the 1970-2014 period between the distribution of fiscal income (from bottom to top percentiles) estimated via the micro-files and via the income tax tabulations, and we find that the two series are virtually identical (see appendix C). Given that the tax tabulations are available annually and are based on the universe of taxpayers (and therefore suffer from no sampling problems), we adopt the tax-tabulations series as our benchmark series for the distribution of fiscal income. ${ }^{25}$ Income tax tabulations also include detailed breakdowns by income categories (wages, self-employment income, dividend, interest, etc.), which we use to estimate separately the distribution of fiscal labor income and fiscal capital income. ${ }^{26}$

Finally, in order to estimate the distribution of pre-tax national income from the distribution of fiscal income, we proceed as follows. Regarding the 1970-2014 period,

\footnotetext{
${ }^{24}$ Our methodology is complicated by the fact that income tax tabulations are based upon a concept of "taxable income" (i.e. fiscal income minus a number of specific deductions instituted by the tax law, such as a $10 \%$ lump-sum deduction for professional expenses of wage earners, etc.) rather than the concept of "fiscal income" that we are interested in (i.e. income reported on fiscal declarations, before any further deduction). Therefore we need to apply a number of corrections in order to take into account the many changes in the tax law that occurred between 1914 and 2014. Another complication comes from the fact that income tax tabulations prior to 1985 only cover tax units that are subject to positive income tax. This calls for other corrections, taking into account the fact that the relevant exemption threshold varies with the marital status and numbers of children. All the different steps are carefully described in Appendix $D$, together with full data files and computer codes.

25 The gaps between the two series are virtually negligible for the post-1988 period (when micro-files start to be annual and of very large size), and are slightly more significant between 1970 and 1984 (when micro-files are of smaller size and are not annual). See Appendix C.

${ }^{26}$ One important limitation of the detailed tabulations by income categories is that, prior to 1945 , they only cover a limited number of years (namely, 1917, 1920, 1932, 1934, 1936 and 1937); they then become annual in 1945. Fortunately there are separate annual tabulations for wages over the 19191938 period, and quasi-annual inheritance tabulations over the 1902-1964 period.
} 
when the micro-files allow for relatively sophisticated imputation procedures by income and asset categories (see above), we naturally use these corrections in order to construct our benchmark series. ${ }^{27}$ Regarding the $1915-1970$ series, our correction procedure is more rudimentary. We start from the presumption that the induced corrections on percentile shares tends to rise over time (at the beginning of the period, tax rates are relatively small, so that incentives for tax optimization are limited, and legal tax exemption regimes are rare). This assumption appears to be confirmed by the detailed fiscal tabulations with breakdowns by labor and capital incomes (which unfortunately are not available on an annual basis before 1945), so we assume for simplicity that correction rates rise linearly from 1915 to 1970 . This is clearly an approximation, but as we will later discuss when we present separately our results for fiscal income and national income series, the impact on our long run patterns is likely to be limited. Finally, note that we do not attempt to provide factor income series nor fully individualized series prior to 1970 (tax tabulations do not include any information on within-couple distribution of income, so one would need to find other data sources in order to do this). More generally, we stress that our longrun series should be viewed as exploratory and incomplete, and we hope that they will be further developed and refined in future research.

\footnotetext{
${ }^{27}$ That is, we compute the national-income/fiscal-income ratios by year and percentile using the microfiles series, and we apply these ratios to the fiscal-income tax-tabulations series. See appendix D for detailed data files, computer codes and robustness checks.
} 


\section{Section 4. Long-run trends in income inequality (1900-2014)}

We now present our main findings regarding the long-run evolution of income inequality over the 1900-2014 period. We start with general trends in income shares before moving on to growth incidence curves.

First, it is useful to have in mind the general evolution of average income in France. As one can see from Figure 1, per adult national income has increased considerably in the long run, from about $5000 €$ around 1900 to $35000 €$ in 2014 (all figures expressed in $2014 €)$. However the growth has been far from steady and happened mostly during the 1945-1980 - often referred to as the "Thirty Glorious Years" in France. That is, the growth rate of per adult national income has been negative during the $1900-1945$ period ( $-0.1 \%$ per year), then jumped to $3.7 \%$ per year over the 1945-1980 period, and finally was divided by almost four over the 1980-2014 period ( $0.9 \%$ per year). We observe similar patterns in most European countries and in Japan, and to a lesser extent in the U.S. and in the U.K (where the shocks created by WW1 and WW2 were less damaging than in Continental Europe and Japan).

Next, we report on Table 1 the income levels, thresholds and shares for 2014. In 2014, average income per adult in France was about $35000 €$. Average income within the bottom $50 \%$ of the distribution was about $16000 €$, i.e. about half of the overall average, so that their income share was about $23 \%$. Average income within the next $40 \%$ of the distribution was about $39000 €$, so that their income share was close to $45 \%$. Finally, average income within the top $10 \%$ was about $110000 €$ (i.e. about 3.2 times average income), so that their income share was about $32 \%$. 
We report on Figures 2 and 3 the evolution of the income shares going to these three groups over the 1900-2014 period. The major long-run transformation is the rise of the share going to the bottom $50 \%$ (the "lower class") and the middle $40 \%$ (the "middle class") and the decline of the share going to the top 10\% (the "upper class"). However this long run evolution has been far from steady. The top $10 \%$ income share fell abruptly during the $1914-1945$ period, from more than $50 \%$ of total income at the eve of World War 1 to slightly more than $30 \%$ of total income in 1945 . One can see a rise in inequality during the reconstruction period and up until 1967-1968. Between 1968 and 1983, we observe a large reduction of inequality, which is well-known to be due to a large compression of wage inequality (driven in particular by very large increases in the minimum wage following the 1968 social protests) and a significant reduction of the capital share. Beginning around 1983, one observes the reverse evolution, as the newly elected left-wing government puts an end to the very fast rise in wages (substantially faster than output growth, particularly for bottom wages) that had occurred between 1968 and 1983. This general periodization of the political and economic history of France during the $20^{\text {th }}$ century is relatively standard and has already been studied elsewhere (see in particular Piketty 2001, 2003, 2014).

The main novelties here are the following. First, we are able to show that both the bottom $50 \%$ and the middle $40 \%$ benefited (in comparable proportions) from the long run decline in the top $10 \%$ share. Next, we can better analyze both the long run pattern as well as the recent trends. 
Regarding the recent trend, we see that the top $10 \%$ income share declined somewhat after the 2008 financial crises, but that it is still significantly higher than in the early 1980s (see Figures 2-3). Most importantly, if we look at the top $1 \%$ income share (Figure 4), we see a very significant increase between 1983 and 2007: the top $1 \%$ share rose from less than $8 \%$ of total income to over $12 \%$ over this period, i.e. by more than $50 \%$. This is less massive than in the United States (where the top $1 \%$ share has reached about $20 \%$ of total income; see below), but this is still fairly spectacular. Between 2008 and 2013, the top 1\% share has fluctuated between 10\% and $12 \%$, which is still significantly larger than in the low inequality point of the early 1980s.

Moreover, the higher we go at the top of the distribution, the higher the rise in top income shares (see Figures 5a-5d). Our detailed series also allow us to see that the rise of very top incomes is due both to the rise of very top labor incomes and very top capital incomes. In certain cases, both can be very related: e.g. top managers can first benefit from very high labor incomes through large bonuses or stock options (the difference between exercise value and option value is generally counted as labor income under French tax law, just like in the U.S.), and then from very high capital incomes derived from their equity participation.

Given the relative stagnation of average income in France since 1980 (at least as compared to the previous decades), this spectacular rise of very top incomes has not gone unnoticed. Even though the macroeconomic impact on the overall top $10 \%$ share and on bottom $90 \%$ incomes has been less massive than in the U.S., this reversal of the previous trends is very significant. Like in other countries, the large 
increase in very top managerial compensation packages in recent decades was largely covered by the media and has shown to the broader public that the "Thirty Glorious Years" are not over for everyone.

One way to better understand the magnitude of the turning point that occurred in the 1980s is to look at growth incidence curves (see Figures 6a-6d and Tables 2a-2b). Between 1983 and 2014, average per adult national income rose by $35 \%$ in real terms in France. However actual cumulated growth was not the same for all income groups: the growth incidence curve is characterized by an impressive upward-sloping part at the top. Cumulated growth between 1983 and 2014 was 33\% on average for the bottom $50 \%$ of the distribution, $27 \%$ for next $40 \%$, and $50 \%$ for the top $10 \%$ (see Table 2). Most importantly, cumulated growth remains below average until the $95^{\text {th }}$ percentile, and then rises steeply, up to as much as $100 \%$ for the top $1 \%$ and $145 \%$ for the top $0,01 \%$ (see Table 2 and Figure $6 a$ ).

The contrast with the 1950-1983 period is particularly striking. In effect, during the "Thirty Glorious Years", we observe the exact opposite pattern as in the following thirty years. Between 1950 and 1983, growth rates were very high for the bottom $95 \%$ of the population (about $3.5 \%$ per year) and fell abruptly above the $95^{\text {th }}$ percentile (1.5\% at the very top); between 1983 and 2014, growth rates were modest for the bottom $95 \%$ of the population (about $1 \%$ per year) and rose sharply above the $95^{\text {th }}$ percentile (3\% at the very top) (see Figure $6 \mathrm{~d}$ ).

Another way to measure these diverging evolutions is to compare the shares of total economic growth going to the different income groups. Between 1900 and 1950, 34\% 
of total growth went to the bottom $50 \%$ of the population, as compared to $7 \%$ for the top $10 \%$. Between 1983 and $2014,22 \%$ of total growth went to the bottom $50 \%$, as compared to $42 \%$ to the top $10 \%$ (including $21 \%$ for the top $1 \%$ alone, i.e. more than for the bottom half of the population). Rising inequality in recent decades has been less massive in France than in the US (where bottom 50\% pre-tax incomes did not grow at all; see section 7 below), but it has nevertheless been fairly substantial.

How can we account for these changing patterns of growth incidence curves, and in particular for the complete reversal that we observe between the 1950-1983 and 1983-2014 sub-periods? Our detailed series show that the sharp rise of very top incomes since the 1980 s is due both to top capital incomes and top labor incomes. Regarding the rise of top capital incomes, one should distinguish between two effects: the rise of the macroeconomic capital share on the one hand (an evolution that is due to a combination of economic and institutional factors, including the decline of labor bargaining power and the lift of rent control, and that was reinforced by corporate privatization policies), and the rise of wealth concentration on the other hand (see section 4 below for a more detailed discussion).

Regarding the rise of top labor incomes, it is worth stressing that it occurred only at the very top, i.e. above the $95^{\text {th }}$ percentile, and mostly within the top $1 \%$ and top $0.1 \%$. It is difficult for standard explanations based upon technical change and changing supply and demand of skills to fully explain this concentration of rising inequality at the very top (for references and discussion, see Piketty 2014, chapter 9). It seems more promising to stress the role of institutional factors governing pay setting processes for top managerial compensation, including corporate governance, 
the decline of unions and collective bargaining processes, and the drop in top income tax rates (see Piketty, Saez and Stantcheva, 2014).

In the bottom part of the distribution, the growth incidence curve also displays interesting variations between 1983 and 2014. In the bottom 20\% of the distribution we observe negative or below average growth, reflecting rising unemployment and under-employment. Between the $20^{\text {th }}$ and the $40^{\text {th }}$ percentile, cumulated growth has been somewhat above average (about $40-50 \%$, as opposed to less than $30 \%$ between the $40^{\text {th }}$ and the $95^{\text {th }}$ percentiles). This reflects the fact that bottom wages and pensions have increased somewhat more than wages and pensions in the middle and upper middle of the distribution. We study theses issues in more detail in our companion paper on post-tax post-transfers inequality (Bozio, Garbinti, GoupilleLebret and Piketty 2017). It should also be noted that if we look at growth incidence curves for individualistic adults - rather than for equal-split adults - we see large gains at the bottom due to rising female participation (see Appendix B and section 6 below). 


\section{Section 5. Inequality breakdowns: labor income vs capital income}

Our new series on income inequality in France include three main novelties: they cover the entire distribution, from bottom to top (so that for we can analyze detailed growth incidence curves; see section 4 above); they include inequality breakdowns by family structure, age and gender (see section 6 below); and they include inequality breakdowns for labor income vs capital income, which we now present.

First, our new series confirm that the long run decline in total income inequality is entirely due to the fall of top capital incomes, which never fully recovered from the 1914-1945 capital shocks. The standard explanation is that the change in policy regime following these shocks (in particular the rise of steeply progressive taxation of income and inheritance) prevented the concentration of wealth and capital income to return to its pre-WW1 levels (Piketty 2001, 2003, 2014). In contrast, there is no longrun decline in labor income inequality (see Figures $7 a-7 b$ ). It is also worth noting that, throughout the 1900-2014 period, bottom and middle incomes are mostly derived from labor income, while capital income becomes predominant at very high incomes. This is still true today (see Figure 8). But the difference is that one needs to go higher in the distribution today for capital income to become dominant, because the concentration of wealth and capital income has declined very substantially.

Our new series allow us to document and analyze in a much more comprehensive manner than previous studies the long-run transformation of wealth and capital income concentration. In particular, we are able to compare very precisely the evolution of the inequality of labor income, total income, capital income and wealth 
throughout the $20^{\text {th }}$ century. One can see that despite its long-run decline, the concentration of wealth has always been much larger than that of labor income. E.g. the top $10 \%$ labor income share has always been around $25 \%-30 \%$ of total labor income, whereas the top $10 \%$ wealth share has always been of the order of two-three times larger: as much as $85 \%-90 \%$ of total wealth in $1900-1910$, and about $55 \%-60 \%$ of total wealth in 2000-2010 (see Figure 9a). The gap is particularly strong at the level of the top $1 \%$ share: about $6-7 \%$ for labor income, as opposed to $55 \%-60 \%$ - in $1900-1910$ - or $25 \%-30 \%$ - in $2000-2010$ - for wealth (see Figure 9b). It is very difficult to account for such a massive gap with life-cycle (or precautionary saving) models of wealth accumulation, according to which wealth inequality should be comparable (or inferior) in magnitude to the inequality of labor income.

It is also worth noting that the concentration of capital income is even larger than that of wealth (see Figures 9a-9b). This reflects the fact that the concentration of highyield assets such as equity is larger than that of lower-yield assets such as deposits or housing (i.e. large wealth portfolios are mostly made of equity and other high-yield assets, while middle-size portfolios largely consist of housing and small asset holdings concentrate on low-yield deposits).

In order to account for these very high levels of wealth concentration, it is well-known that one needs to go beyond life-cycle or precautionary saving models and introduce additional ingredients, such as inheritance, long horizons and multiplicative random shocks (see e.g. Piketty and Zucman (2015)). In our companion paper (Garbinti, Goupille-Lebret and Piketty, 2016), we provide quantitative simulations of a simple dynamic model of steady-state wealth concentration in order to further investigate 
this issue. In particular, we use our detailed wealth and income series in order to estimate the distribution of synthetic saving rates and rates of return by wealth group. The general conclusion is that the large observed dispersion in saving rates and rates of return can naturally magnify the steady-state level of wealth concentration (for a given level of labor income inequality). We also show that relatively small changes in structural parameters (e.g. the fact that growth slowdown since the 1980s has been accompanied by a significant decline of saving rates of the lower income and wealth groups, from small but positive levels until the 1970s to near-zero levels since the 1980s) can have huge long-run consequences. This allows us to discuss the conditions under which wealth concentration might keep rising in the coming decades, and might possibly return to pre-WW1 levels. In particular, this modelling framework can be used to quantify the extent to which progressive taxation (via its impact on the inequality of disposable income and saving rates) can have an impact on long-run wealth concentration.

Our detailed income-wealth synthetic micro-files can also be used to analyze the changing correlations between labor income and wealth. If we compute the average wealth rank as a function of labor income rank, we find an upward-sloping pattern throughout the distribution - reflecting a positive correlation between labor income and wealth, particularly for top percentile ranks. The general slope seems relatively stable over the 1970-2010 period, possibly with a rising correlation over time (see Figure 10a). However if we look at the very top we see a very clear change in pattern. I.e. the probability for top labor earners to belong to top wealth groups has declined regularly since the 1970s (see Figures 10b-10c). 
Two contradictory effects are at play here. On the one hand, the rise of top labor income shares in recent decades should in principle make it easier for top labor earners to accumulate large wealth holdings. On the other hand, the very large rise in the aggregate wealth-income ratio and the aggregate inheritance flow makes it more difficult for top labor earners with no family wealth to access top wealth groups. Our results suggest that the second effect tends to dominate. This is consistent with the estimates by Piketty (2011) comparing the living standards attained by top labor earners and top inheritors across cohorts, and concluding that the latter were catching up with the former in recent decades (see also Alvaredo, Garbinti and Piketty (2017) for estimates of the recent rise of the share of inheritance in aggregate wealth accumulation). 


\section{Section 6. Inequality breakdowns: age and gender}

We now present a number of new findings from our detailed inequality breakdowns by family structure, age and gender. We start with the issue of family structure and then move on to age and gender.

There are two main differences between the new income inequality series presented in this paper and the previous series (Piketty 2001, 2003, 2014). First, the new series cover the entire distribution, from bottom and top percentiles, and all forms of income, both taxable and tax-exempt (including tax-exempt capital income such as retained earnings or imputed rent). Next, the new series take into account the changing distribution of family structure. In particular, our benchmark series measure the distribution of income between "equal-split adults" (in the sense that the income of married couples is divided by two).

In terms of overall inequality levels, these two main differences tend to compensate each other. On the one hand, our new national-income series tend to deliver higher inequality levels than the fiscal-income series for the recent decades, because the latter miss a rising part of capital income (see Figure 11a). On the other hand, moving from tax-unit series from equal-split series has the opposite effect on inequality levels, given the rise of the fraction of singles (see Figure 11b). We tend to prefer equal-split series, but we should stress that if we are interested in the inequality of purchasing power and living standards, then the truth is probably in between the two series, depending on the exact equivalence scale than one favors for couples as compared to singles. 
We now move to the age profile. As one can see from Figures $12 \mathrm{a}-12 \mathrm{~b}$, the age-labor income and the age-income profiles have always been upward sloping over the 1970-2014 period, at least between age 20 and 60 , and this has not changed a lot over this period. Over age 60, the profile is generally quite flat, except in 1970, when it was downward sloping, reflecting the fact that the pension system was less generous at the time, and has gradually become more generous over time. It is also striking to see that the age-capital income profile (and the age-wealth profile, see our companion paper) is much more strongly upward sloping than the age-labor income profile (see Figure 12c). If we now look at inequality, we find that it is almost as large within each age group as for the population taken as a whole (see Figure 13).

We now come to gender gaps. Here the main novelty is that we are able to offer detailed annual series on gender gaps, with reliable data on top incomes. The general conclusion is that although gender gaps have declined significantly in recent decades, they are still extremely high. As of 2012, we find that men earn in average 1.25 times more than women when they are 25 (taking into account all men and women in a given age group, whether they work or not), and that this gender gap continuously increases with age, up to 1.64 when they are 65 (see Figure 14a). This reflects the fact that women face much lower probabilities to be promoted to higherwage jobs during their career.

If we take a longer temporal perspective, we find that the gender gap used to be much larger. In particular, the French labor model around 1970 appears clearly as a "patriarchal" model, with men earning 3.5 to 4 times more labor income than women 
between age 30 and 55 (see Figure 14b). In effect, money income at that time was not something destined to women. While we document a continuous decline of gender inequality in labor income during recent decades (partly due to a dramatic increase of the share of working women from $45 \%$ in 1970 to $80 \%$ in 2012 , see Figure 15a), our series also make clear that women still do not access higher-paying jobs. In 2012, female share is only $16 \%$ among top 1\% labor earners (and 12\% among top $0.1 \%$ ), with a very moderate upward trend observed since 1994. If we extrapolate from the recent trends, one would need to wait 2102 for women to reach $50 \%$ of top $1 \%$ labor earners, 2144 to reach $50 \%$ of top $0.1 \%$ (see Figure $15 \mathrm{~b}$ ).

It should also be noted that if we measure income inequality between individualistic adults (i.e. allocating labor income to each adult individual) rather than among equalsplit, then we find a large rise in bottom $50 \%$ income share and a substantial reduction of overall inequality (see Figure 16). This "individualistic-adult" viewpoint on inequality should in our view be considered as complementary to the "equal-splitadult" perspective on inequality. I.e. to the extent that individual income contributes to determine the balance of power in couples - and in society at large - the decline in individualistic-adult inequality does indeed correspond to a very substantial evolution, namely the gradual - but incomplete - decline of gender inequality. 


\section{Section 7. International comparisons: France vs US}

We now put our findings in comparative perspective. One of the objectives of the DINA series is that the levels of income and inequality can be more easily compared across countries. Unfortunately DINA series are available solely for France and the US at this stage, so we limit our comparison to these two countries.

It is useful to start with a comparison between average income in France and the US. Measured in purchasing power parity terms, average per adult national income in France was less than $50 \%$ of the US level in the immediate aftermath of World War 2 (as compared to $60 \%-80 \%$ in the pre-WW1 and interwar periods). It then recovered and reached about $70 \%-80 \%$ of the US level since the 1970 s-1980s. It has remained around this level since then, with a slight decline in recent years (67\% in 2014). It is worth noting, however, that the gap between U.S. and French per adult national income levels is entirely due to a difference in working hours. I.e. productivity - as measured by GDP per hour of work - has been roughly at the same level in the two countries since the 1990 s. The difference in working hours is itself due to a complex combination of factors: it partly reflects involuntary - and arguable welfare-reducing factors (such as higher unemployment in France); ${ }^{28}$ and it also partly reflects voluntary - and arguably welfare-enhancing - factors (such as longer vacations and shorter working weeks in France). A complete analysis of this gap and its welfare impact falls well beyond the scope of the present paper, but it is nevertheless useful

\footnotetext{
${ }^{28}$ Note however the gap in unemployment rates - of the order of $5 \%$ - can explain only a limited part of the $30 \%$ gap in working hours.
} 
to have in mind these basic aggregate facts when making income and inequality comparisons between the two countries. ${ }^{29}$

Regarding the evolution of income inequality, we first confirm that top income shares increased much more in the U.S. than in France since the 1980s (see Figures 18a18b). France used to more unequal than the U.S. until World War 1 (particularly regarding wealth concentration), and had a level of inequality that was roughly comparable to the U.S. until the 1960s-1970s. France is now substantially more equal than the U.S., thereby illustrating the fact that country differences in inequality are not permanent and deterministic, and can vary a lot over time, depending on the country-specific histories, institutions and policy regimes. The rise of U.S. inequality happened mostly since 1980, and certainly involves a complex combination of factors, including changing labor market rules (with a large fall in U.S. federal minimum wage), a highly unequal education system (including a growing gap between the financing of top universities and that of bottom and middle-tier colleges and high schools), changing governance and incentives for top executive pay-setting (including a sharp drop in top income tax rates); for a more detailed discussion, see Piketty (2014) and Piketty, Saez and Stantcheva (2014).

In our view, the most striking finding is that although per adult national income is about $30 \%$ smaller in France, bottom $50 \%$ average income is about $30 \%$ higher in France (see Figures 19a-19b, as well as Figures 20a-20b for the corresponding growth incidence curves). Given the greater extent of redistribution and public spending in France, this conclusion is likely to be reinforced if we look at after-tax

\footnotetext{
29 See Appendix A for series on working hours and hourly GDP for France, the US and other developed countries. We should stress that existing working hour series (which we borrow to the OECD and the BLS) are far from being perfectly comparable across countries and over time.
} 
after-transfer inequality. But it is interesting to see that this is already the case for pre-tax pre-transfers inequality. In particular, the collapse in the bottom $50 \%$ pre-tax income share in the US since the 1970 s - from $20 \%$ to $12 \%$ of total income, i.e. approximately the opposite evolution as the top $1 \%$ income share - is strikingly different from the evolution observed in France.

In effect, the level of the average pre-tax income of the bottom $50 \%$ did not grow at all in real terms since 1970 in the US, and has been gradually overtaken by its French counterpart, in spite of the fact that the US bottom $50 \%$ income level was much higher in the 1950s-1960s, and in spite of rising French unemployment since the 1970s. This suggests that different institutions and policies - including education, minimum wage, labor market, corporate governance, as well as the impact of tax progressivity on wage bargaining and pre-tax inequality - can contribute to different distributional outcomes and welfare levels for large segments of the population. This also suggests that different policies and institutions can have a large impact on pretax pre-transfer inequality, and not only on post-tax post-transfer inequality. 


\section{Section 8. Concluding comments and research perspectives}

In this paper, we have combined fiscal data, national accounts and survey data in order to produce unified DINA (Distributional National Accounts) series covering the entire distribution of income in France over the period 1900-2014.

The contribution is both methodological and substantive. At the methodological level, we have shown that it is possible to reconcile micro-level and macro-level concepts and data sources in order to estimate distributional trends. We hope that this work will contribute to stimulate similar work in other countries. Inequality measurement is still in its infancy. We need to further combine data sources and refine our methodological approaches before we can reach a deeper understanding of the underlying mechanisms.

At a more substantive level, we document large changes in inequality both over time and across countries that cannot be seen as the results of any natural economic "laws" and seem more likely to be the product of changes in institutions and public policies. While World Wars led to massive capital destruction, they also contributed together with the Great Depression and the Bolshevik Revolution - to the emergence of a new policy regime which led to a sustained reduction in inequality. However growth slowdown and policy and ideological changes since the 1980s have led to an upturn in inequality trends which still seem to be underway. We have stressed how relatively small changes in structural parameters can lead to large long-run effects on growth incidence curves as well as on steady-state wealth inequality. We have also noticed very large variations in gender inequality - which are again difficult to explain 
if we were to adopt a purely economic perspective on inequality and to neglect the political dimension. This work is due to be extended to lots of countries. The comparison between countries with diverse institutions and different tax and transfer systems may help to better understand the specific role of public policies and, more specifically, how they shape income and gender inequalities. 


\section{References}

J. Accardo, V. Bellamy, G. Consalès, M. Fesseau, S. Le Laidier, E. Raynaud, «Les inégalités entre ménages dans les comptes nationaux, une décomposition du compte des ménages », 2009, L'économie française - Comptes et dossiers.

A. Alstadsaeter, N. Johannesen, G. Zucman, "Tax Evasion and Inequality", NBER Working Papers n²3772, 2017.

F. Alvaredo, A. Atkinson, T. Piketty, E. Saez, G. Zucman, The World Wealth and Income Database (WID.world), 2011-2016.

F. Alvaredo, A. Atkinson, L. Chancel, T. Piketty, E. Saez, G. Zucman, "Distributional National Accounts (DINA): Concepts and Methods used in the WID", WID Working Paper, http://www.wid.world, version V1 (december 2016).

F. Alvaredo, B. Garbinti, T. Piketty, "On the Share of Inheritance in Aggregate Wealth: Europe and the USA, 1900-2010", Economica, 2017

A. Atkinson, "Top Incomes in the UK over the Twentieth Century", Journal of the Royal Statistical Society, vol. 168, no 2, 2005, p. 325-343

A. Atkinson \& T. Piketty (eds.), Top Incomes Over the Twentieth Century, vol.1, Oxford University Press, 2007, 585p. 
A. Atkinson \& T. Piketty (eds.), Top Incomes - A Global Perspective, vol.2, Oxford University Press, 2010, 776p.

A. Atkinson, T. Piketty \& E. Saez, "Top Incomes in the Long-Run of History", Journal of Economic Literature, vol. 49, no 1, 2011, p. 3-71.

A. Bozio, B. Garbinti, J. Goupille-Lebret, M. Guillot and T. Piketty, "Inequality and Redistribution in France, 1900-2014: Evidence from Post-Tax Distributional National Accounts (DINA)", PSE, 2018, in progress.

EUROSTAT, IMF, OECD, UN, WB, System of National Accounts 2008, New York, 2009

Fixler, Dennis, and David S. Johnson, "Accounting for the Distribution of Income in the US National Accounts," in Measuring Economic Stability and Progress, D. Jorgenson, J. S.Landefeld, and P. Schreyer, editors, University of Chicago Press, 2014.

Fixler, Dennis, David Johnson, Andrew Craig, Kevin Furlong, "A Consistent Data Series to Evaluate Growth and Inequality in the National Accounts," BEA Working Paper 2015.

T. Blanchet, J. Fournier, T. Piketty, "Generalized Pareto curves: Theory and application using income and inheritance tabulations for France and the US", WID.world Working Paper, 2017. 
B. Garbinti, J. Goupille-Lebret and T. Piketty, "Accounting for Wealth Inequality Dynamics: Methods, Estimates and Simulations for France (1800-2014)", WID.world Working Paper n²016/5, 2016

J. Goupille-Lebret and J. Infante, "Behavioral Responses to Inheritance Tax: Evidence from Notches in France”, INSEAD Working Paper n²017/76/EPS, 2017.

S. Kuznets, "Shares of Upper Income Groups in Income and Savings", New York: National Bureau of Economic Research, 1953

C. Landais, "Le quotient familial a-t-il stimulé la natalité française ? ", Économie publique/Public economics, 2003

C. Landais, T. Piketty and E. Saez, Pour une révolution fiscale - Un impôt sur le revenu pour le $21^{\text {eme }}$ siècle, Seuil, 2011

T. Piketty, Les hauts revenus en France au $20^{\circ}$ siècle. Inégalités et redistributions, 1901-1998, Grasset, 2001

T. Piketty, "Income inequality in France, 1901-1998", Journal of political economy, vol. 111, no 5, 2003, p. 1004-1042.

T. Piketty, "On the Long-Run Evolution of Inheritance: France 1820-2050", Quarterly Journal of Economics, 2011 
T. Piketty, Capital in the $21^{\text {st }}$ century, Harvard University Press, 2014

T. Piketty and E. Saez, "Income Inequality in the United States, 1913-1998", Quarterly Journal of Economics, vol. 118, no 1, 2003, p. 1-39.

T. Piketty, E. Saez, and G. Zucman, "Distributional National Accounts: Methods and Estimates for the United States, 1913-2013", Quarterly Journal of Economics, 2018, forthcoming

T. Piketty, G. Zucman, "Capital is back: wealth-income ratios in rich countries 17002010", Quarterly Journal of Economics, vol.129, no.3, 2014, p.1155-1210.

T. Piketty, G. Zucman, "Wealth and Inheritance in the Long-Run", Handbook of Income Distribution, 2015

E. Saez and G. Zucman, "Wealth Inequality in the United States since 1913: Evidence from Capitalized Income Tax Data", Quarterly Journal of Economics, vol.131, no 2, 2016, p.519-578

R. Stone, "The Accounts of Society", Nobel Lecture, 1984

J. Zwijnenburg, S. Bournot and F. Giovannelli, "Expert Group on Disparities in a National Accounts Framework: Results from the 2015 Exercise", OECD Statistics Working Papers, No. 2016/10, OECD Publishing, Paris. 
Table 1 : Income thresholds and income shares in France, 2014

\begin{tabular}{|c|c|c|c|c|}
\hline $\begin{array}{l}\text { Income } \\
\text { group }\end{array}$ & Number of adults & Income threshold & Average income & $\begin{array}{c}\text { Income } \\
\text { share }\end{array}$ \\
\hline Full Population & 51721510 & $0 €$ & $34580 €$ & $100.0 \%$ \\
\hline Bottom $50 \%$ & 25860755 & $0 €$ & $15530 €$ & $22.5 \%$ \\
\hline Middle $40 \%$ & 20688604 & $27500 €$ & $38800 €$ & $44.9 \%$ \\
\hline Top 10\% & 5172151 & $58080 €$ & $112930 €$ & $32.7 \%$ \\
\hline incl. Top 1\% & 517215 & $167120 €$ & $374200 €$ & $10.8 \%$ \\
\hline incl. Top $0.1 \%$ & 51722 & $563800 €$ & $1286100 €$ & $3.7 \%$ \\
\hline incl. Top $0.01 \%$ & 5172 & $2072730 €$ & $4550250 €$ & $1.3 \%$ \\
\hline incl. Top $0.001 \%$ & 517 & $7554110 €$ & $14424800 €$ & $0.4 \%$ \\
\hline
\end{tabular}


Table 2a : Income growth and inequality in France by time periods

\begin{tabular}{|c|c|c|c|c|c|c|c|c|c|}
\hline & \multicolumn{3}{|c|}{$1900-1950$} & \multicolumn{3}{|c|}{ 1950-1983 } & \multicolumn{3}{|c|}{ 1983-2014 } \\
\hline $\begin{array}{l}\text { Income } \\
\text { group }\end{array}$ & $\begin{array}{c}\text { Average } \\
\text { annual } \\
\text { growth rate }\end{array}$ & $\begin{array}{c}\text { Total } \\
\text { cumulated } \\
\text { growth }\end{array}$ & $\begin{array}{c}\text { Share of } \\
\text { total } \\
\text { cumulated } \\
\text { growth }\end{array}$ & $\begin{array}{c}\text { Average } \\
\text { annual } \\
\text { growth rate }\end{array}$ & $\begin{array}{c}\text { Total } \\
\text { cumulated } \\
\text { growth }\end{array}$ & $\begin{array}{c}\text { Share of } \\
\text { total } \\
\text { cumulated } \\
\text { growth }\end{array}$ & $\begin{array}{c}\text { Average } \\
\text { annual } \\
\text { growth rate }\end{array}$ & $\begin{array}{c}\text { Total } \\
\text { cumulated } \\
\text { growth }\end{array}$ & $\begin{array}{c}\text { Share of } \\
\text { total } \\
\text { cumulated } \\
\text { growth }\end{array}$ \\
\hline Full Population & $1.0 \%$ & $64 \%$ & $100 \%$ & $3.3 \%$ & $194 \%$ & $100 \%$ & $1.0 \%$ & $35 \%$ & $100 \%$ \\
\hline Bottom 50\% & $1.8 \%$ & $144 \%$ & $30 \%$ & $3.7 \%$ & $236 \%$ & $24 \%$ & $0.9 \%$ & $31 \%$ & $21 \%$ \\
\hline Middle $40 \%$ & $1.5 \%$ & $108 \%$ & $61 \%$ & $3.4 \%$ & $203 \%$ & $48 \%$ & $0.8 \%$ & $27 \%$ & $37 \%$ \\
\hline Top 10\% & $0.2 \%$ & $11 \%$ & $8 \%$ & $2.9 \%$ & $157 \%$ & $27 \%$ & $1.3 \%$ & $49 \%$ & $42 \%$ \\
\hline incl. Top $10-1 \%$ & $0.6 \%$ & $38 \%$ & $16 \%$ & $3.1 \%$ & $177 \%$ & $21 \%$ & $0.9 \%$ & $33 \%$ & $21 \%$ \\
\hline incl. Top 1\% & $-0.5 \%$ & $-23 \%$ & $-8 \%$ & $2.3 \%$ & $111 \%$ & $6 \%$ & $2.2 \%$ & $98 \%$ & $21 \%$ \\
\hline incl. Top $0.1 \%$ & $-1.2 \%$ & $-44 \%$ & $-7 \%$ & $1.8 \%$ & $81 \%$ & $1 \%$ & $2.7 \%$ & $128 \%$ & $8 \%$ \\
\hline incl. Top $0.01 \%$ & $-2.0 \%$ & $-64 \%$ & $-5 \%$ & $1.8 \%$ & $77 \%$ & $0 \%$ & $3.2 \%$ & $162 \%$ & $3 \%$ \\
\hline
\end{tabular}

Notes: This table reports statistics on the distribution of pre-tax national income among equal-split adults in France. The unit is the adult individual (20-year-old and over; income of married couples is splitted into two). Fractiles are defined relative to the total number of adult individuals in the population. Corrected estimates (combining survey, fiscal, wealth and national accounts data). Source: Appendix B. 
Table $2 b$ : Income growth and inequality in France by time periods

\begin{tabular}{|c|c|c|c|c|c|c|c|c|c|}
\hline & \multicolumn{3}{|c|}{$1900-2014$} & \multicolumn{3}{|c|}{ 1900-1950 } & \multicolumn{3}{|c|}{ 1950-2014 } \\
\hline $\begin{array}{l}\text { Income } \\
\text { group }\end{array}$ & $\begin{array}{c}\text { Average } \\
\text { annual } \\
\text { growth rate }\end{array}$ & $\begin{array}{c}\text { Total } \\
\text { cumulated } \\
\text { growth }\end{array}$ & $\begin{array}{c}\text { Share of } \\
\text { total } \\
\text { cumulated } \\
\text { growth }\end{array}$ & $\begin{array}{c}\text { Average } \\
\text { annual } \\
\text { growth rate }\end{array}$ & $\begin{array}{c}\text { Total } \\
\text { cumulated } \\
\text { growth }\end{array}$ & $\begin{array}{c}\text { Share of } \\
\text { total } \\
\text { cumulated } \\
\text { growth }\end{array}$ & $\begin{array}{c}\text { Average } \\
\text { annual } \\
\text { growth rate }\end{array}$ & $\begin{array}{c}\text { Total } \\
\text { cumulated } \\
\text { growth }\end{array}$ & $\begin{array}{c}\text { Share of } \\
\text { total } \\
\text { cumulated } \\
\text { growth }\end{array}$ \\
\hline Full Population & $1.7 \%$ & $551 \%$ & $100 \%$ & $1.0 \%$ & $64 \%$ & $100 \%$ & $2.2 \%$ & $296 \%$ & $100 \%$ \\
\hline Bottom 50\% & $2.1 \%$ & $978 \%$ & $24 \%$ & $1.8 \%$ & $144 \%$ & $30 \%$ & $2.3 \%$ & $341 \%$ & $23 \%$ \\
\hline Middle $40 \%$ & $1.8 \%$ & $702 \%$ & $46 \%$ & $1.5 \%$ & $108 \%$ & $61 \%$ & $2.1 \%$ & $286 \%$ & $44 \%$ \\
\hline Top 10\% & $1.3 \%$ & $325 \%$ & $30 \%$ & $0.2 \%$ & $11 \%$ & $8 \%$ & $2.1 \%$ & $284 \%$ & $32 \%$ \\
\hline incl. Top $10-1 \%$ & $1.4 \%$ & $408 \%$ & $21 \%$ & $0.6 \%$ & $38 \%$ & $16 \%$ & $2.1 \%$ & $269 \%$ & $21 \%$ \\
\hline incl. Top 1\% & $1.0 \%$ & $219 \%$ & $9 \%$ & $-0.5 \%$ & $-23 \%$ & $-8 \%$ & $2.3 \%$ & $317 \%$ & $11 \%$ \\
\hline incl. Top $0.1 \%$ & $0.7 \%$ & $131 \%$ & $2 \%$ & $-1.2 \%$ & $-44 \%$ & $-7 \%$ & $2.2 \%$ & $315 \%$ & $4 \%$ \\
\hline incl. Top $0.01 \%$ & $0.5 \%$ & $67 \%$ & $1 \%$ & $-2.0 \%$ & $-64 \%$ & $-5 \%$ & $2.4 \%$ & $365 \%$ & $1 \%$ \\
\hline
\end{tabular}

Notes: This table reports statistics on the distribution of pre-tax national income among equal-split adults in France. The unit is the adult individual (20-year-old and over; income of married couples is splitted into two). Fractiles are defined relative to the total number of adult individuals in the population. Corrected estimates (combining survey, fiscal, wealth and national accounts data). Source: Appendix B. 
Figure 1: The uneven rise of per adult national income in France, 1900-2014 (€ 2014)

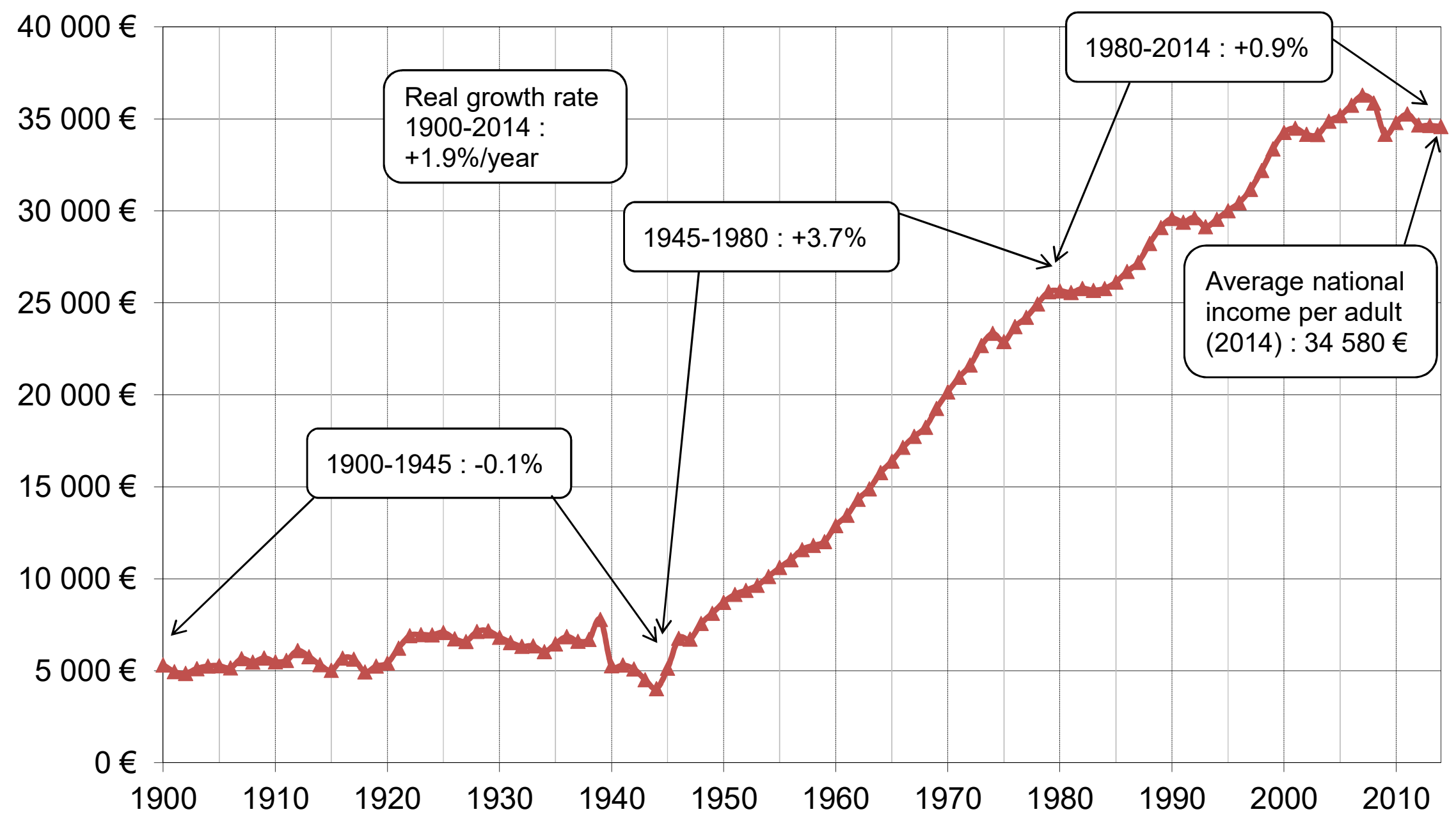

National income divided by adult population. National income $=$ GDP - capital depreciation + net foreign income. 


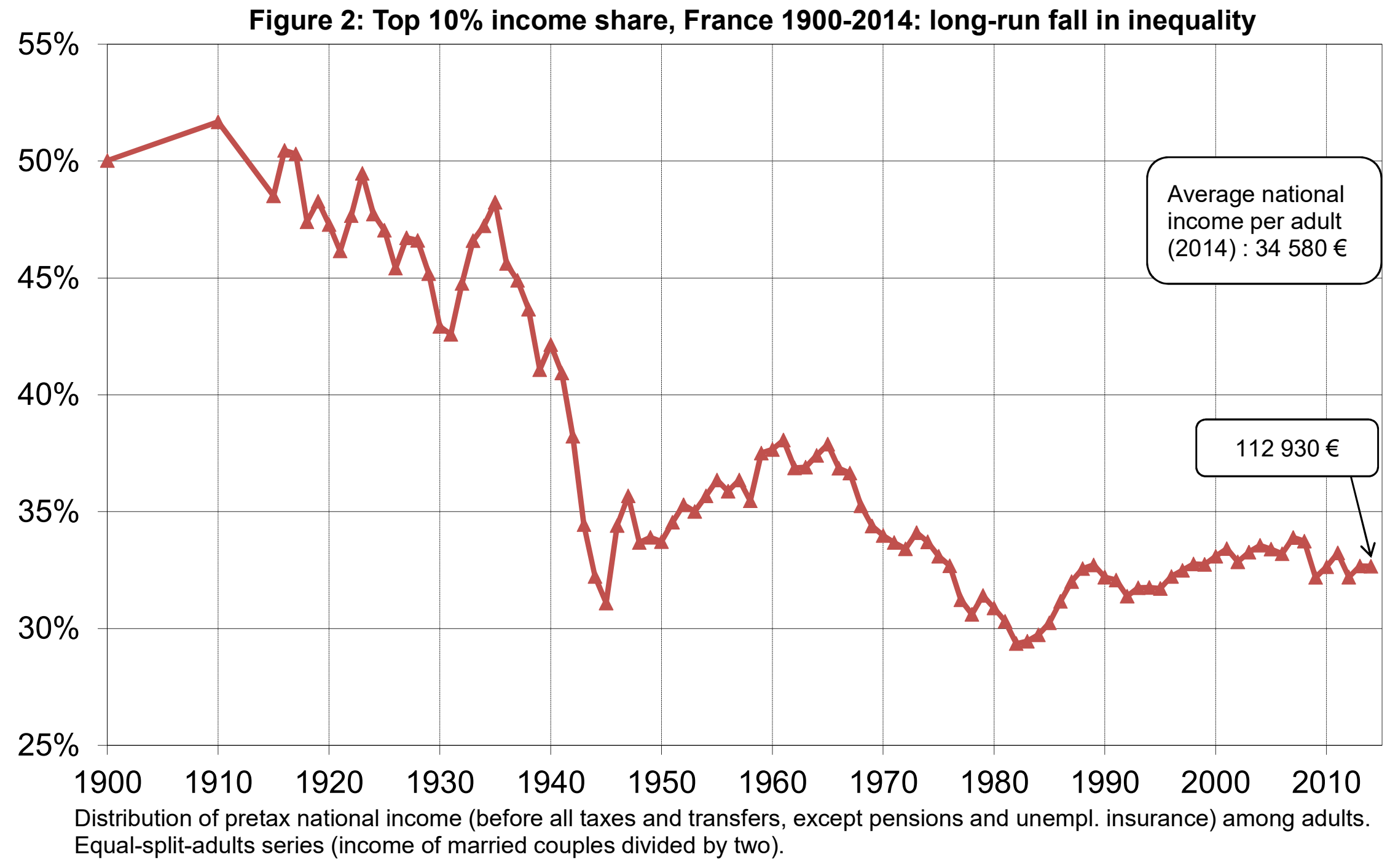




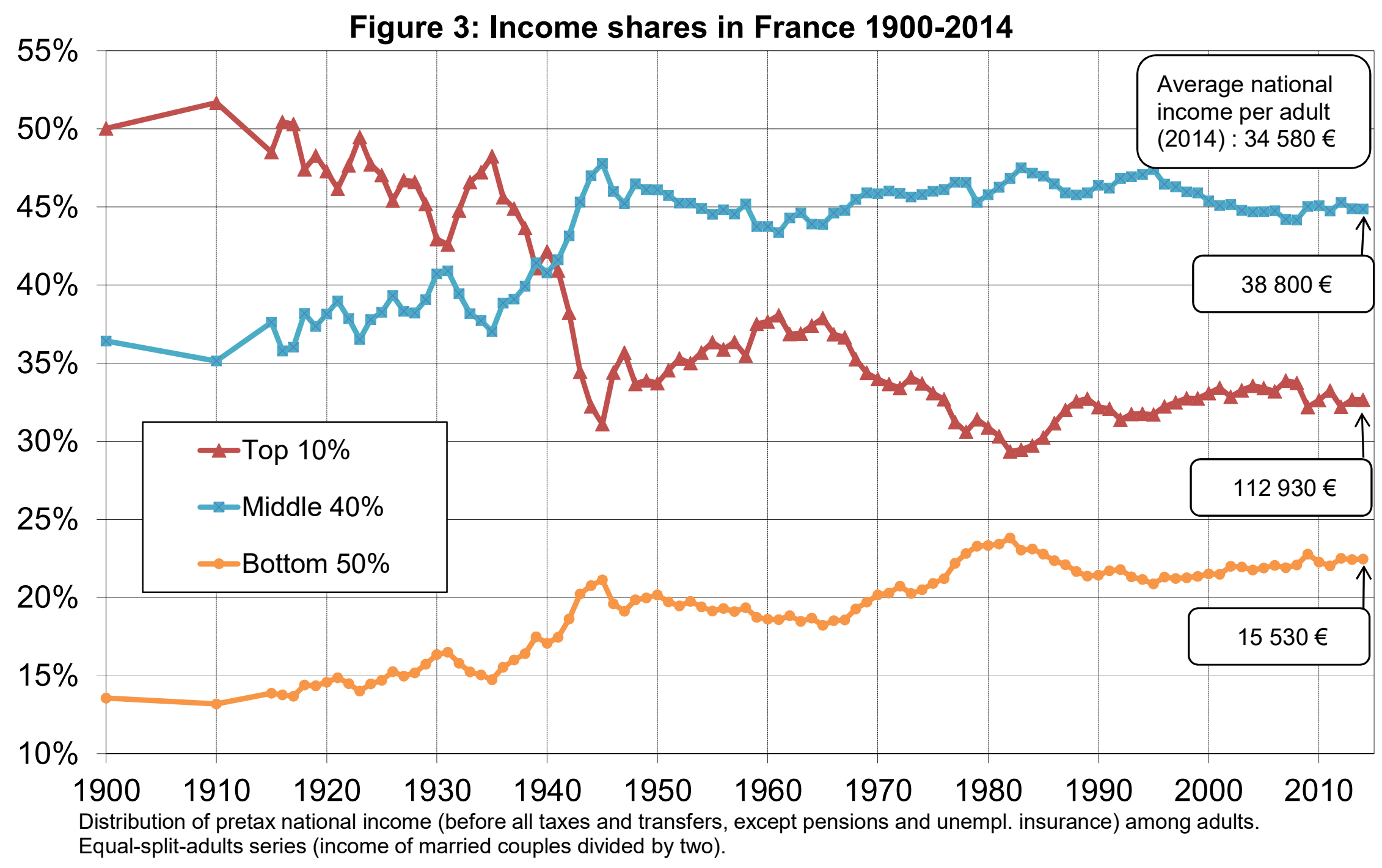


Figure 4: Top 1\% income share in France 1900-2014

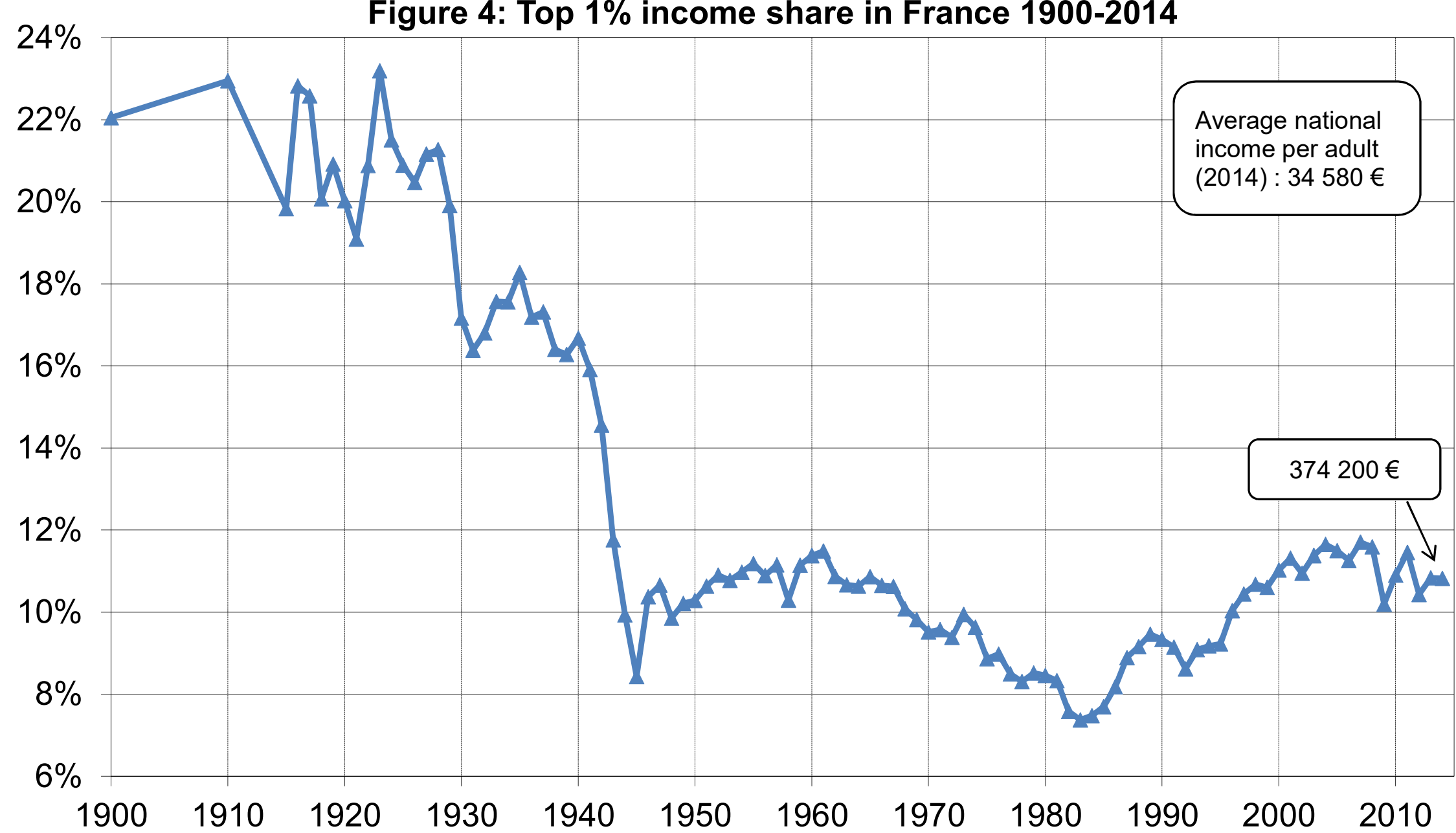

Distribution of pretax national income (before all taxes and transfers, except pensions and unempl. insurance) among adults. Equal-split-adults series (income of married couples divided by two). 


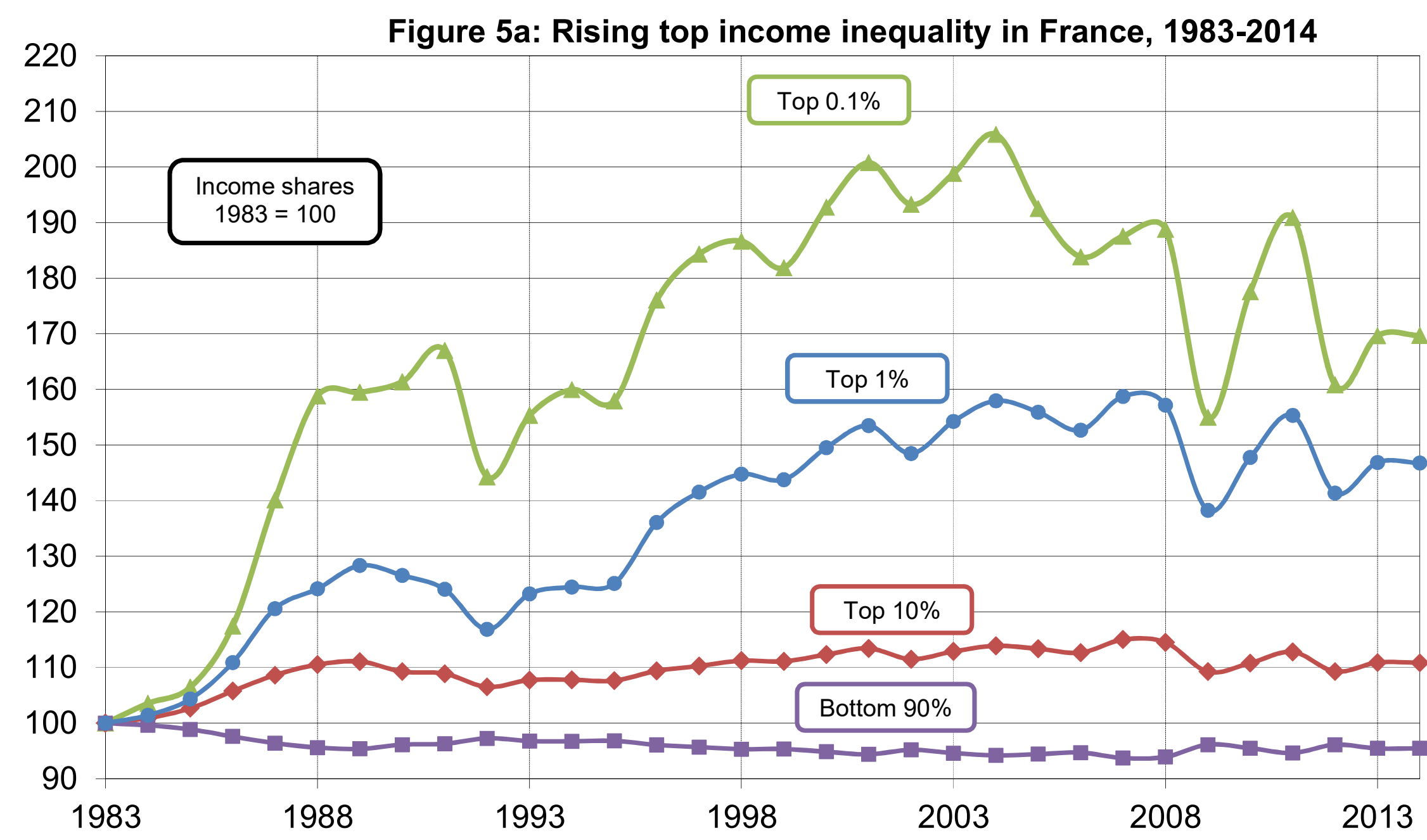

Distribution of pretax national income (before all taxes and transfers, except pensions and unempl.insurance) among adults. Equal-split-adults series (income of married couples divided by two). 
Figure 5b: Top 0.1\% income share in France 1970-2014

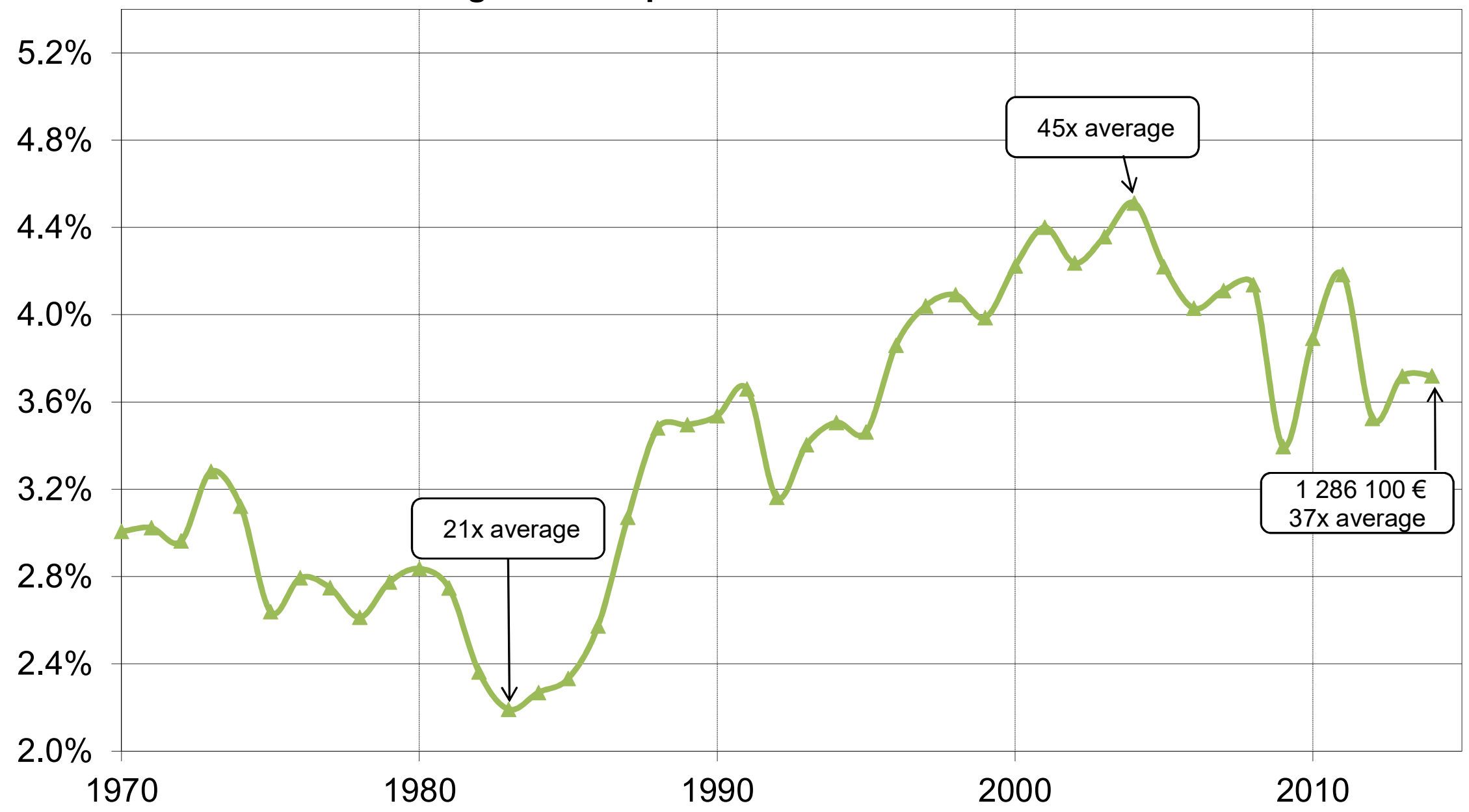

Distribution of pretax national income (before all taxes and transfers, except pensions and unempl.insurance) among adults.

Equal-split-adults series (income of married couples divided by two). 
Figure 5c: Top 0.01\% income share in France 1970-2014

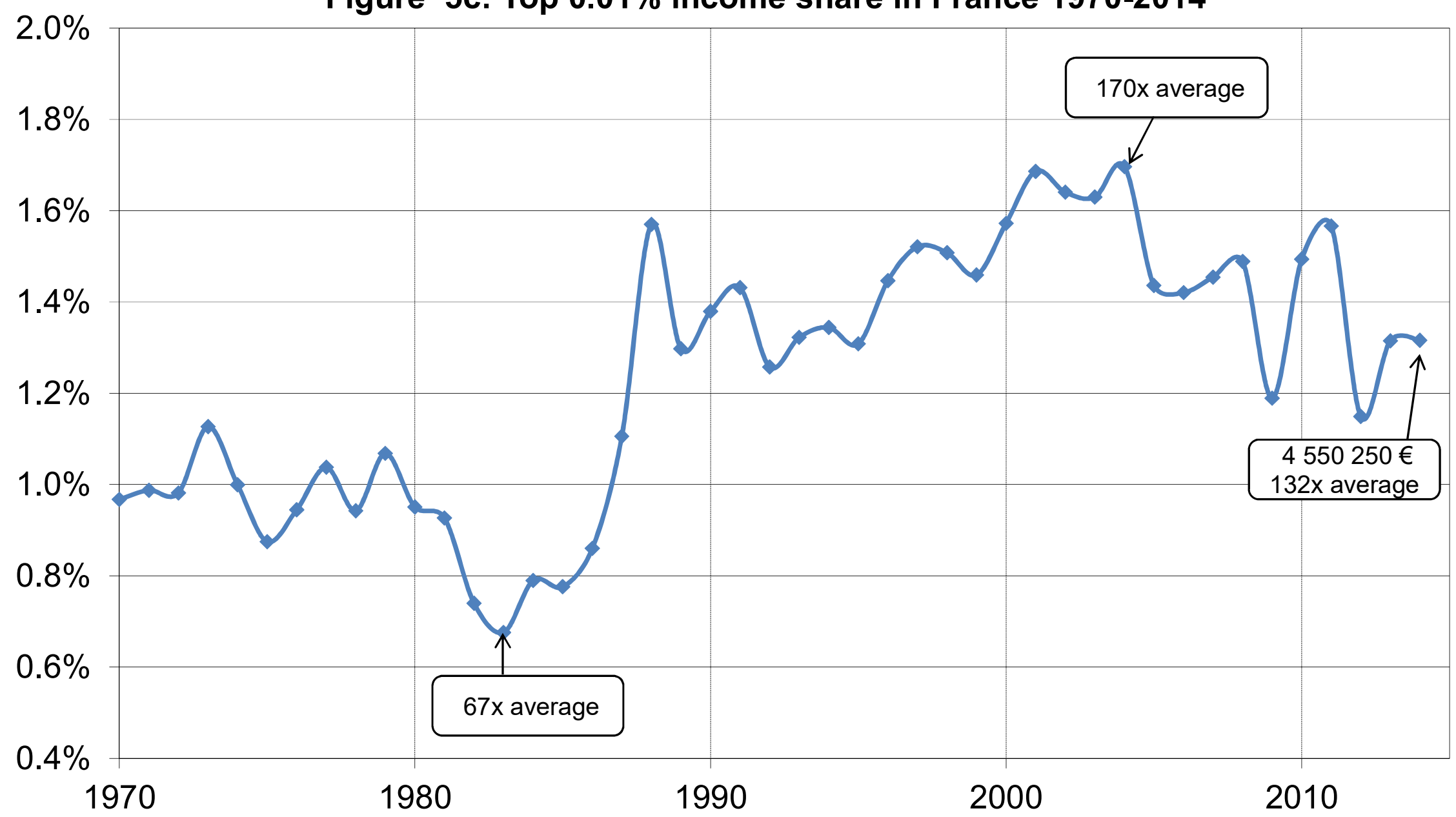

Distribution of pretax national income (before all taxes and transfers, except pensions and unempl.insurance) among adults. Equal-split-adults series (income of married couples divided by two). 


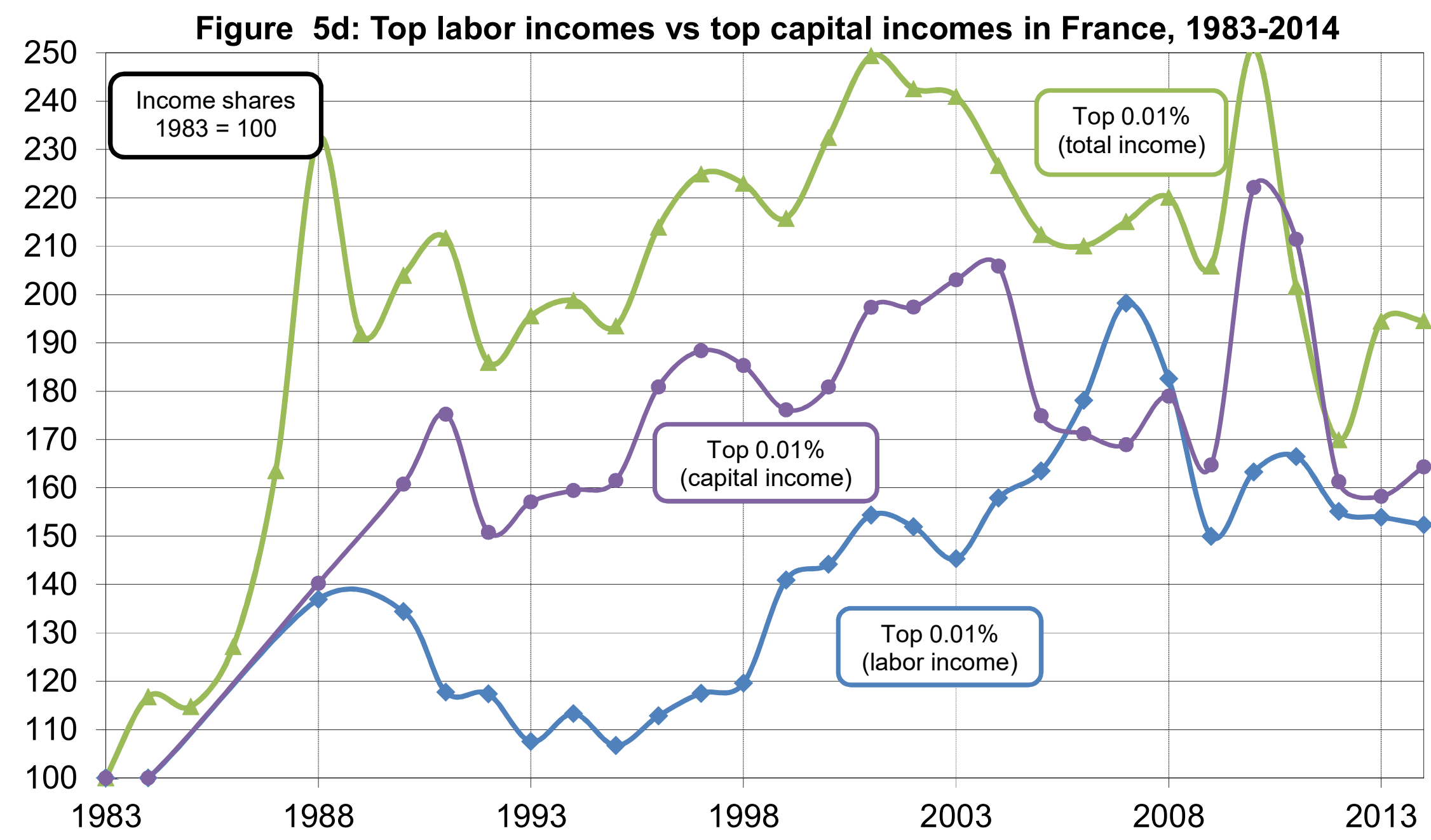

Distributions of total income, capital income and labor income among adults.

Equal-split-adults series (income of married couples divided by two). 


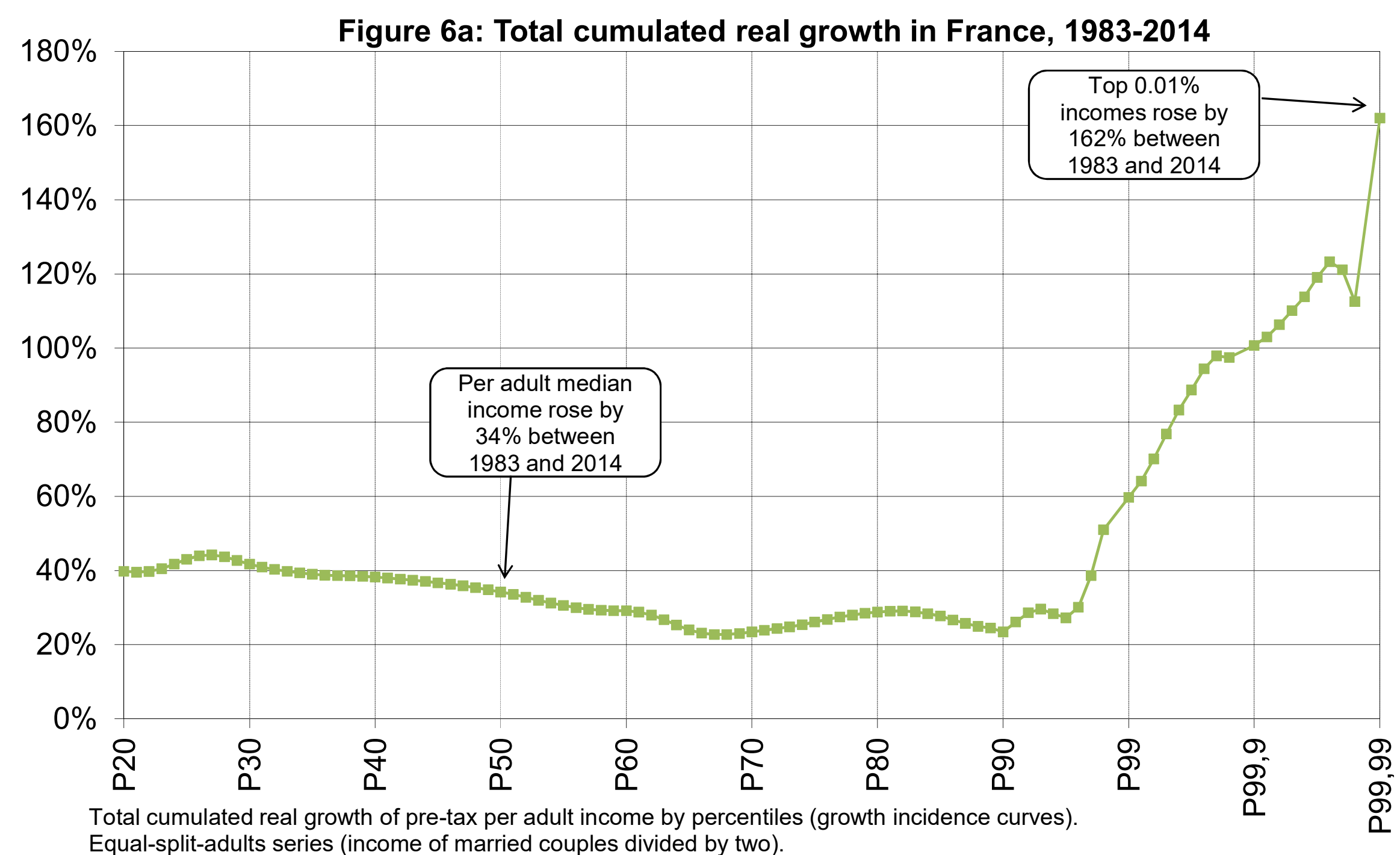




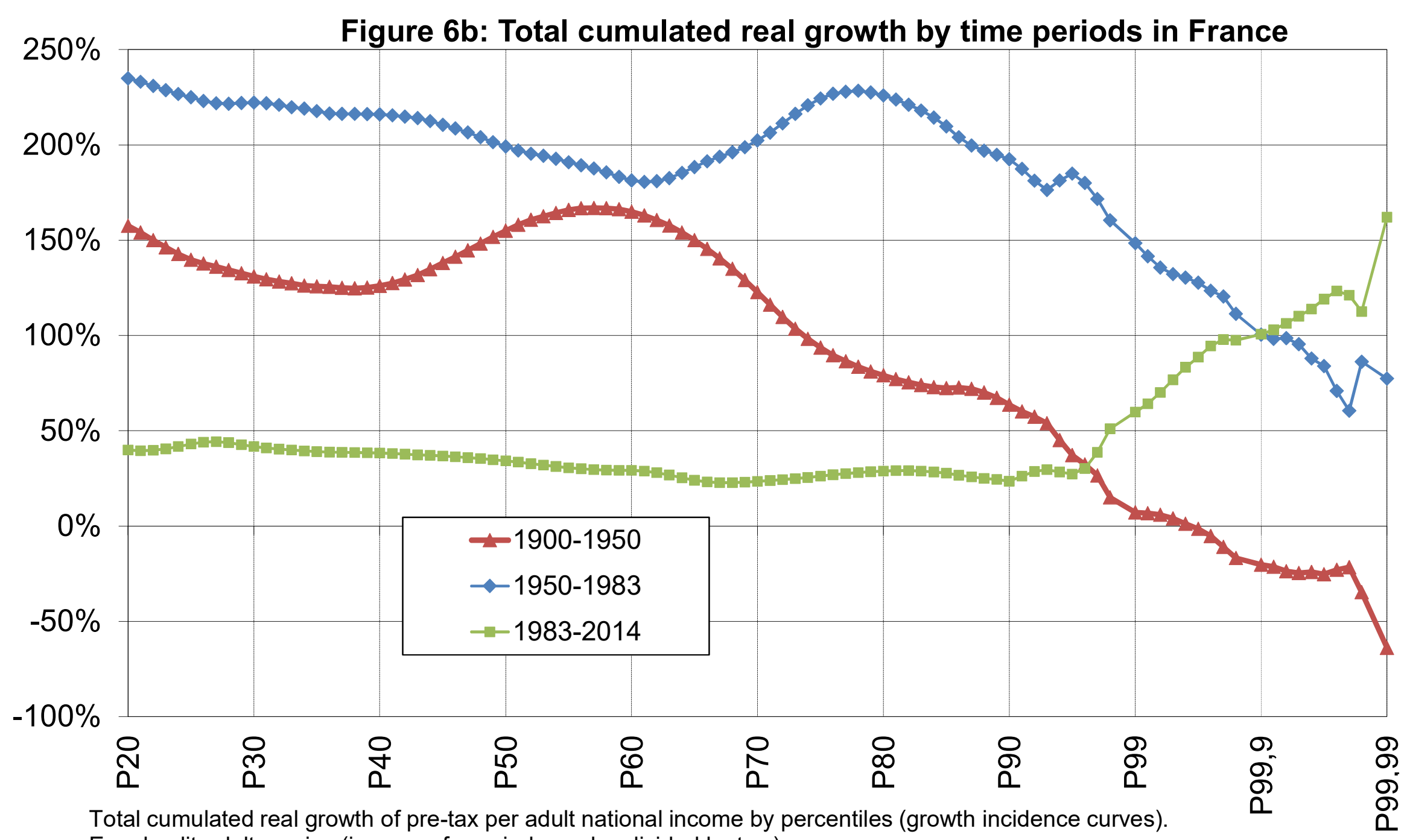

Equal-split-adults series (income of married couples divided by two). 


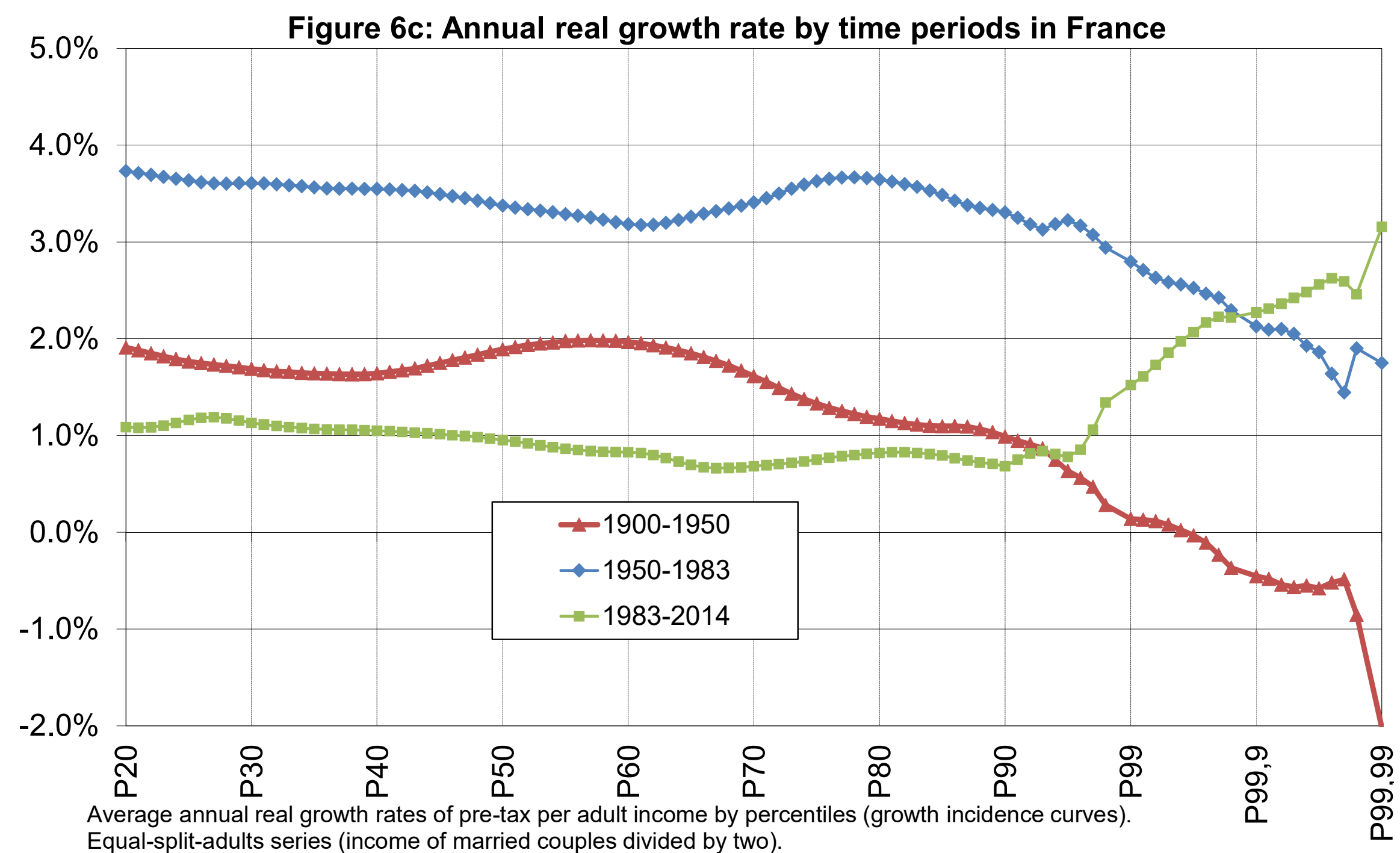




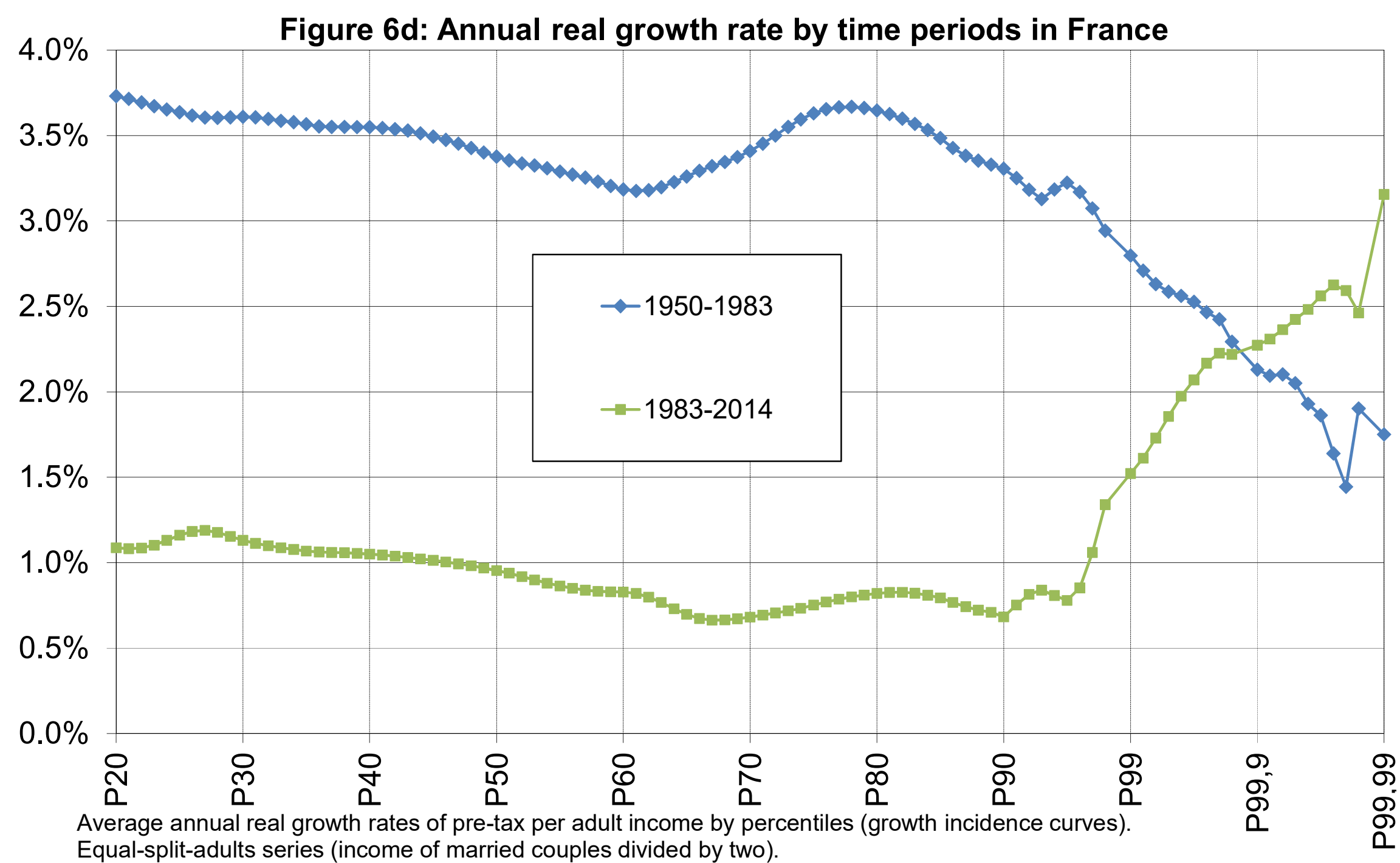




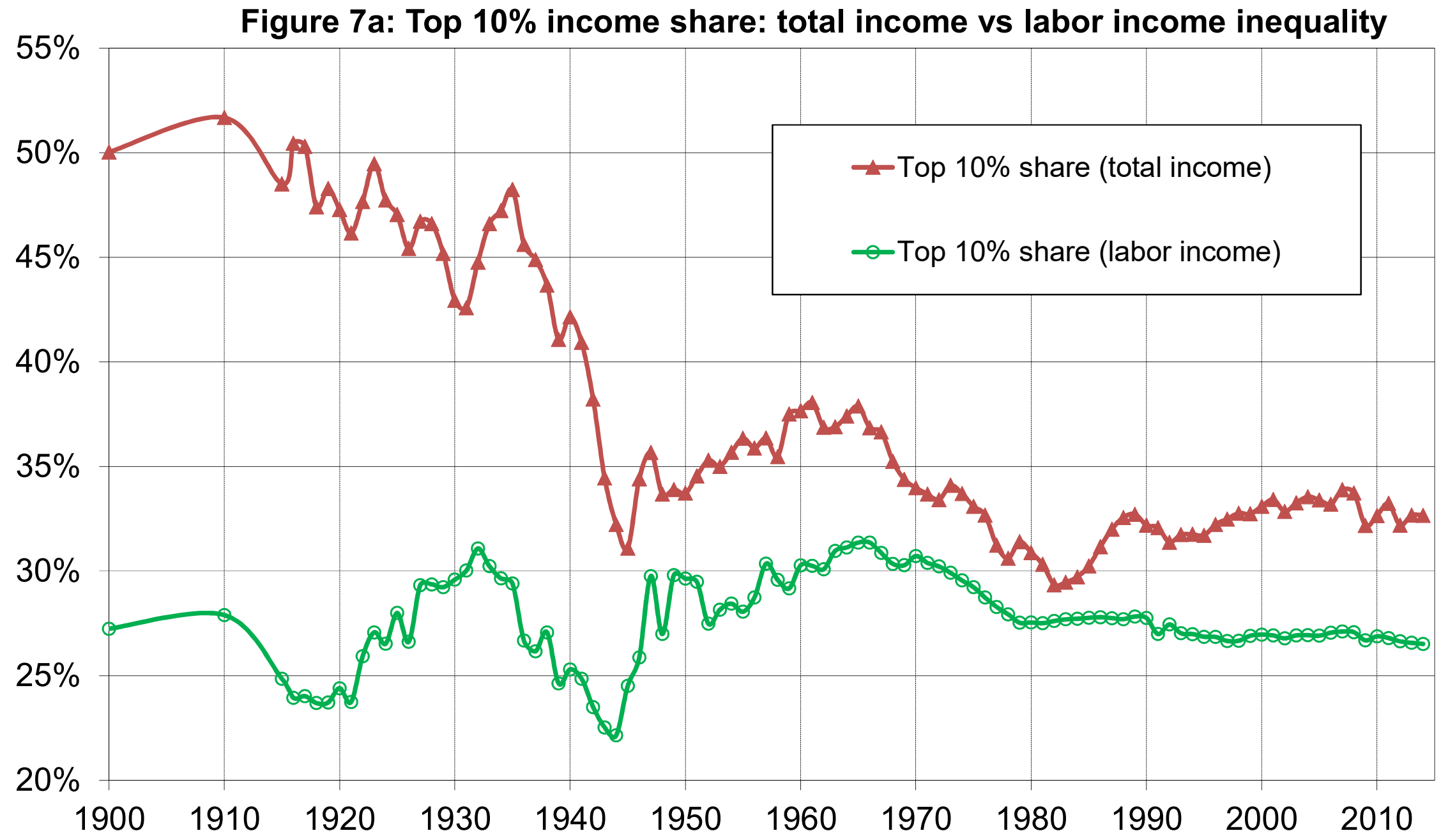

Distribution of pretax national income (before all taxes and transfers, except pensions and unempl. insurance) among adults. Equal-split-adults series (income of married couples divided by two). 


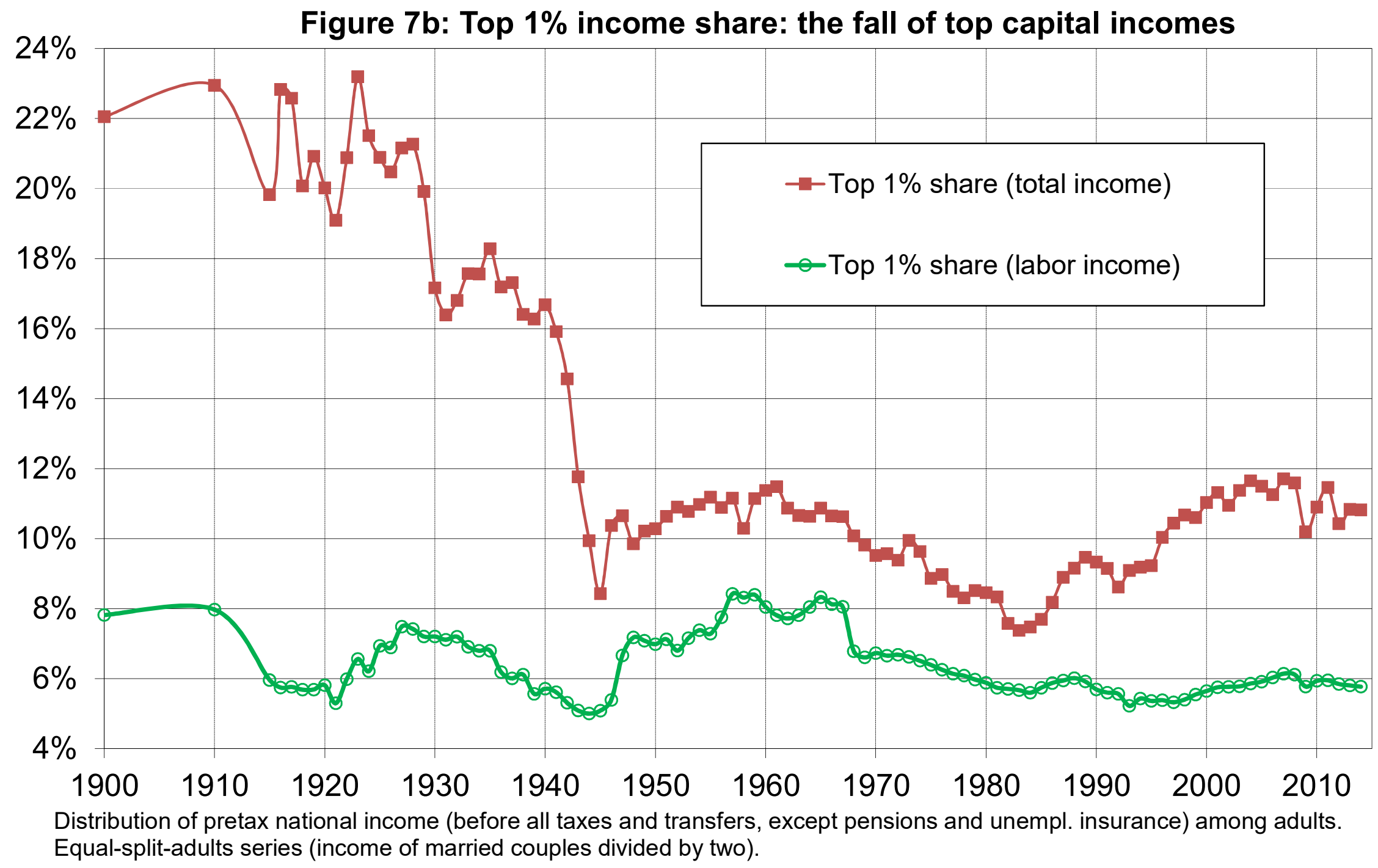




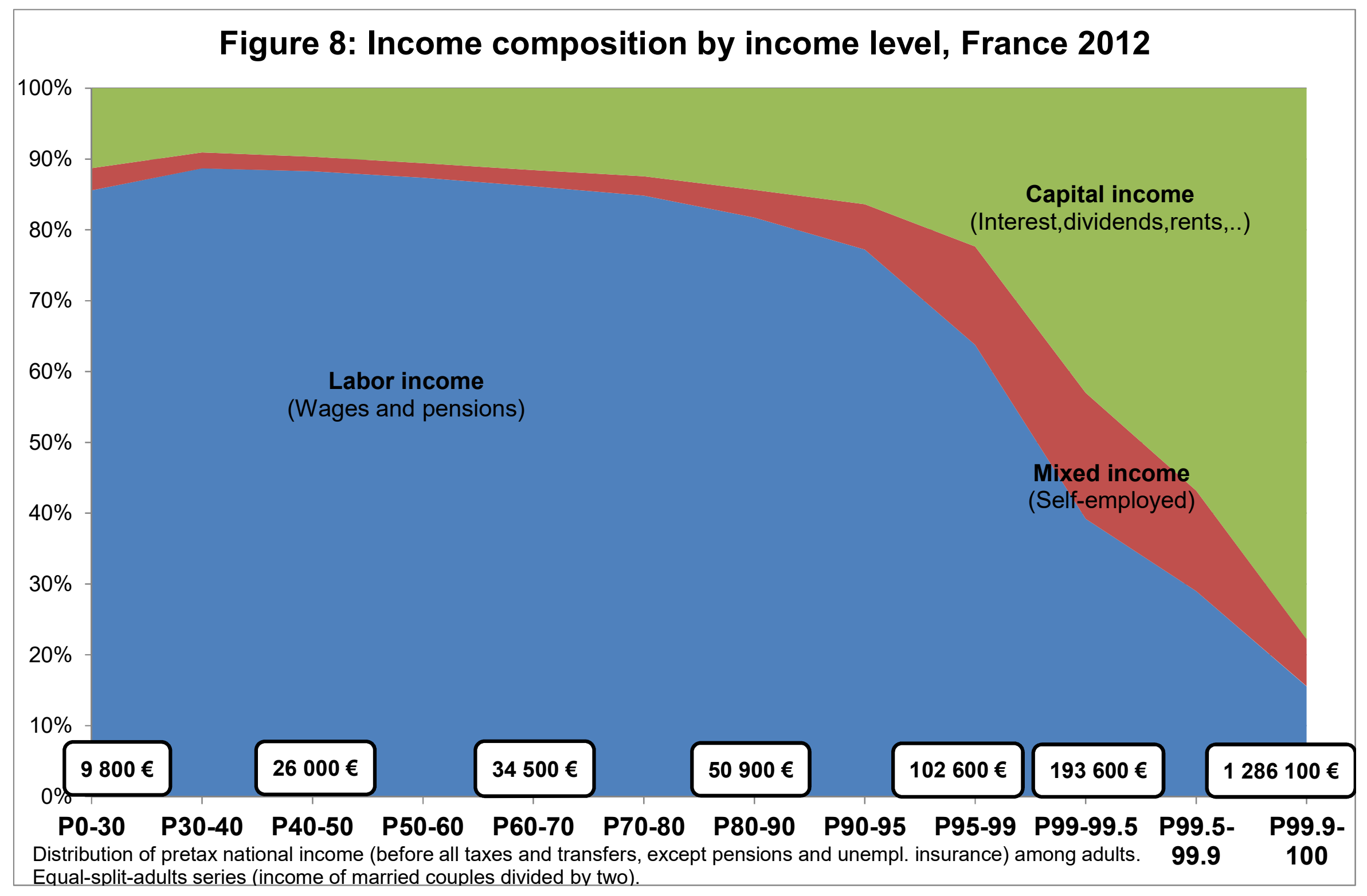


Figure 9a: Top 10\% share: income vs wealth

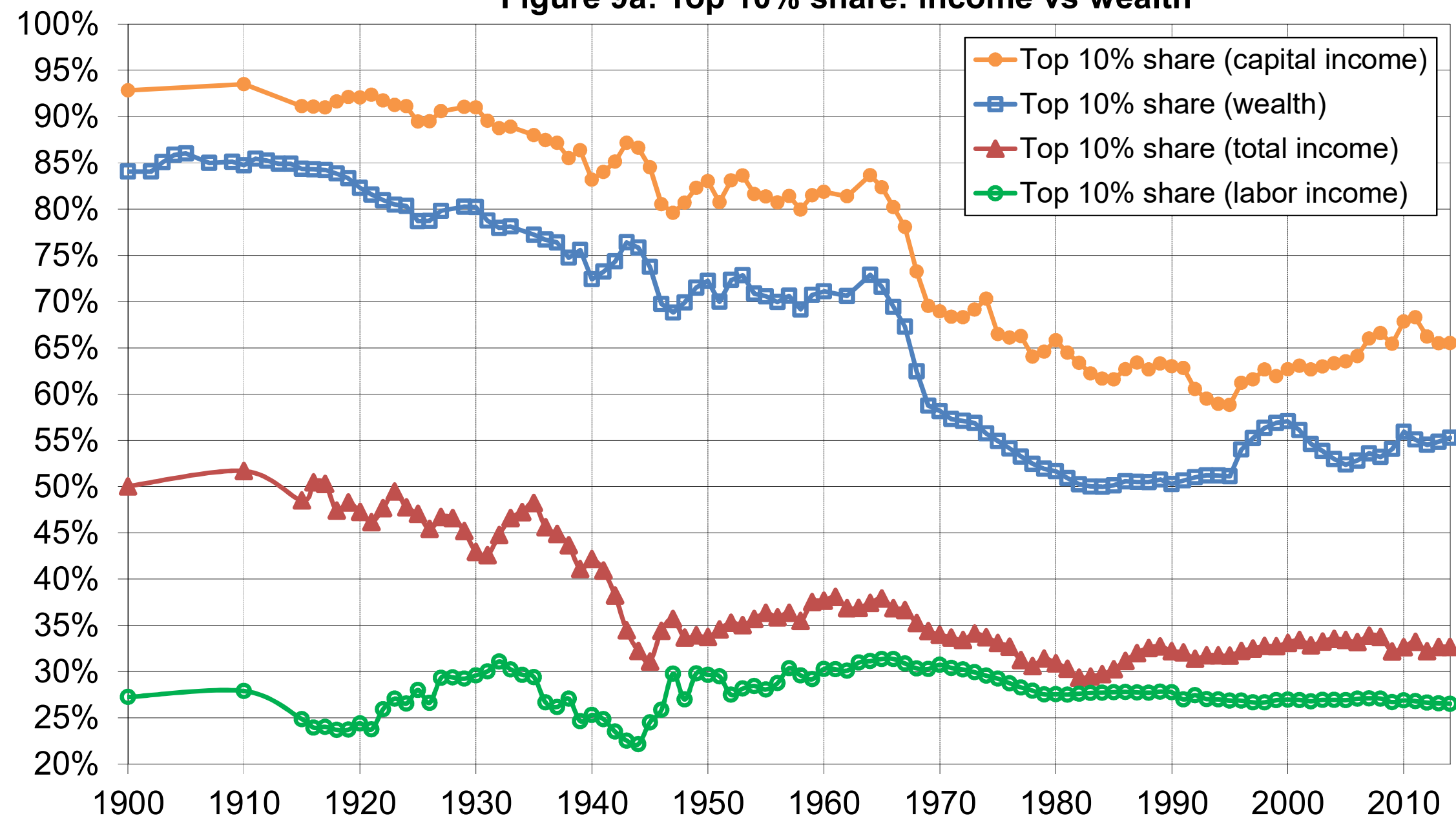

Distribution of total income, labor income, capital income and net wealth among adults.

Equal-split-adults series (income and wealth of married couples divided by two). 
Figure 9b: Top $1 \%$ share: income vs vs wealth

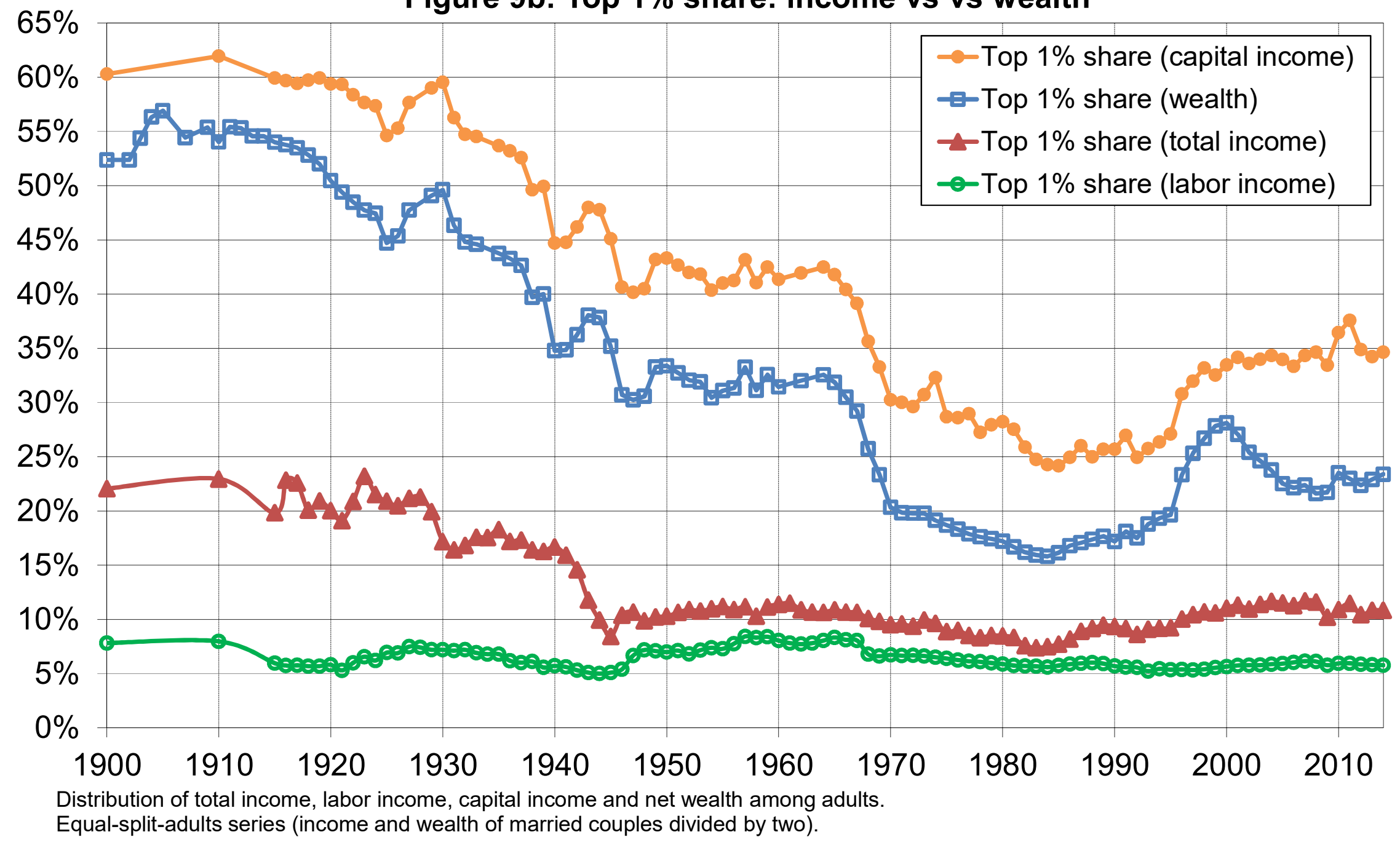


Figure 10a: Labor income rank vs mean wealth rank

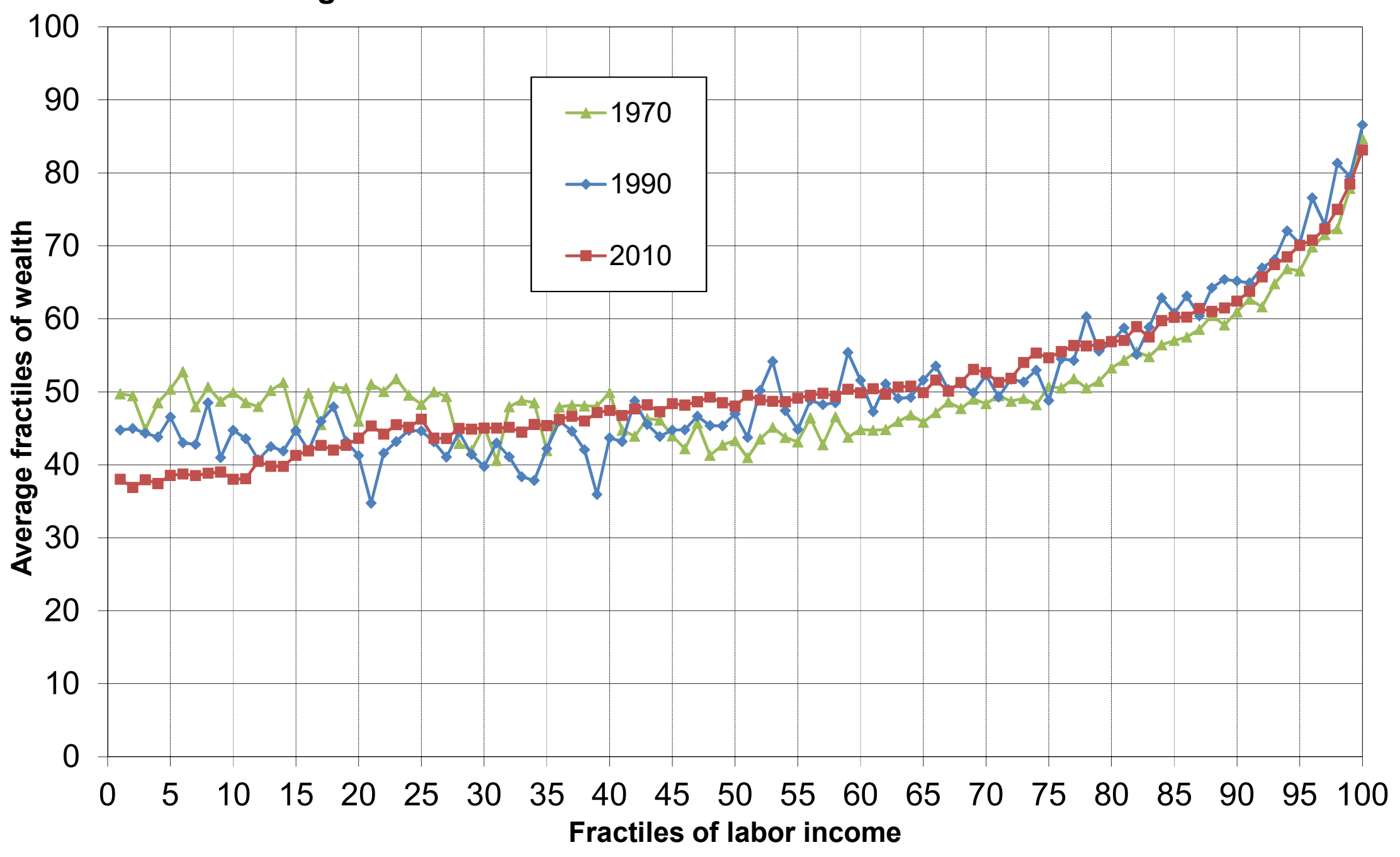


Figure 10b: Probability for top labor earners to belong to the top $1 \%$ wealth group

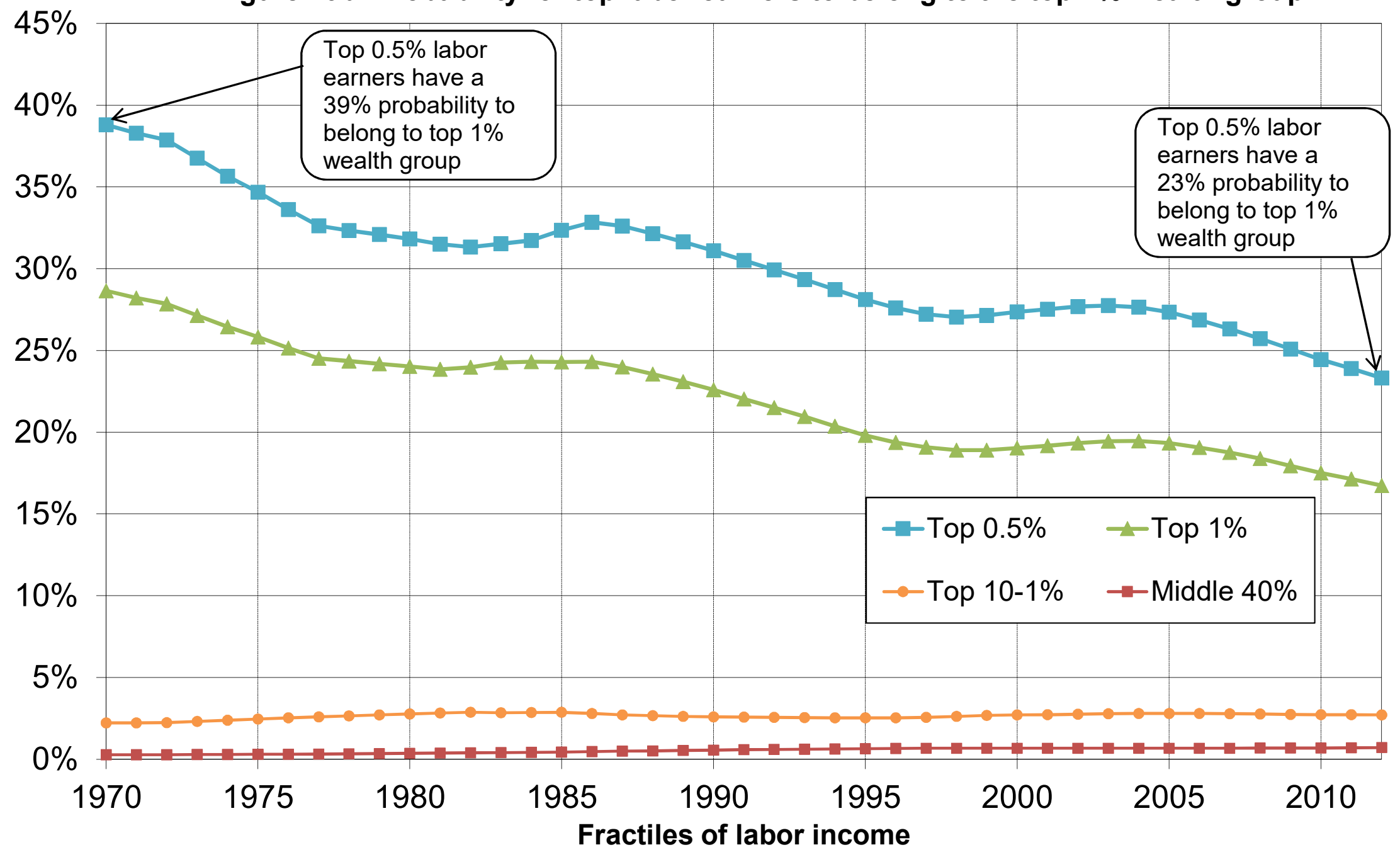




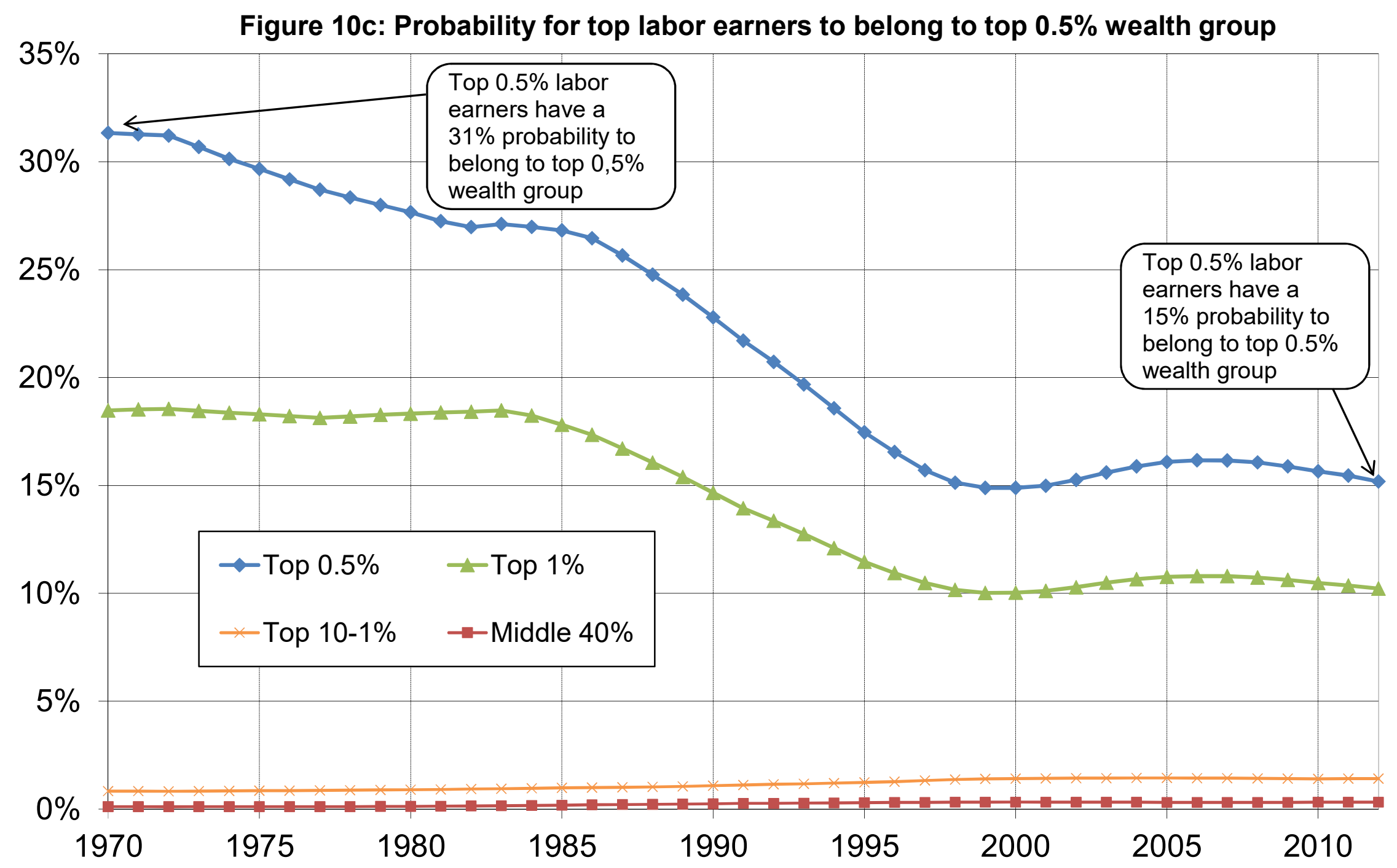




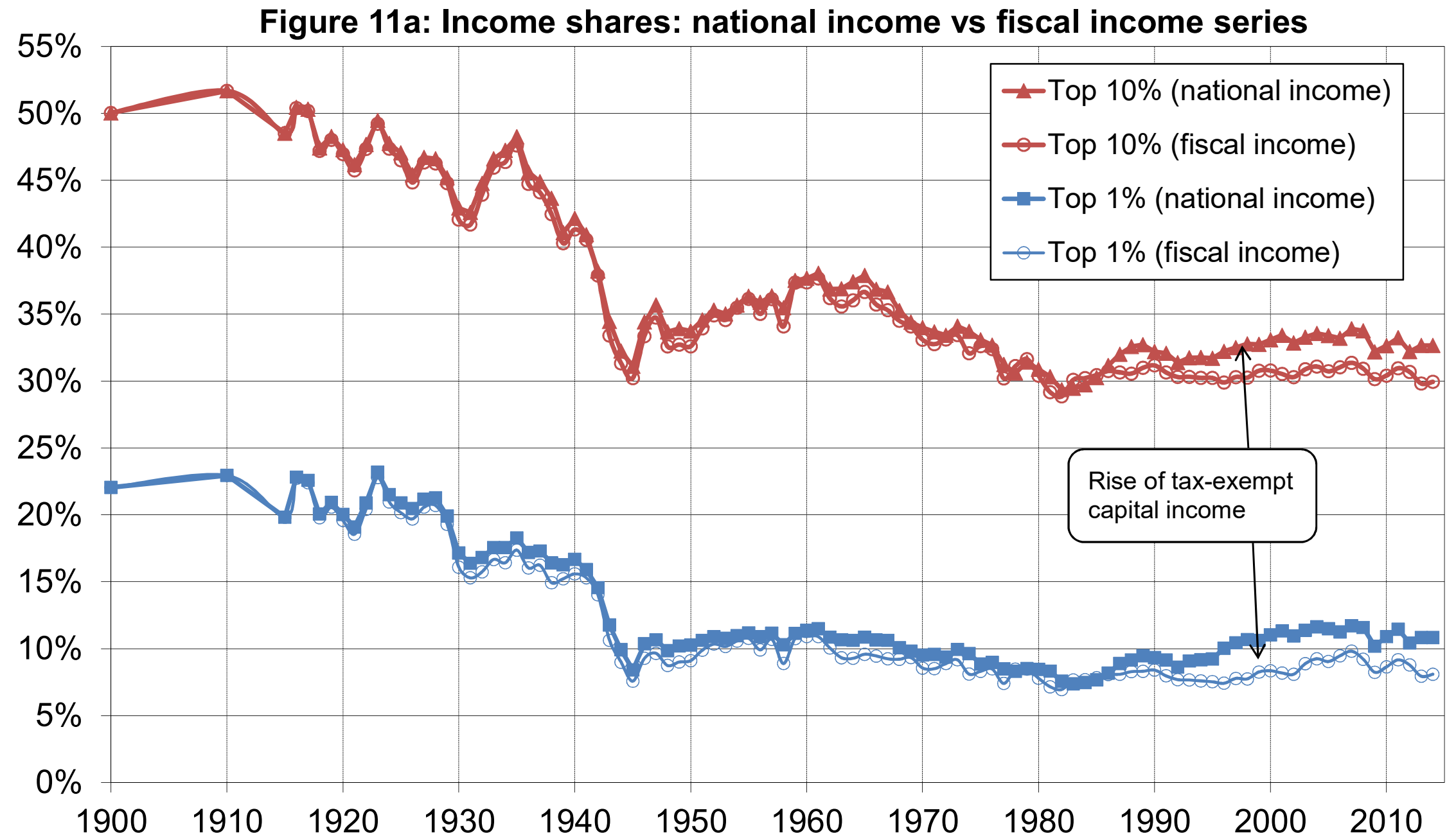

Distribution of pretax national income (incl. tax-exempt labor and capital income) vs pretax fiscal income (reported on income tax returns). Equal-split-adults series (income of married couples divided by two). 


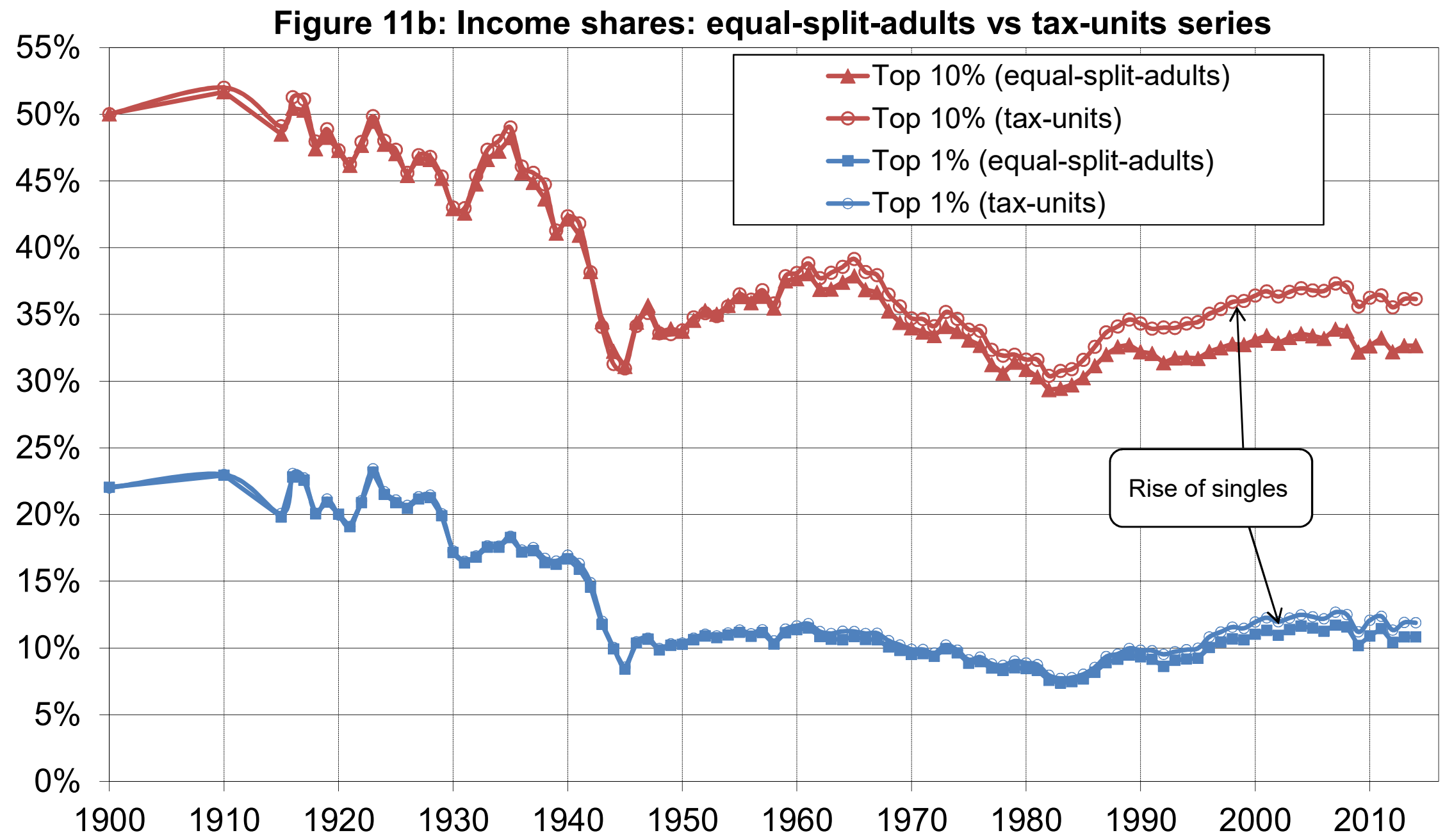

Distribution of pretax national income (before all taxes and transfers, except pensions and unempl. insurance) among adults. Equal-split-adults series (income of married couples divided by two) vs tax-units series (singles and married couples). 


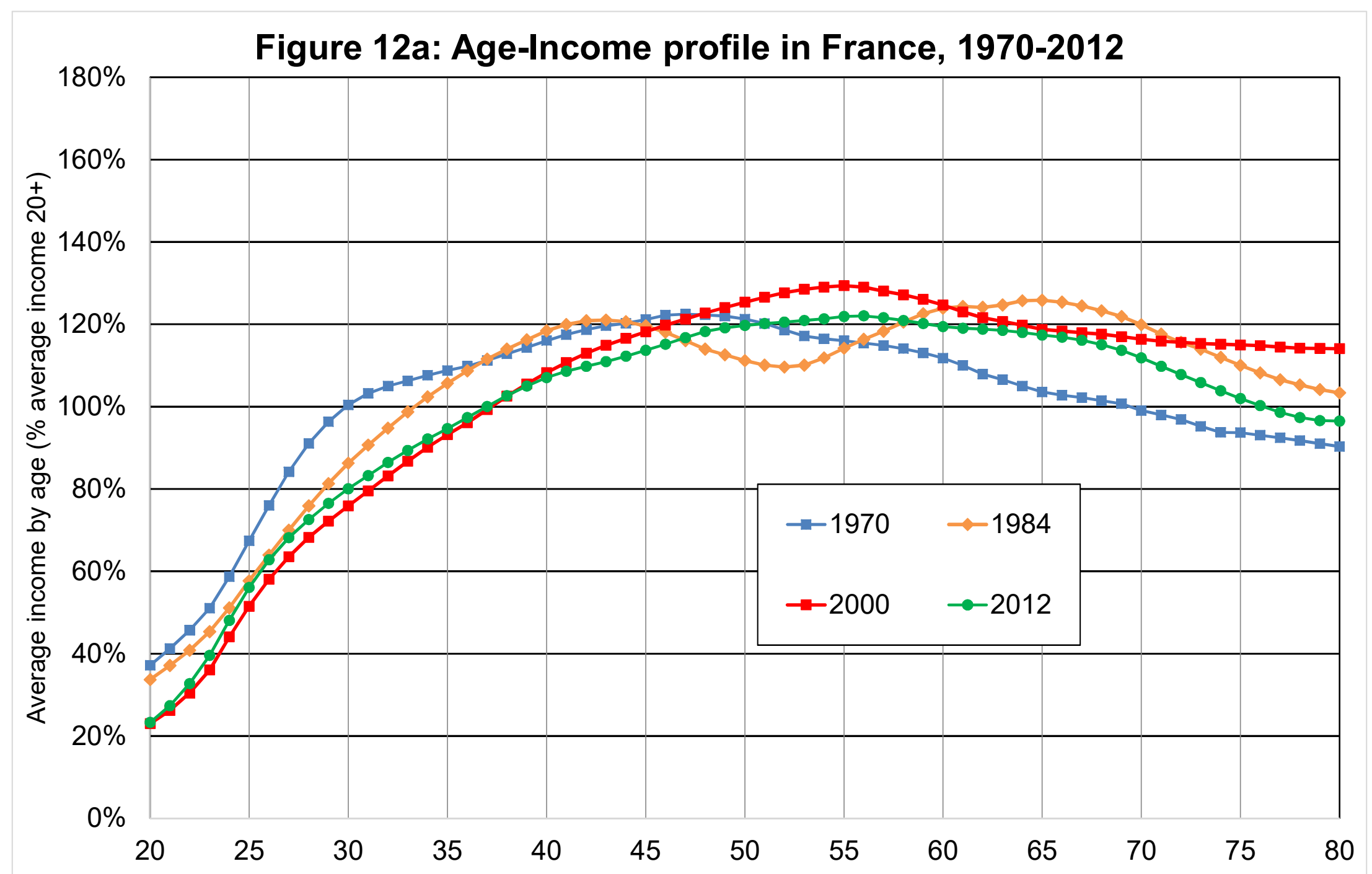

Distribution of pretax national income (before all taxes and transfers, except pensions and unempl. insurance) among adults. Equal-split-adults series (income of married couples divided by two). 


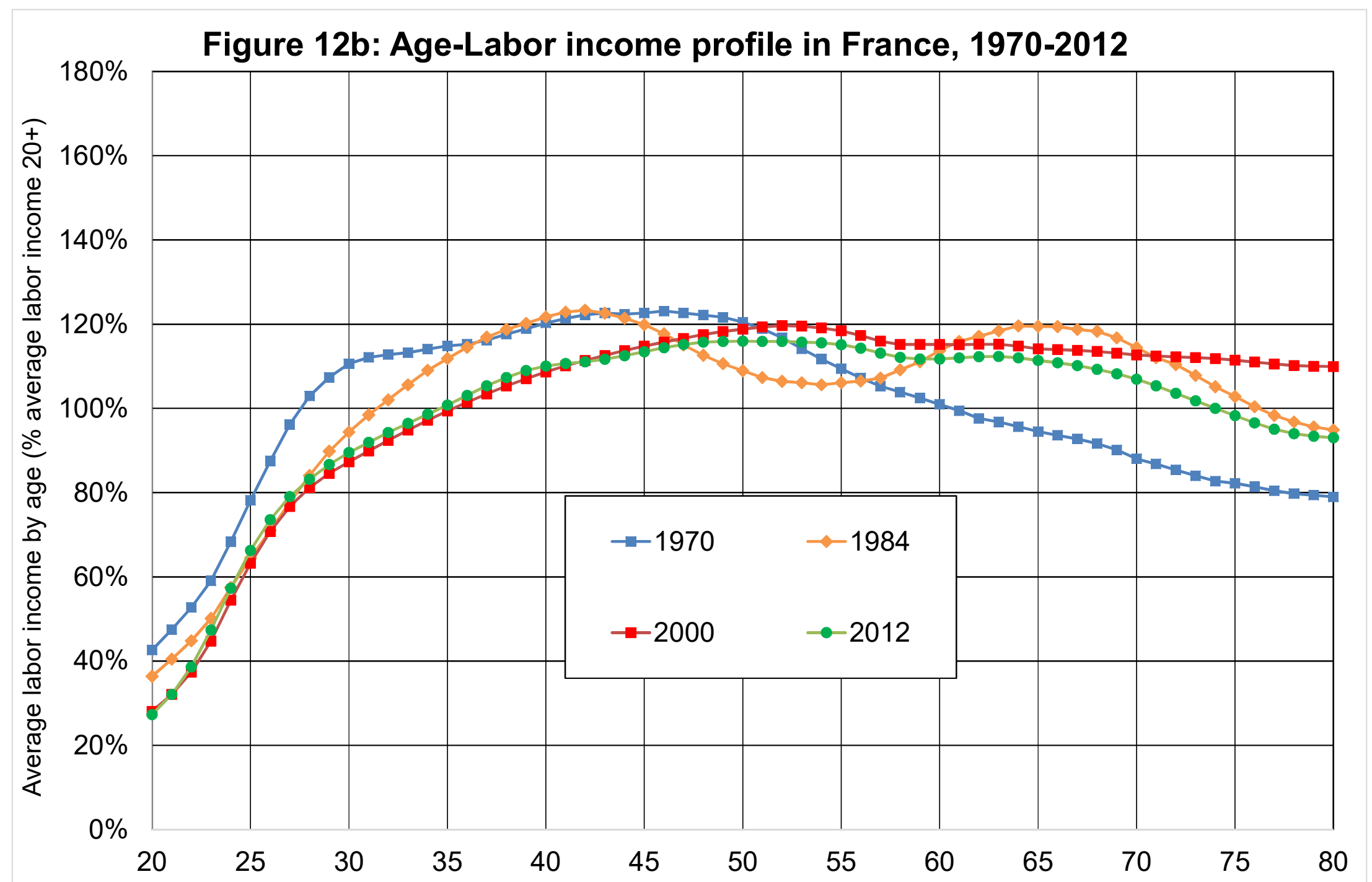

Distribution of pretax labor income (incl. pensions, unempl. insurance and $70 \%$ of mixed income) among adults. Equal-split-adults series (income of married couples divided by two). 


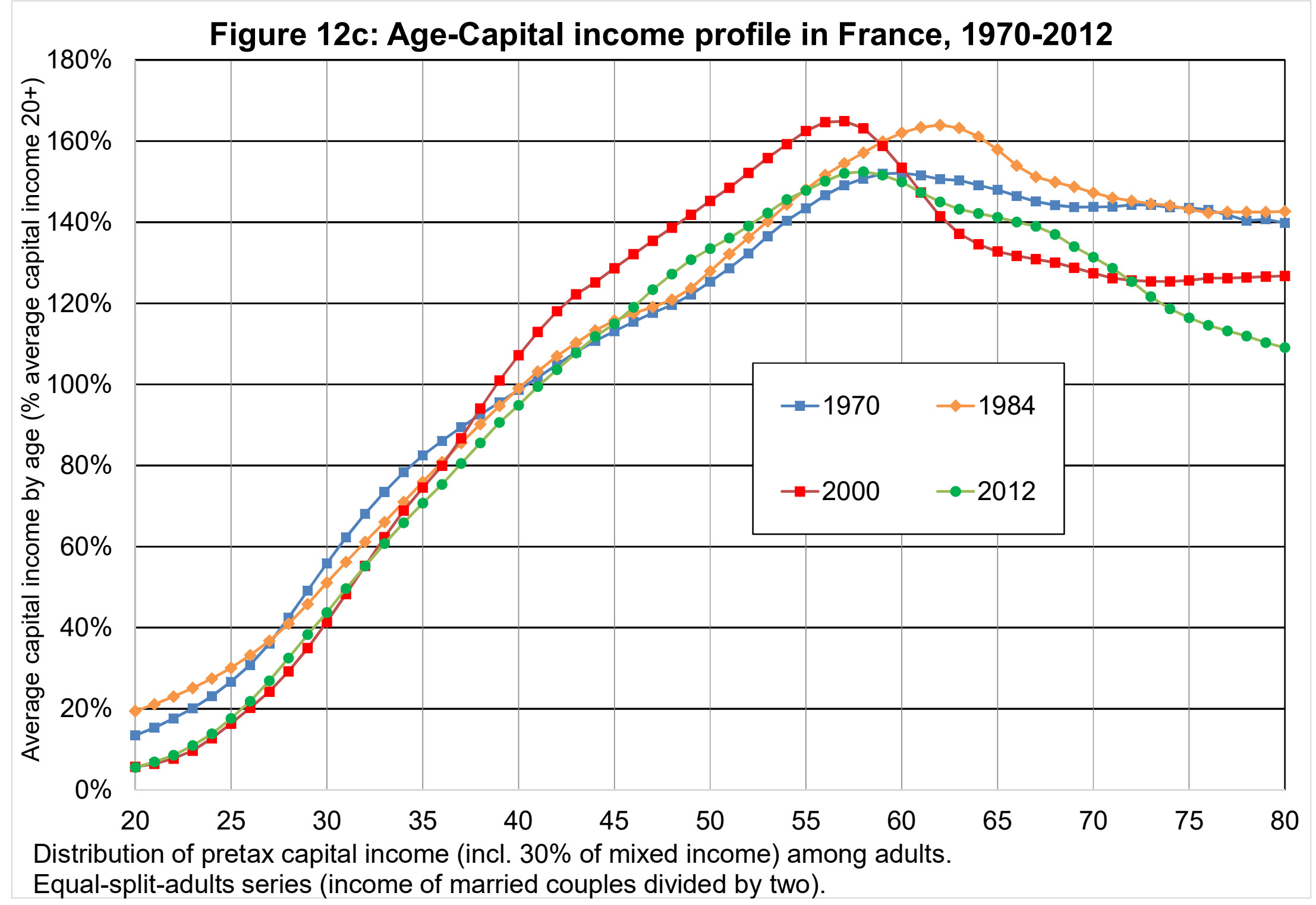




\section{Figure 13: Income concentration by age group, France 1970-2012}

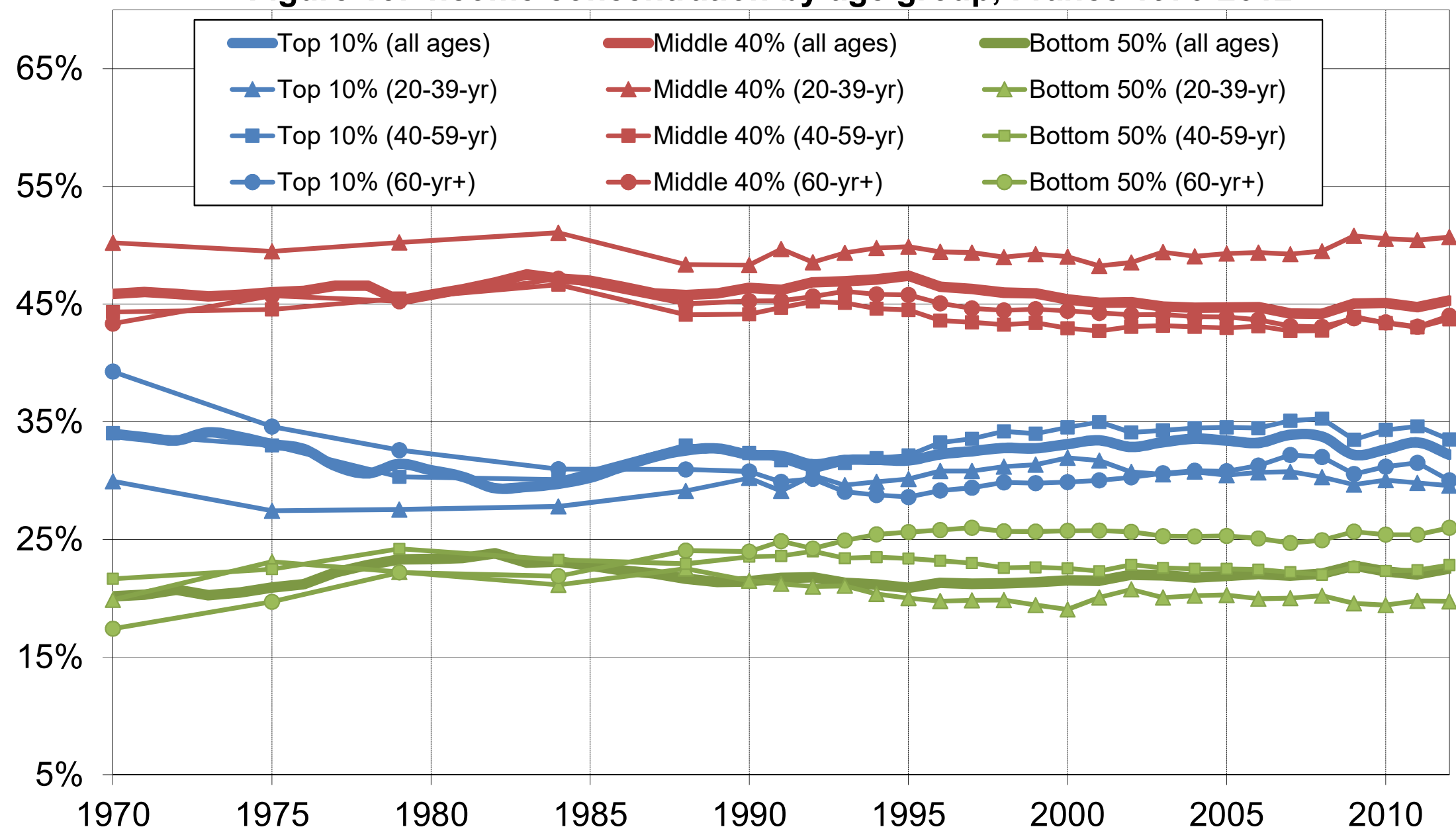

Distribution of pretax national income (before all taxes and transfers, except pensions and unempl. insurance) among adults. Equal-split-adults series (income of married couples divided by two). 


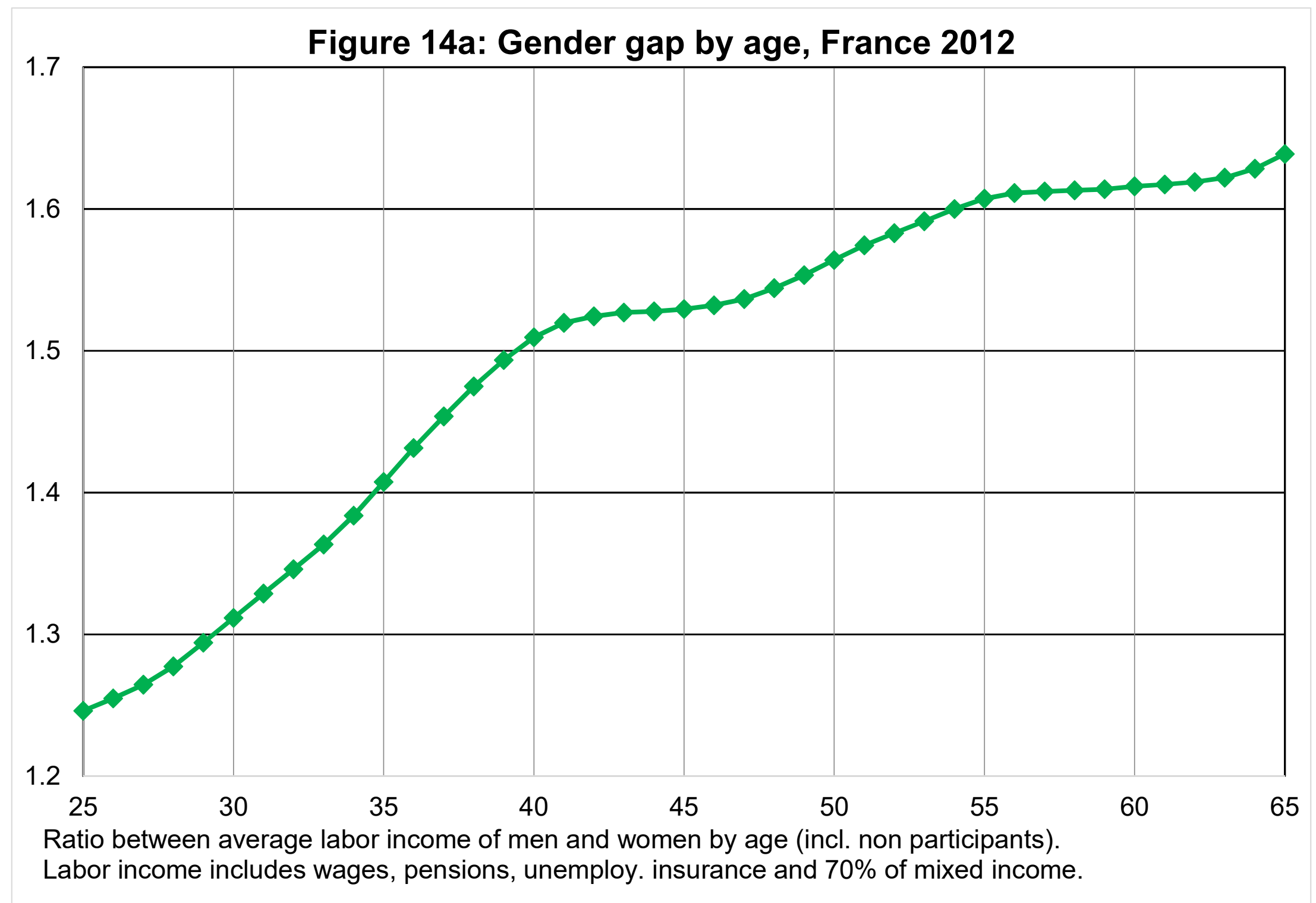




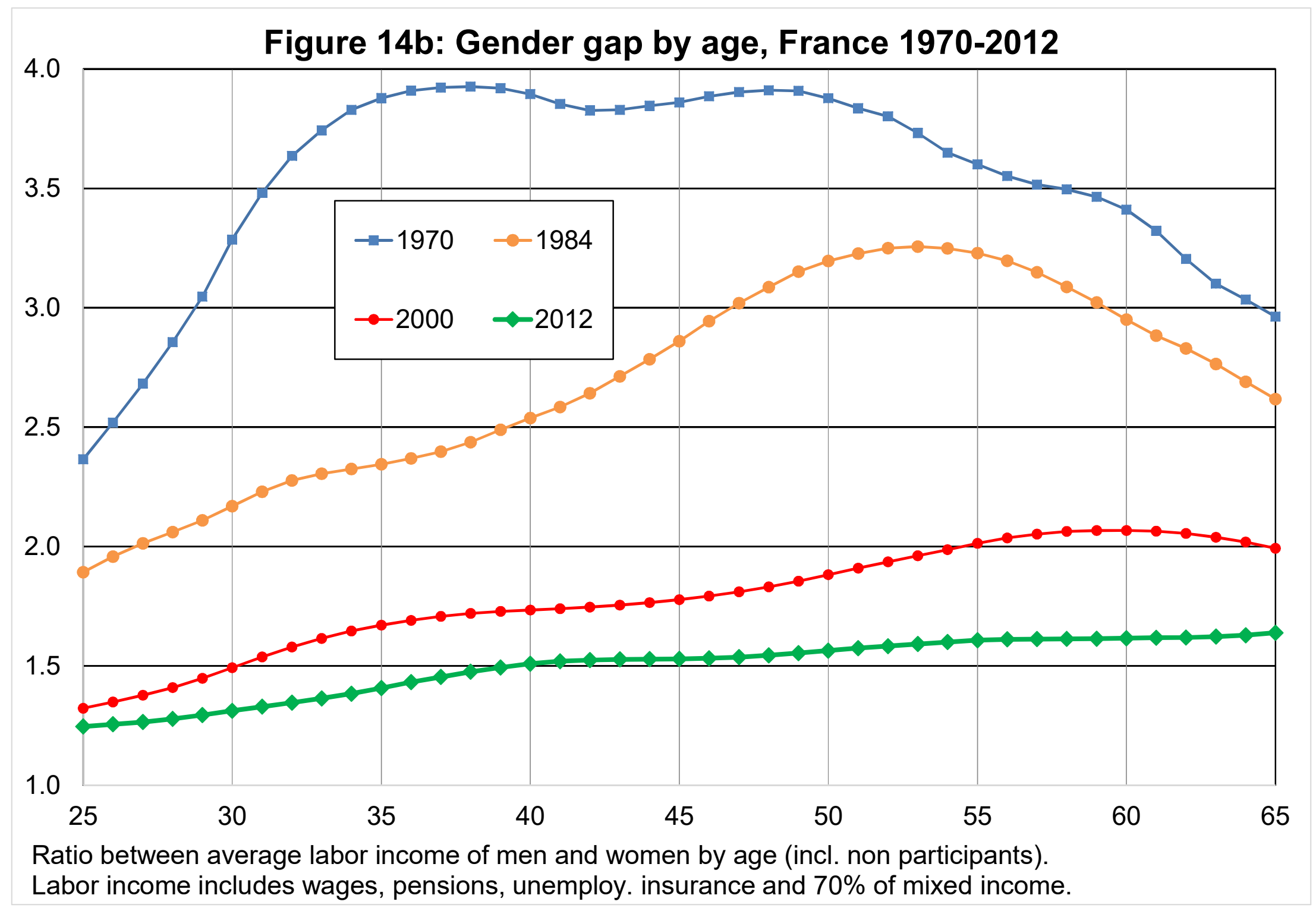


Figure 15a: Labor market participation by gender, France 1970-2014

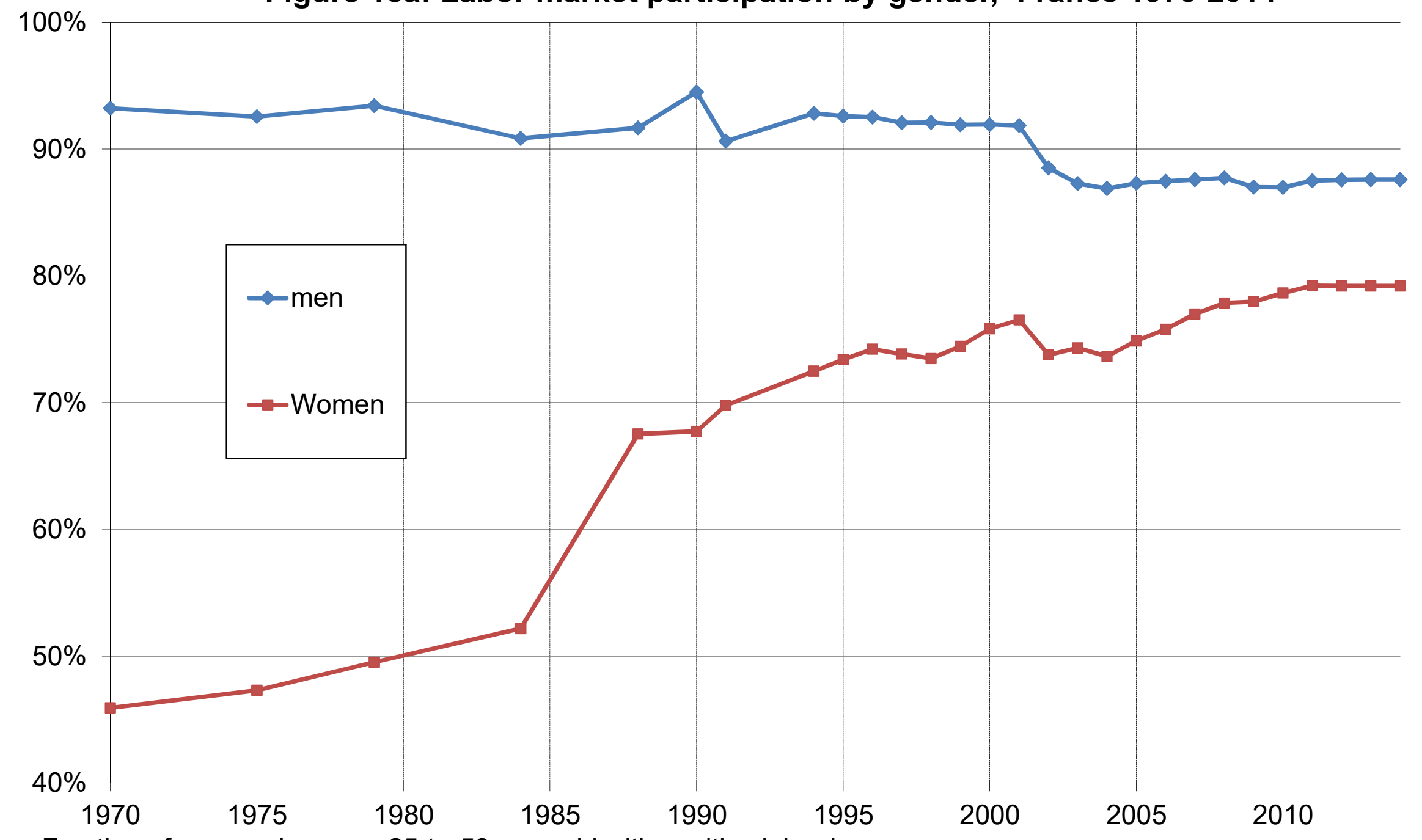

Fraction of men and women 25-to-59-year-old with positive labor income.

Labor income includes wages and $70 \%$ of mixed income. 
Figure 15b: Share of women in fractiles of top labor incomes in France,1970-2012

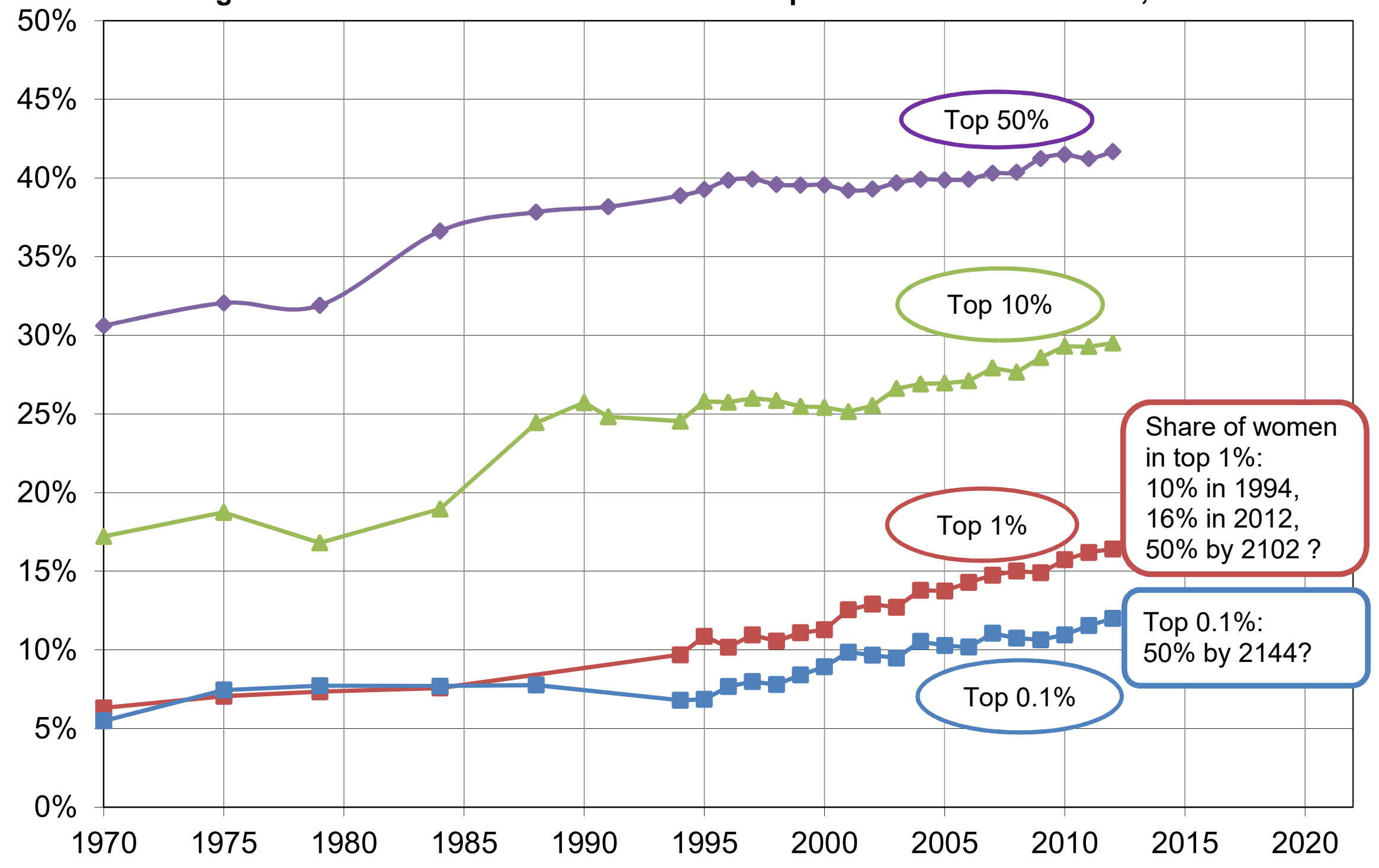




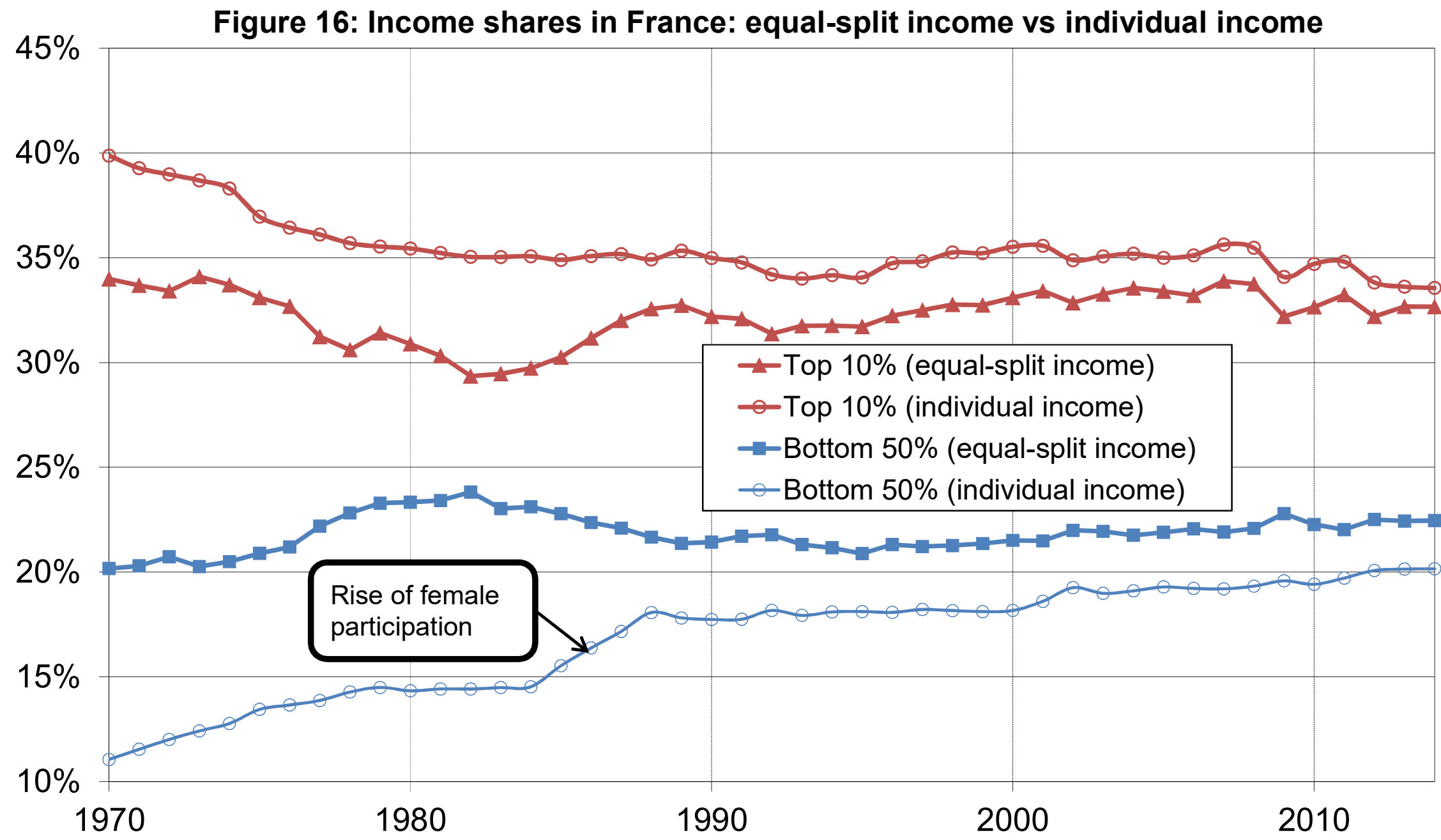

Distribution of pretax national income: equal-split income series (income of married couples divided by two) vs individual income series (capital income of married income divided by two, but labor income allocated to each individual). 


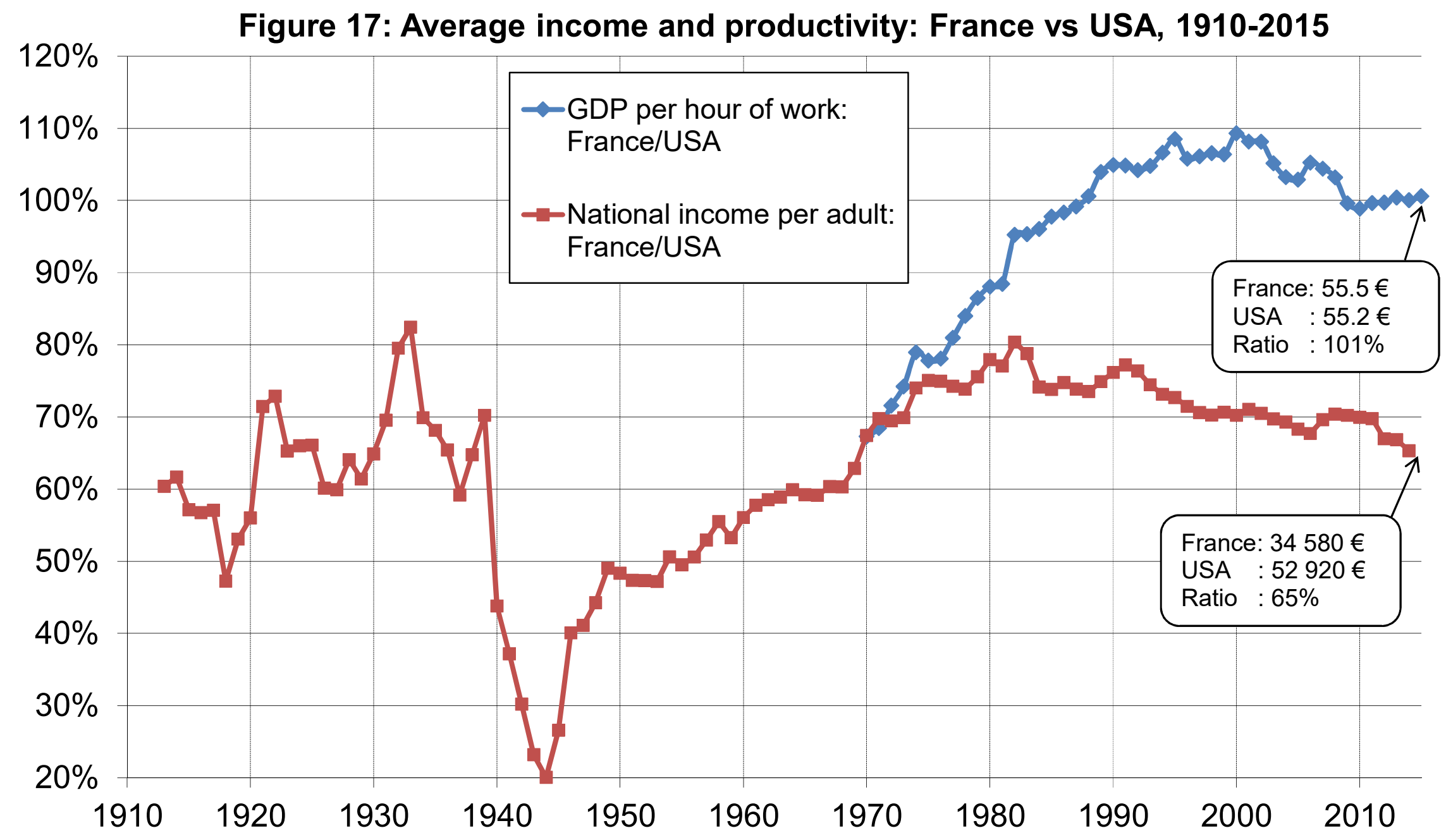

Ratios France/USA for GDP per hour of work (OECD series) and per adult national income (WID.world). Both series are expressed in PPP $2015 €$. 


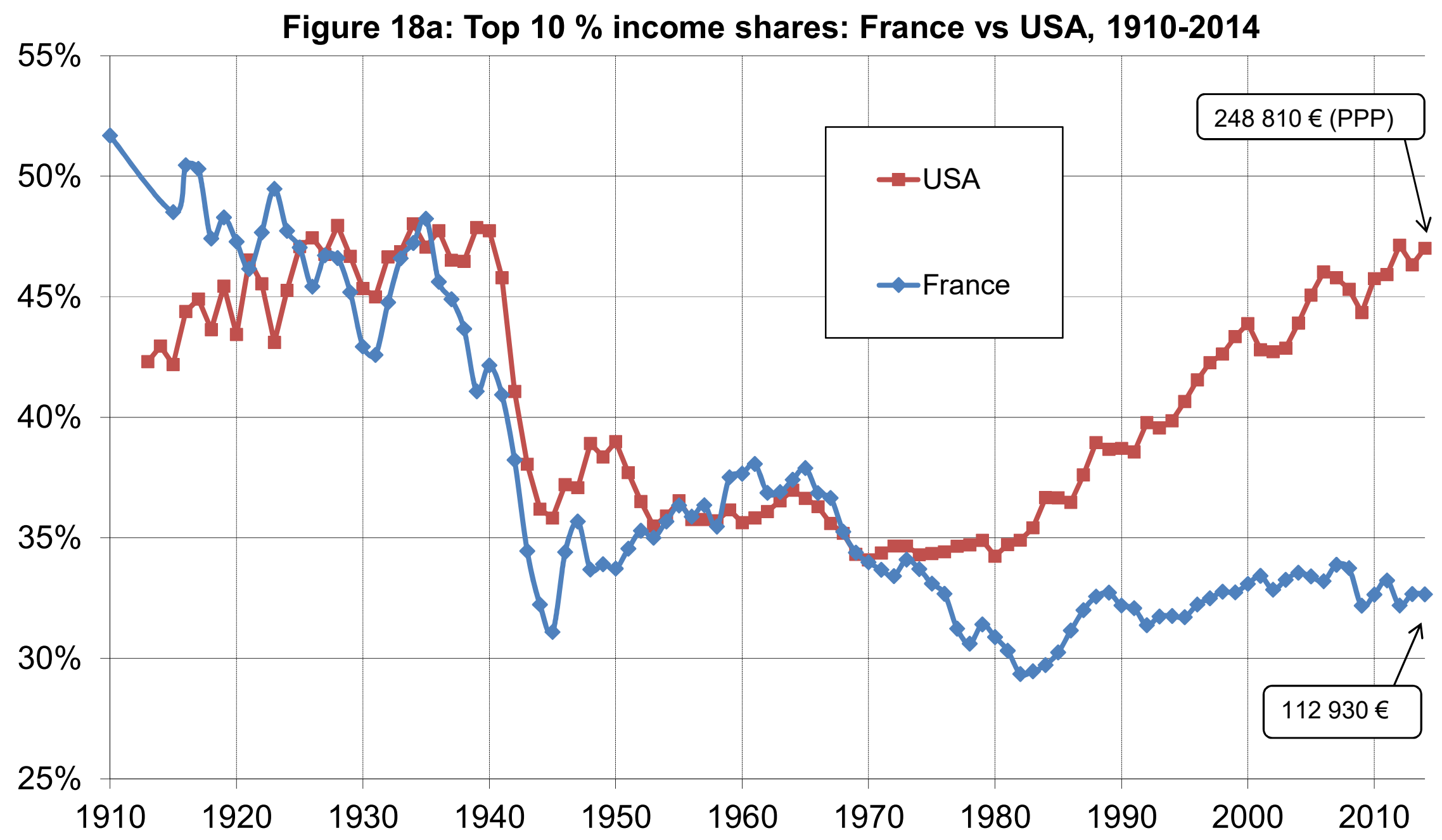

Distribution of pretax national income (before all taxes and transfers, except pensions and unempl. insurance) among adults.

Equal-split-adults series (income of married couples divided by two). 
Figure 18b: Top $1 \%$ income shares: France vs US, 1910-2014

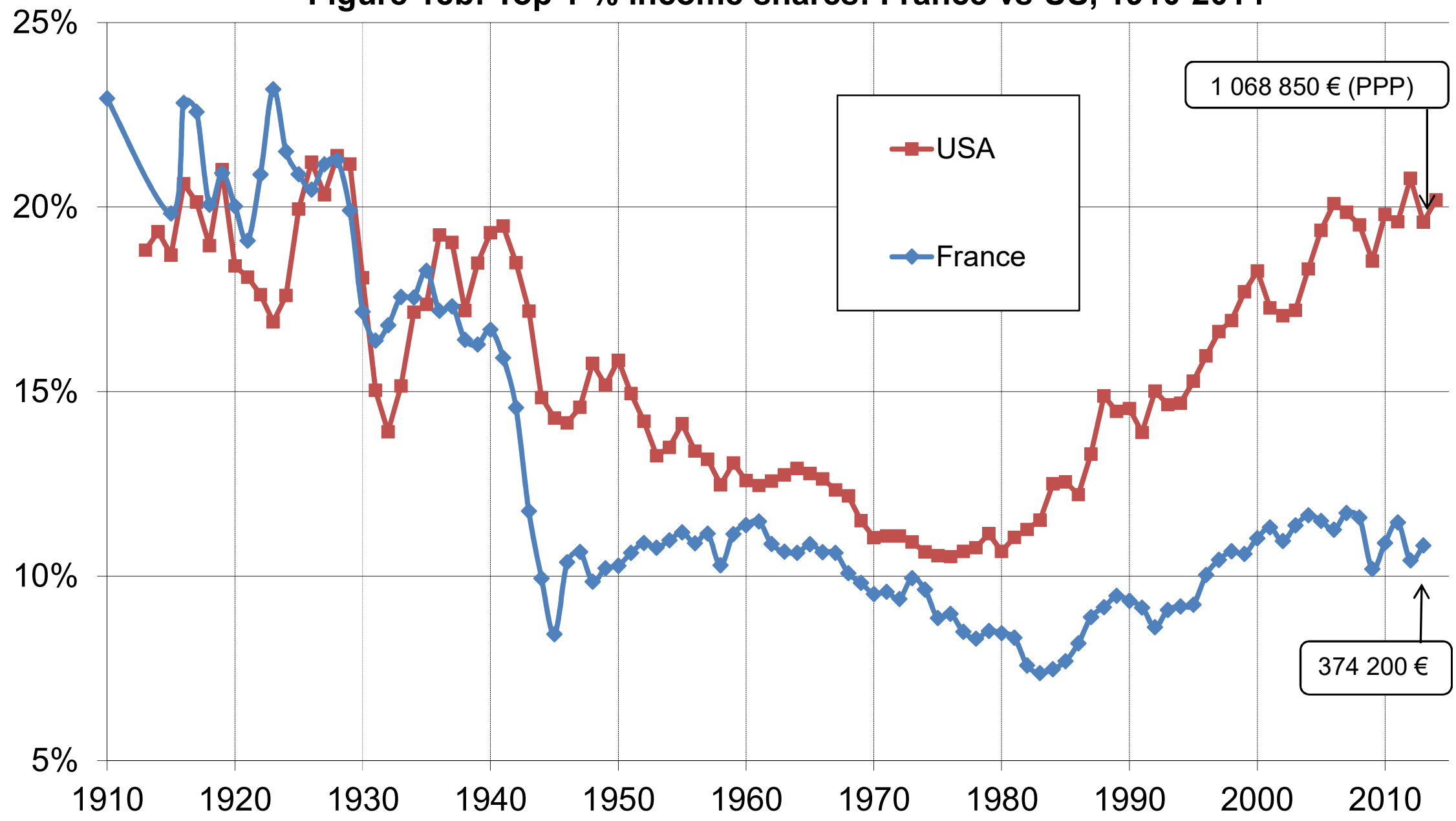

Distribution of pretax national income (before all taxes and transfers, except pensions and unempl. insurance) among adults.

Equal-split-adults series (income of married couples divided by two). 


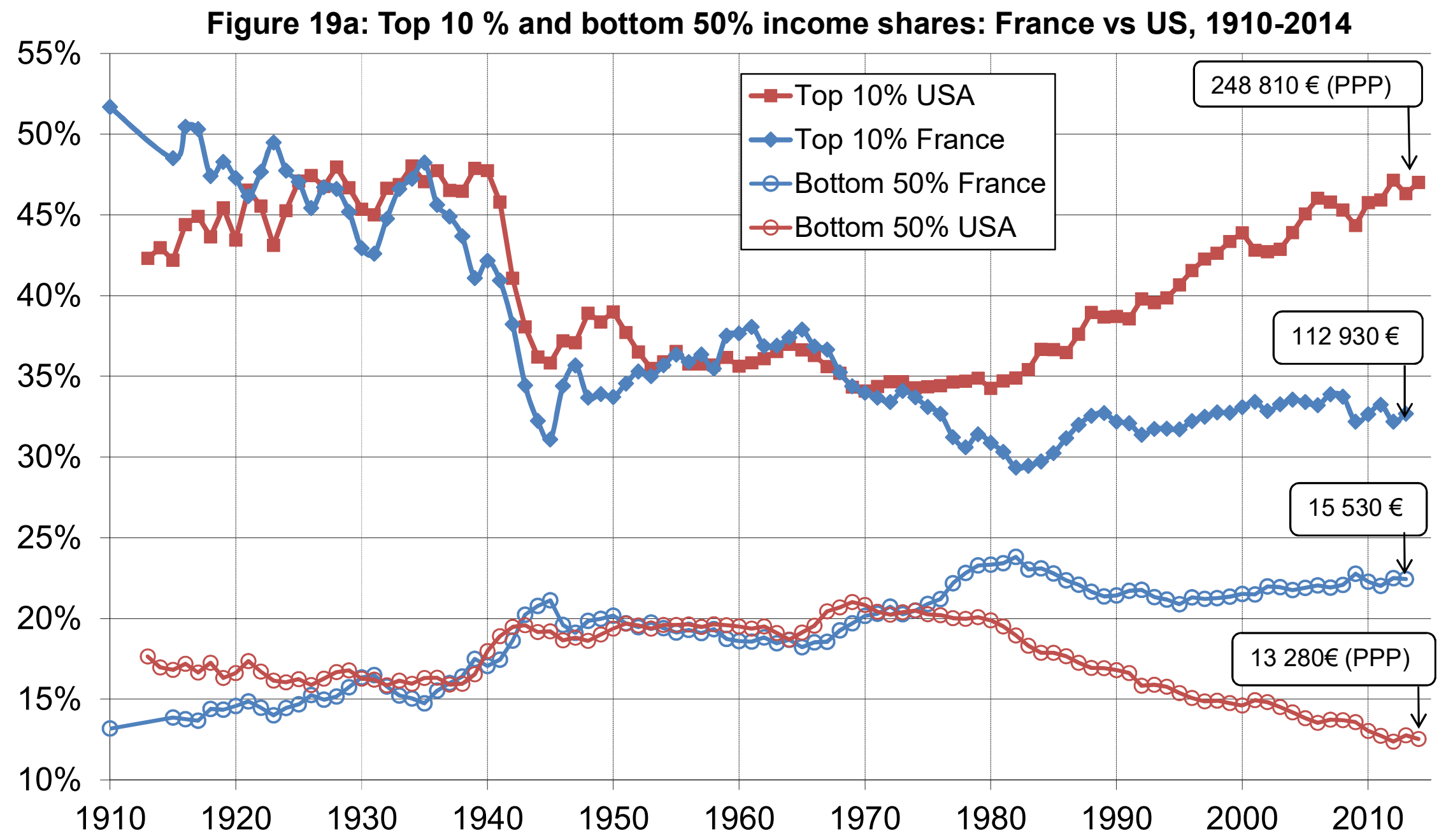

Distribution of pretax national income (before all taxes and transfers, except pensions and unempl. insurance) among adults.

Equal-split-adults series (income of married couples divided by two). 


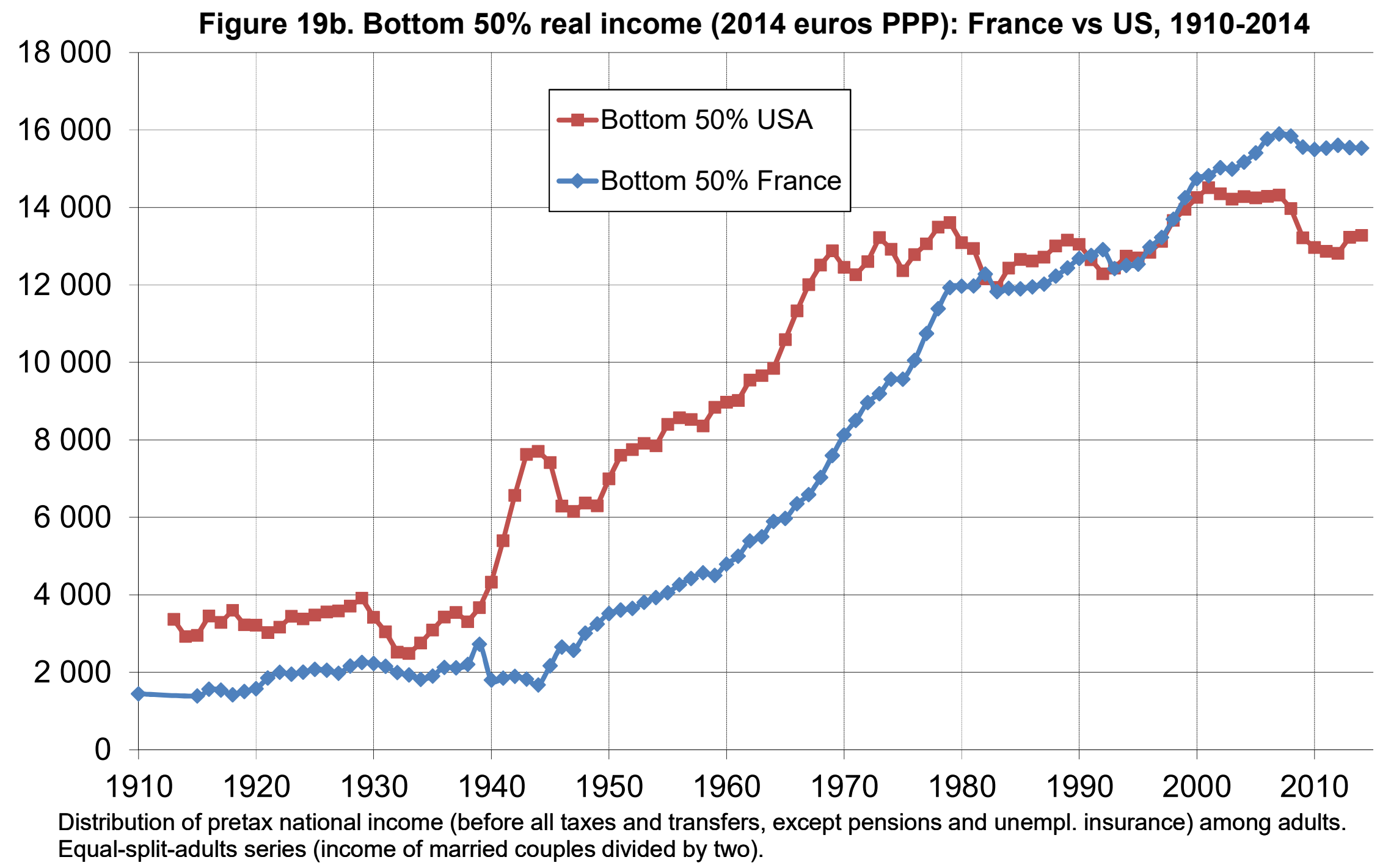




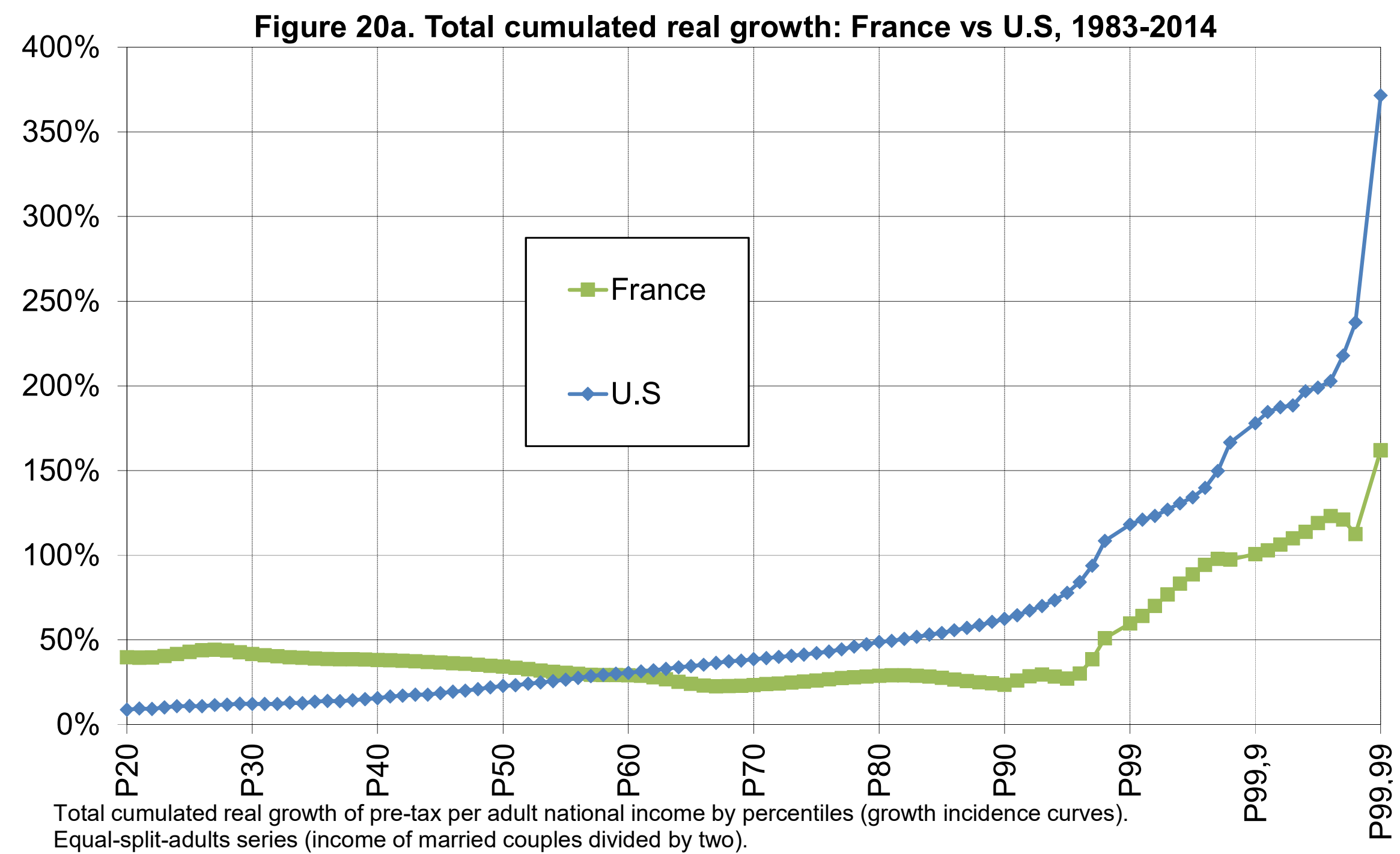


Figure 20b. Annual real growth: France vs U.S, 1983-2014

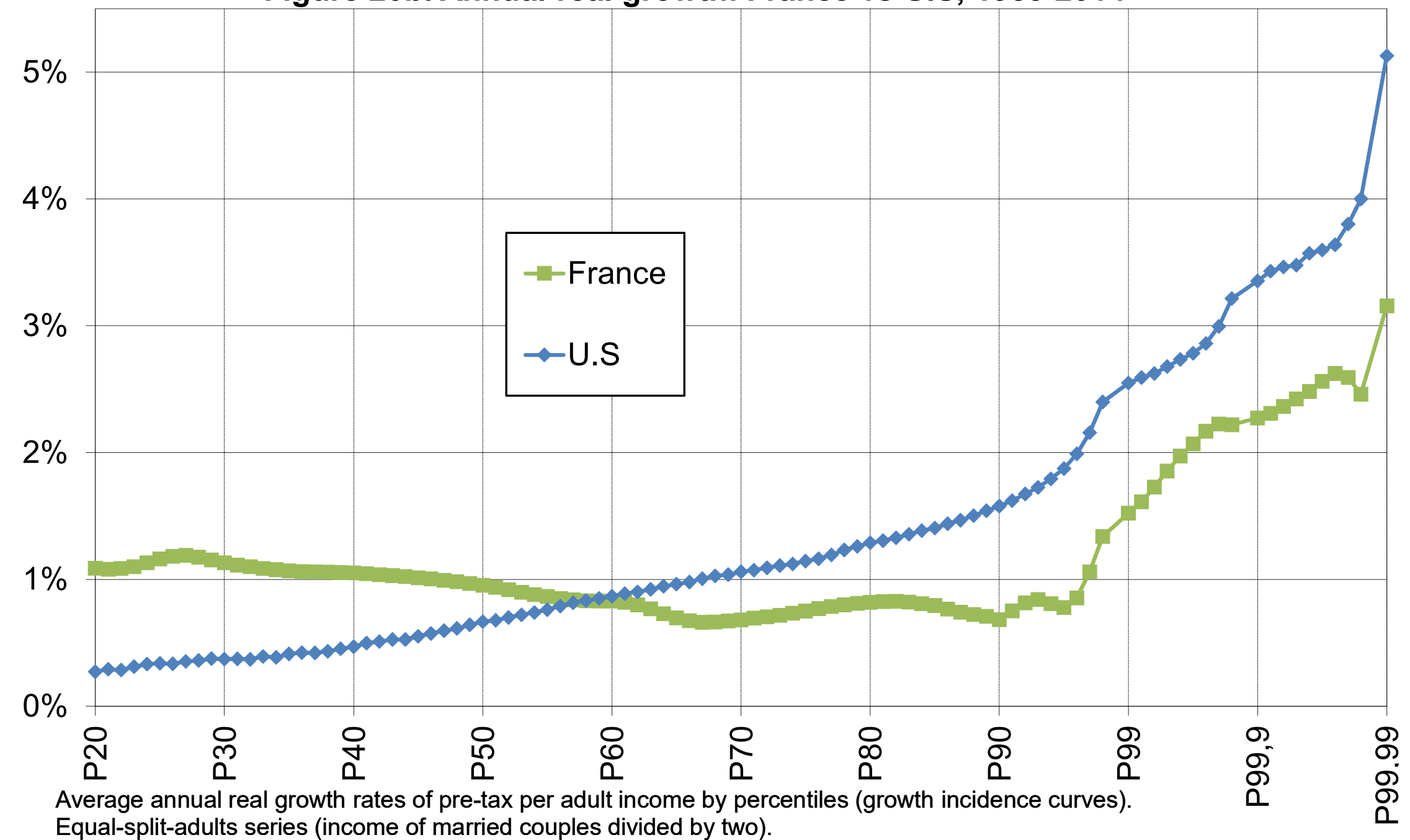

